\title{
WestVirginiaUniversity
}

THE RESEARCH REPOSITORY @ WVU

Graduate Theses, Dissertations, and Problem Reports

2006

\section{Productivity index of multilateral wells}

Upender Naik Nunsavathu

West Virginia University

Follow this and additional works at: https://researchrepository.wvu.edu/etd

\section{Recommended Citation}

Nunsavathu, Upender Naik, "Productivity index of multilateral wells" (2006). Graduate Theses, Dissertations, and Problem Reports. 1740.

https://researchrepository.wvu.edu/etd/1740

This Thesis is protected by copyright and/or related rights. It has been brought to you by the The Research Repository @ WVU with permission from the rights-holder(s). You are free to use this Thesis in any way that is permitted by the copyright and related rights legislation that applies to your use. For other uses you must obtain permission from the rights-holder(s) directly, unless additional rights are indicated by a Creative Commons license in the record and/ or on the work itself. This Thesis has been accepted for inclusion in WVU Graduate Theses, Dissertations, and Problem Reports collection by an authorized administrator of The Research Repository @ WVU. For more information, please contact researchrepository@mail.wvu.edu. 


\title{
PRODUCTIVITY INDEX OF MULTILATERAL WELLS
}

\author{
Upender Naik Nunsavathu
}

Thesis Submitted to the College of Engineering and Mineral Resources

At West Virginia University In partial fulfillments of the requirements

For the degree of

Master of Science

In

Petroleum and Natural Gas Engineering

Dr. H. Ilkin Bilgesu, Chair of Committee

Prof. Samuel Ameri

Dr. Daniel E. Della-Giustina

Department of Petroleum and Natural Gas Engineering Morgantown, West Virginia

2006

Keywords: Petroleum \& Natural Gas Engineering, Multilateral wells, Productivity index, Dimensionless time, Dimensionless pressure. 


\section{Abstract \\ Productivity Index of Multilateral wells \\ Upender Naik Nunsavathu}

In the history of petroleum science there are a vast variety of productivity solutions for different well types, well configurations and flow regimes. The main well types that were considered for calculating the productivity indexes were vertical wells and horizontal wells. The configurations considered were multilayer perforations, dual lateral wells with laterals at same depths, stacked wells etc. There are few solutions to estimate the well productivity for complex configurations like multilateral wells.

The main objective of this work is to identify a numerical solution method for calculating productivity indexes for different well configurations like single vertical well, single horizontal well, dual lateral well with laterals at same depth, dual laterals with laterals at different depths and four laterals well. A three-phase, three-dimensional black oil reservoir simulator (ECLIPSE) is used in this thesis. Apart from comparing the productivity indexes of different well configurations, dimensionless pressure derivatives with respect to dimensionless time is also compared for all the above well configurations. 


\section{ACKNOWLEDGEMENTS}

At the first place, I would like to express my deepest gratitude and appreciation to my advisor Dr. Ilkin Bilgesu. Throughout his support, guidance and encouragements during my graduate program, I have completed my studies and the thesis, which culminated in the achievement of my degree. He entirely changed my life and without him this would never be possible.

Sincerely thanks to Professor and Department Chair Samuel Ameri for guidance and support during my graduate studies at West Virginia University. I also appreciate his enthusiasm to be on my committee.

I sincerely thank Dr. Daniel E. Della-Giustina for his guidance, support in my research work and for being on my committee.

Many thanks to my professors in the Department of West Virginia University for the knowledge they shared with me.

I would like to acknowledge Schlumberger for providing the software (ECLIPSE) used in this study.

Great portion of help and encouragements that I had during my graduate studies I owe to all my friends. Thank you for the time you spent with me.

Great thanks to my family, especially to my brother Aravind Nunsavathu, for the constant encouragement and support. He is the best friend I have ever had in my life.

Finally, I dedicate my work to my loving parents, wife and to my brother for all of their belief, guidance, support, and encouragement. 
ABSTRACT ii

ACKNOWLEDGEMENTS

TABLE OF CONTENTS iv

LIST OF FIGURES vi

LIST OF TABLES $\quad$ xi

CHAPTER I. INTRODUCTION

$\begin{array}{ll}\text { 1.1. Overview } & 1\end{array}$

1.1.1. Background 1

1.1.2. General Definition 3

1.1.3. Geometry of Multi-Lateral and Multi-branched wells 3

1.1.4. Classification System (TAML) 4

1.1.5. Advantages of Multilateral wells 6

1.1.6. Drawbacks of Multilateral wells 6

$\begin{array}{ll}\text { CHAPTER II. THEORY } & 7\end{array}$

$\begin{array}{ll}\text { 2.1. Unsteady state } & 8\end{array}$

2.2. Pseudo - steady State 9

$\begin{array}{ll}\text { 2.3. Steady State } & 10\end{array}$

$\begin{array}{ll}\text { 2.4. } & \text { Late Transient State } \\ \end{array}$

CHAPTER III. PREDICTION OF PRODUCTIVITY METHODS 11

$\begin{array}{lll}3.1 & \text { Steady-state PI } & 11\end{array}$

$\begin{array}{lll}\text { 3.1.1 Borisov method } & 11\end{array}$

3.1.2 The Giger - Reiss - Jourdan method 11 
$\begin{array}{ll}3.1 .3 & \text { Joshi's method }\end{array}$

$\begin{array}{ll}\text { 3.1.4 The Renard - Dupuy method } & 13\end{array}$

$\begin{array}{lll}3.2 & \text { Pseudo-Steady State PI } & 14\end{array}$

$\begin{array}{ll}\text { 3.2.1 Babu - Odeh method } & 14\end{array}$

$\begin{array}{lll}3.2 .2 & \text { Kuchuk method } & 14\end{array}$

$\begin{array}{ll}\text { 3.2.3 Economides method } & 15\end{array}$

$\begin{array}{lll}3.3 & \text { Literature Review } & 15\end{array}$

$\begin{array}{ll}\text { 3.3.1 Analytical Solution } & 16\end{array}$

CHAPTER IV. RESERVOIR SIMULATIONS 18

4.1 Numerical Simulation Models for Multilateral wells 18

CHAPTER V. RESULTS AND DISCUSSION 53

CHAPTER VI. CONCLUSION AND FUTURE WORK 101

$\begin{array}{ll}\text { APPENDIX } & 103\end{array}$

$\begin{array}{ll}\text { REFERENCES } & 104\end{array}$ 
Figure 1.1 Russia's first Multilateral well 2

Figure 1.2 Different Well Configurations 3

Figure 2.1 Representation of Infinite - acting (or) Transient state 8

Figure 2.2 Representation of Pseudo - steady state 9

Figure 2.4 Representation of Late Transient state $\quad 10$

Figure $4.1500 \mathrm{ft}$. Single Lateral Well $\quad 19$

Figure 4.2 Grid structure for the $500 \mathrm{ft}$. Single Lateral Well 20

Figure $4.31000 \mathrm{ft}$. Single Lateral Well $\quad 21$

Figure 4.4 Grid structure for the $1000 \mathrm{ft}$. Single Lateral Well 22

Figure $4.51500 \mathrm{ft}$. Single Lateral Well 23

Figure 4.6 Grid structure for the $1500 \mathrm{ft}$. Single Lateral Well 24

Figure 4.7 $2000 \mathrm{ft}$. Single Lateral Well 25

Figure 4.8 Grid structure for the $2000 \mathrm{ft}$. Single Lateral Well 26

Figure $4.9500 \mathrm{ft}$. Dual Lateral Well 27

Figure 4.10 Grid structure for the $500 \mathrm{ft}$. Dual Lateral Well 28

Figure 4.11 $1000 \mathrm{ft}$. Dual Lateral Well 29

Figure 4.12 Grid structure for the $1000 \mathrm{ft}$. Dual Lateral Well 30

Figure 4.13 $1500 \mathrm{ft}$. Dual Lateral Well 31

Figure 4.14 Grid structure for the $1500 \mathrm{ft}$. Dual Lateral Well 32

Figure 4.15 $2000 \mathrm{ft}$. Dual Lateral Well 33

Figure 4.16 Grid structure for the $2000 \mathrm{ft}$. Dual Lateral Well 34

Figure $4.17500 \mathrm{ft}$. Dual Lateral Well with laterals at different depths $\quad 35$

Figure $4.18 \mathrm{Grid}$ structure for the $\mathbf{5 0 0} \mathrm{ft}$. Dual Lateral Well with laterals at different depths $\quad 36$

Figure 4.19 $1000 \mathrm{ft}$. Dual Lateral Well with laterals at different depths $\quad 37$

Figure 4.20 Grid structure for the $1000 \mathrm{ft}$. Dual Lateral Well with laterals at different depths $\quad 38$

Figure 4.21 $1500 \mathrm{ft}$. Dual Lateral Well with laterals at different depths $\quad 39$

Figure 4.22 Grid structure for the $1500 \mathrm{ft}$. Dual Lateral Well with laterals $\begin{array}{ll}\text { at different depths } & 40\end{array}$

Figure $4.232000 \mathrm{ft}$. Dual Lateral Well with laterals at different depths $\quad 41$ 
Figure 4.24 Grid structure for the $2000 \mathrm{ft}$. Dual Lateral Well with laterals at different depths

Figure $4.25500 \mathrm{ft}$. 4-Laterals Well 43

Figure 4.26 Grid structure for the $500 \mathrm{ft}$. 4-Laterals Well 44

Figure $4.271000 \mathrm{ft}$. 4-Laterals Well 45

Figure 4.28 Grid structure for the $1000 \mathrm{ft}$. 4-Laterals Well 46

Figure $4.291500 \mathrm{ft}$. 4-Laterals Well $\quad 47$

Figure 4.30 Grid structure for the $1500 \mathrm{ft}$. 4-Laterals Well 48

Figure $4.312000 \mathrm{ft}$. 4-Laterals Well 49

Figure 4.32 Grid structure for the $2000 \mathrm{ft}$. 4-Laterals Well 50

Figure 4.33 Single Vertical well 51

Figure 4.34 Grid structure for the Vertical Well 52

Figure 5.1 Variation of Productivity Index with time for a Single lateral well with $\mathbf{5 0 0} \mathrm{ft}$ lateral length $\quad 56$

Figure 5.2 Variation of dimensionless pressure and its derivative with dimensionless time for a Single lateral well with $500 \mathrm{ft}$ lateral $\begin{array}{ll}\text { length } & 57\end{array}$

Figure 5.3 Variation of Productivity Index with time for a Single lateral well with $1000 \mathrm{ft}$ lateral length $\quad 58$

Figure 5.4 Variation of dimensionless pressure and its derivative with dimensionless time for a Single lateral well with $1000 \mathrm{ft}$ lateral length $\quad 59$

Figure 5.5 Variation of Productivity Index with time for a Single lateral well with $1500 \mathrm{ft}$ lateral length

Figure 5.6 Variation of dimensionless pressure and its derivative with dimensionless time for a Single lateral well with $1500 \mathrm{ft}$ lateral length.

Figure 5.7 Variation of Productivity Index with time for a Single lateral well with $2000 \mathrm{ft}$ lateral length

Figure 5.8 Variation of dimensionless pressure and its derivative with dimensionless time for a Single lateral well with $2000 \mathrm{ft}$ lateral length

Figure 5.9 Variation of Productivity Index with time for a Dual Lateral well 
with $\mathbf{5 0 0} \mathrm{ft}$ lateral lengths, which are at the same depth

Figure 5.10 Variation of dimensionless pressure and its derivative with dimensionless time for a Dual Lateral well with $500 \mathrm{ft}$ lateral lengths, which are at the same depth

Figure 5.11 Variation of Productivity Index with time for a Dual Lateral well with $1000 \mathrm{ft}$ lateral lengths, which are at the same depth

Figure 5.12 Variation of dimensionless pressure and its derivative with dimensionless time for a Dual Lateral well with $1000 \mathrm{ft}$ lateral lengths, which are at the same depth

Figure 5.13 Variation of Productivity Index with time for a Dual Lateral well with $1500 \mathrm{ft}$ lateral lengths, which are at the same depth

Figure 5.14 Variation of dimensionless pressure and its derivative with dimensionless time for a Dual Lateral well with $1500 \mathrm{ft}$ lateral lengths, which are at the same depth

Figure 5.15 Variation of Productivity Index with time for a Dual Lateral well with $\mathbf{2 0 0 0} \mathrm{ft}$ lateral lengths, which are at the same depth

Figure 5.16 Variation of dimensionless pressure and its derivative with dimensionless time for a Dual Lateral well with $2000 \mathrm{ft}$ lateral lengths, which are at the same depth

Figure 5.17 Variation of Productivity Index with time for a Dual Lateral well with $\mathbf{5 0 0} \mathbf{f t}$ lateral lengths, which are at different depths

Figure 5.18 Variation of dimensionless pressure and its derivative with dimensionless time for a Dual Lateral well with $500 \mathrm{ft}$ lateral lengths, which are at different depths

Figure 5.19 Variation of Productivity Index with time for a Dual Lateral well with $1000 \mathrm{ft}$ lateral lengths, which are at different depths

Figure 5.20 Variation of dimensionless pressure and its derivative with dimensionless time for a Dual Lateral well with $1000 \mathrm{ft}$ lateral lengths, which are at different depths

Figure 5.21 Variation of Productivity Index with time for a Dual Lateral well with $1500 \mathrm{ft}$ lateral lengths, which are at different depths

Figure 5.22 Variation of dimensionless pressure and its derivative with dimensionless time for a Dual Lateral well with 
$1500 \mathrm{ft}$ lateral lengths, which are at different depths

Figure 5.23 Variation of Productivity Index with time for a Dual Lateral well with 2000 ft lateral lengths, which are at different depths

Figure 5.24 Variation of dimensionless pressure and its derivative with dimensionless time for a Dual Lateral well with $2000 \mathrm{ft}$ lateral lengths, which are at different depths

Figure 5.25 Variation of Productivity Index with time for a 4-lateral well with $\mathbf{5 0 0} \mathbf{f t}$ lateral lengths, which are at the same depth

Figure 5.26 Variation of dimensionless pressure and its derivative with dimensionless time for a 4-lateral well with $500 \mathrm{ft}$ lateral lengths, which are at the same depth

Figure 5.27 Variation of Productivity Index with time for a 4-lateral well with $\mathbf{1 0 0 0} \mathrm{ft}$ lateral lengths, which are at the same depth

Figure 5.28 Variation of dimensionless pressure and its derivative with dimensionless time for a 4-lateral well with $1000 \mathrm{ft}$ lateral lengths, which are at the same depth

Figure 5.29 Variation of Productivity Index with time for a 4-lateral well with $1500 \mathrm{ft}$ lateral lengths, which are at the same depth

Figure 5.30 Variation of dimensionless pressure and its derivative with dimensionless time for a 4-lateral well with $1500 \mathrm{ft}$ lateral lengths, which are at the same depth

Figure 5.31 Variation of Productivity Index with time for a 4-lateral well with $\mathbf{2 0 0 0} \mathrm{ft}$ lateral lengths, which are at the same depth

Figure 5.32 Variation of dimensionless pressure and its derivative with dimensionless time for a 4-lateral well with $2000 \mathrm{ft}$ lateral lengths, which are at the same depth

Figure 5.33 Variation of Productivity Index with time for a single Vertical Well

Figure 5.34 Variation of dimensionless pressure and its derivative with dimensionless time for a single Vertical Well

Figure 5.35 Variation of Productivity Index with time for a single lateral well with $500 \mathrm{ft}, 1000 \mathrm{ft}, 1500 \mathrm{ft}$ and $2000 \mathrm{ft}$ lateral lengths

Figure 5.36 Variation of Productivity Index with time for a dual lateral 
well with $500 \mathrm{ft}, 1000 \mathrm{ft}, 1500 \mathrm{ft}$ and $2000 \mathrm{ft}$ lateral lengths, which are at the same depth

Figure 5.37 Variation of Productivity Index with time for a dual lateral well with $500 \mathrm{ft}, 1000 \mathrm{ft}, 1500 \mathrm{ft}$ and $2000 \mathrm{ft}$ lateral lengths, which are at different depths

Figure 5.38 Variation of Productivity Index with time for a 4-lateral well with $500 \mathrm{ft}, 1000 \mathrm{ft}, 1500 \mathrm{ft}$ and $2000 \mathrm{ft}$ lateral lengths, which are at the same depth

Figure 5.39 Variation of dimensionless pressure and its derivative with dimensionless time for a single lateral well with $500 \mathrm{ft}$, $1000 \mathrm{ft}, 1500 \mathrm{ft}$ and $2000 \mathrm{ft}$ lateral lengths

Figure 5.40 Variation of dimensionless pressure and its derivative with dimensionless time for a dual lateral well with $500 \mathrm{ft}$, $1000 \mathrm{ft}, 1500 \mathrm{ft}$ and $2000 \mathrm{ft}$ lateral lengths, which are at the same depth

Figure 5.41 Variation of dimensionless pressure and its derivative with dimensionless time for a dual lateral well with $500 \mathbf{f t}$, $1000 \mathrm{ft}, 1500 \mathrm{ft}$ and $2000 \mathrm{ft}$ lateral lengths, which are at different depths

Figure 5.42 Variation of dimensionless pressure and its derivative with dimensionless time for a 4-lateral well with $500 \mathrm{ft}$, $1000 \mathrm{ft}, 1500 \mathrm{ft}$ and $2000 \mathrm{ft}$ lateral lengths, which are at the same depth 


\section{LIST OF TABLES}

Page

Table 1.1 Complexity raking of multilateral wells 


\section{CHAPTER I. INTRODUCTION}

\subsection{Overview}

\subsubsection{Background}

Deliverability of wells is the main focus of petroleum industry anywhere in the world. Advances in science and technology applied to drilling and production engineering resulted in a modern well design, ability to drill and complete a well with complicated trajectory in order to reach a certain part of the reservoir. As most of the oil and gas reserves are much more extensive in their horizontal dimensions than in their vertical (thickness) dimensions, the concept of horizontal drilling technology came into existence. Advances in computer hardware and software development triggered a new approach to the reservoir enabling a more detailed and better quality analysis and selection of the drainage strategy and field development concept. Multilateral wells are the part of advanced horizontal drilling technology. The first multilateral well was drilled in Russia in 1950's (Figure 1.1) ${ }^{1}$. Europe's first multi-lateral wells were completed by Elf Aquitaine in 1984 in the Paris Basin, France. Norsk Hydro completed successfully the first ever Level 5 multilateral well in the Oseburg Field, North Sea during 1996. In USA, Shell successfully completed its first Level 6 multilateral well during 1998. 


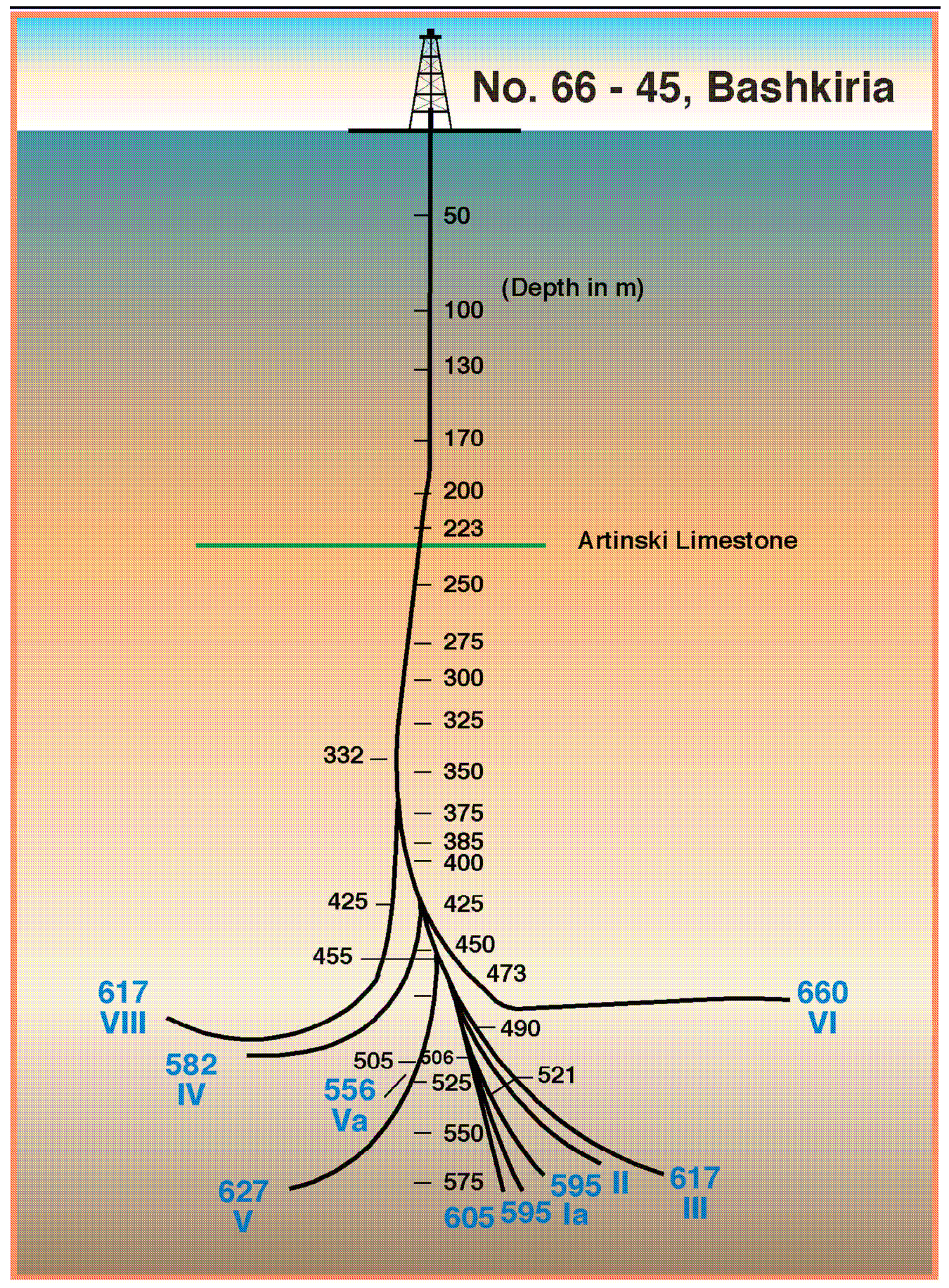

Figure 1.1- Russia's first Multilateral well ${ }^{1}$. 


\subsubsection{General Definition}

A multilateral well as defined by $\operatorname{TAML}^{1}$ group (Technical Advancements of Multilaterals) is one in which there will be more than one horizontal or near horizontal lateral well drilled from a single side (mother-bore) and connected back to a single bore.

\subsubsection{Geometry of Multi-Lateral and Multi-branched wells}

Well geometry of multi-lateral wells named according to their configuration and number of laterals. e.g. Stacked Tri-lateral, Radial Quadrilateral etc.

Different well configurations are shown in Figure $1.2^{1}$

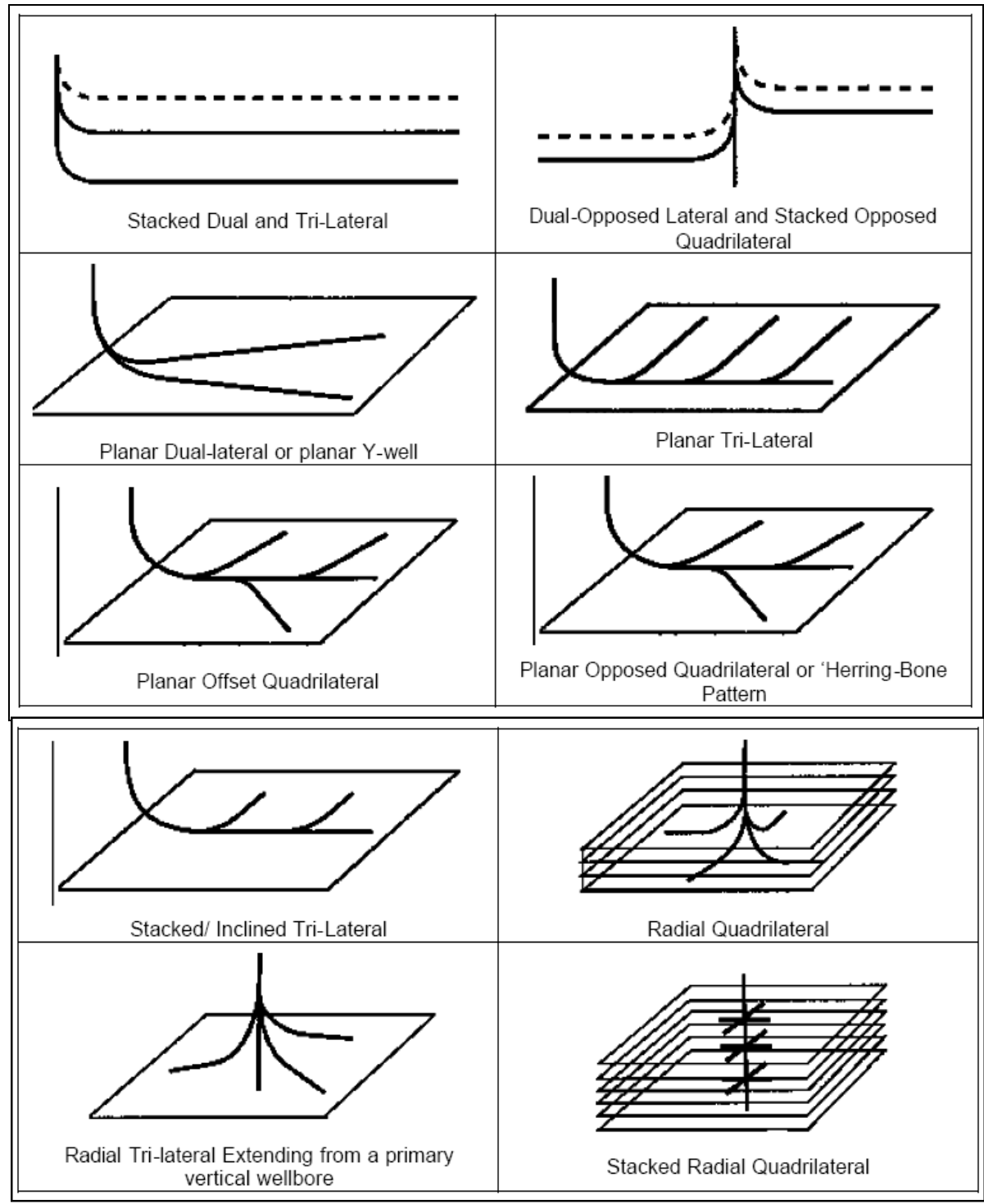

Figure 1.2 - Different Well Configurations 


\subsubsection{Classification System (TAML)}

There are two tiers of TAML classifications:

- Complexity ranking.

- Functional classification.

\section{- Complexity ranking}

A number between 1 and 6 defines multilateral junction complexity. Table 1.1 illustrates the complexity ratings.

\section{- Functionality classification}

This provides more technical detail on the major Multilateral/Multi-branched well attributes. This is divided into two sections:

1. Well description.

2. Junction description. 
Table 1.1- Complexity raking of multilateral wells ${ }^{1}$.

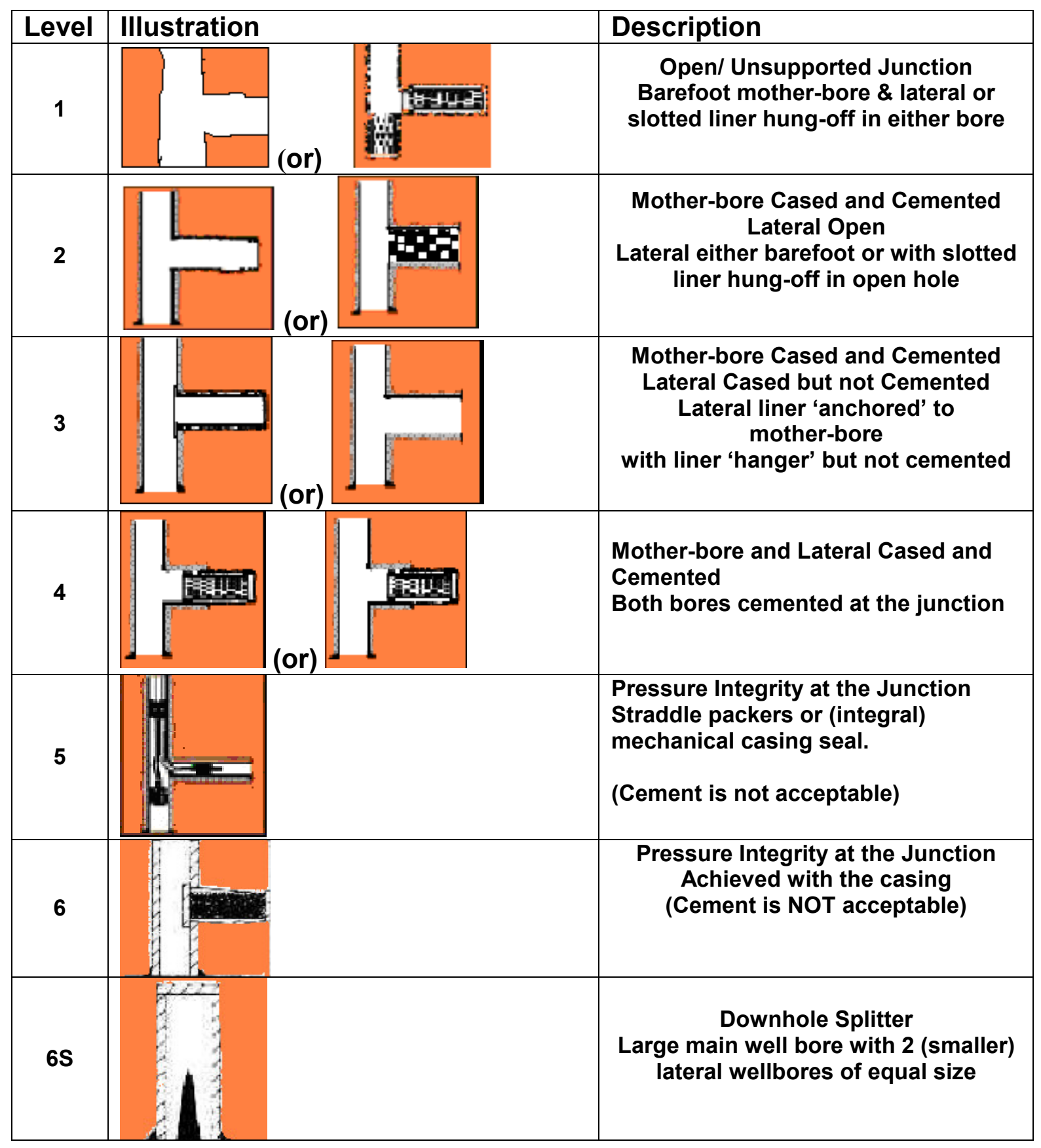




\subsubsection{Advantages ${ }^{2}$ of Multilateral wells}

The advantages of multilateral wells are:

- Higher productivity indexes.

- Relatively thin layer drainage can be accomplished.

- Decreased water and gas conning.

- Exposure to natural fractures will be high.

- In secondary and EOR applications, long horizontal injection wells provide higher injectivity rates.

- Better vertical and areal sweep (particularly for irregular or odd-shaped drainages).

- These are alternative to infill drilling operations because existing surface installations can be utilized.

- In heterogeneous reservoirs, more oil and gas pockets can be exploited and an increased number of fissures can be intersected.

\subsubsection{Disadvantages ${ }^{2}$ of Multilateral wells}

The disadvantages of multilateral wells are:

- Higher costs.

- Highly sensitive to heterogeneities and anisotropies (both stress and permeability).

- Very complicated drilling, completion and production technologies are used.

- Complicated and expensive stimulation techniques are used.

- Selection of appropriate candidates is difficult.

- Interference of well branches may occur (Cross flow may take place). 


\section{CHAPTER II. THEORY}

In general the production data in the form of flow rate and flowing pressure are available in an oil and gas producing field. Additionally, testing of a well yields reservoir pressure and other formation properties such as permeability, skin, and drainage area. One practical approach is to use productivity index $(\mathrm{PI})$ to characterize the performance of a well and also compare it with similar wells. The productivity index is also denoted by letter ' $\mathrm{J}$ ' and mathematically expressed for an oil well as:

$$
J=\frac{q}{\Delta p}=\frac{q}{\left(\bar{p}-p_{w}\right)}
$$

In general, units used are bbl/day/psi or $\mathrm{m}^{3} /$ day/kPa.

Productivity index is also considered as the measure of the capacity of the well. In this form PI represents a steady state flow condition. 
During the operational life, the hydrocarbon producing well passes through various stages. These stages mainly depend on the pressure drop and the boundary conditions. There are four different flow scenarios, which occur during the operational life of the well. They are:

- Unsteady state.

- Pseudo - steady state.

- Steady state.

- Late Transient.

\subsection{Unsteady state:}

This is the condition of the well when the pressure disturbance caused by the flow has not reached any of the reservoir boundaries. This is also known as Infinite - acting or Transient state (Figure 2.1).

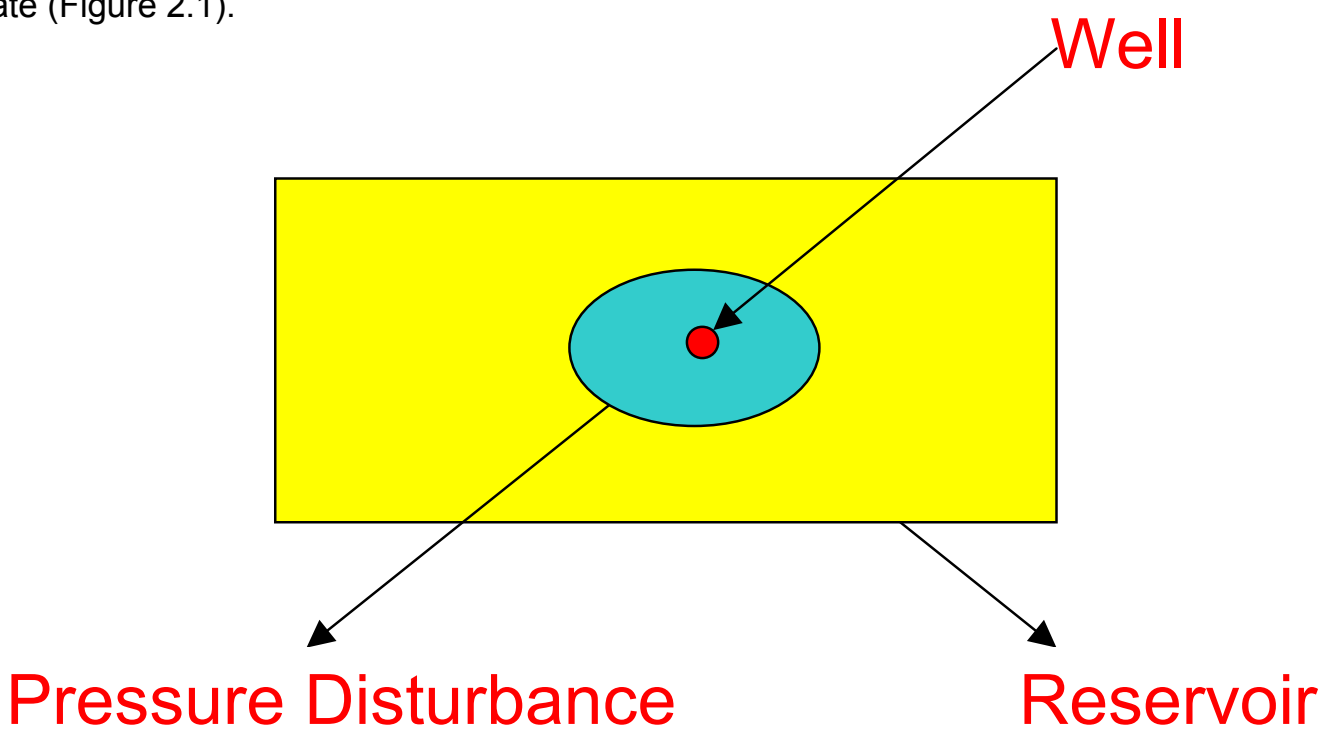

Figure 2.1. - Representation of Infinite - acting (or) Transient state.

Mathematically, unsteady state is defined as:

$$
\frac{\partial P}{\partial t}=f(r, t)
$$




\subsection{Pseudo - steady State:}

This is the condition of the well in a bounded reservoir when the pressure disturbance caused by the flow has reached all of the reservoir boundaries. During this flow regime the reservoir behaves like a tank. The pressure throughout the reservoir decreases at the same constant rate. (Figure 2.2)

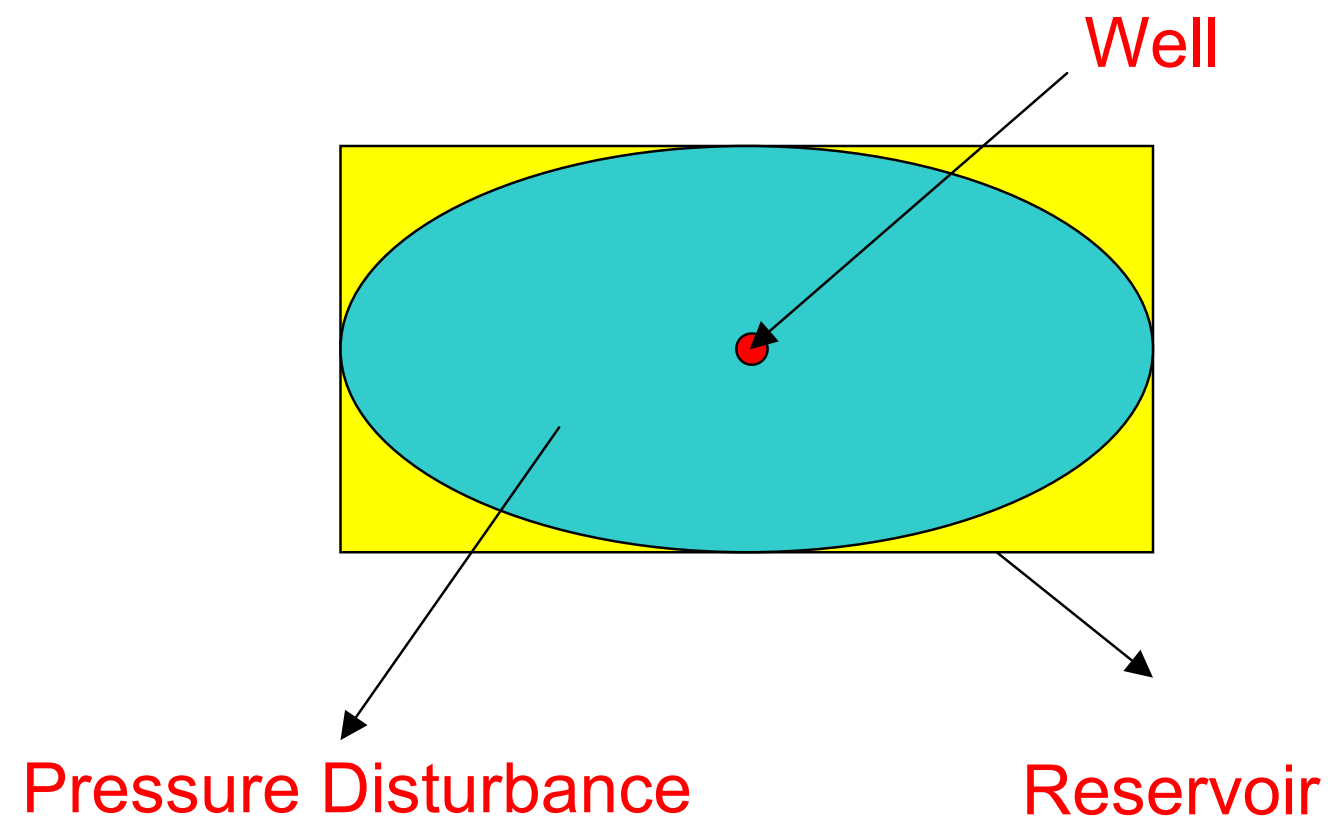

Figure 2.2. - Representation of Pseudo - steady state.

Mathematically, pseudo-steady state is given as:

$$
\frac{\partial P}{\partial t}=\text { constant }
$$




\subsection{Steady state:}

This condition occurs during the late time region when a constant pressure boundary exists. Constant pressure boundaries arise when the reservoir has aquifer support or gas cap expansion support.

Mathematically, steady state is given as:

$$
\frac{\partial P}{\partial t}=0
$$

\subsection{Late Transient State:}

This is the state between unsteady state and pseudo - steady state. During this regime the pressure distribution reaches some of the boundaries but not all of it. (Figure 2.4)

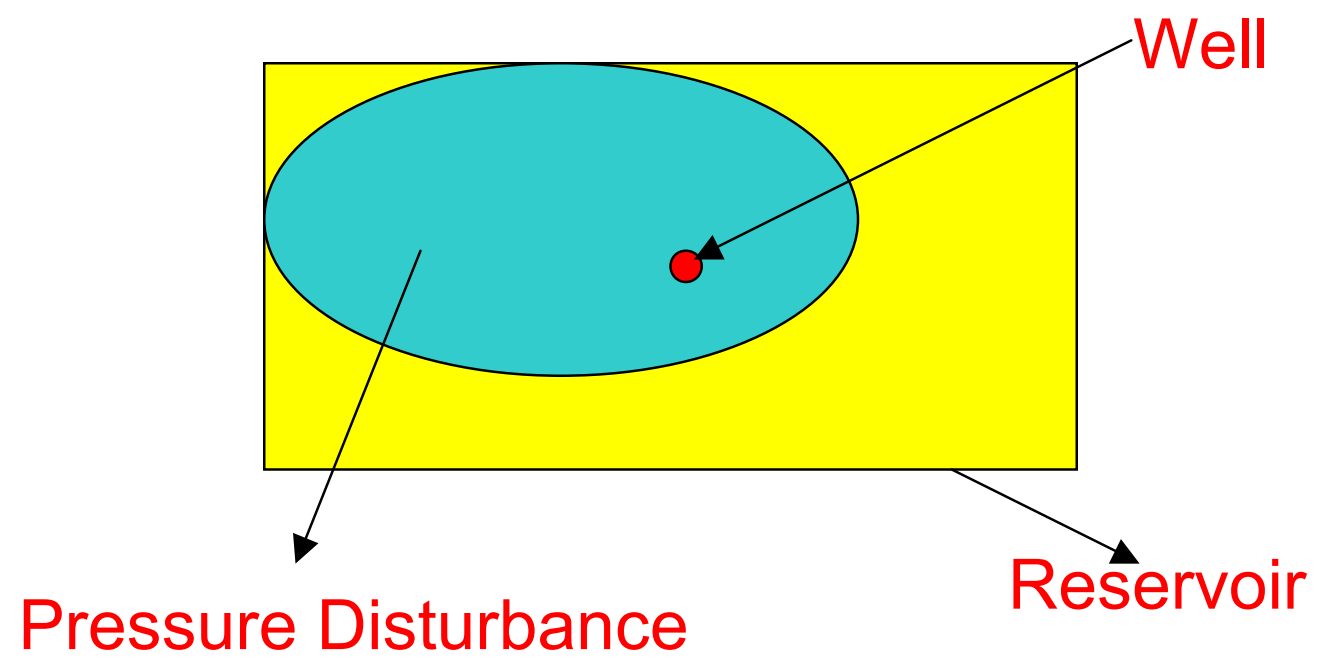

Figure 2.4. - Representation of Late Transient state. 


\section{CHAPTER III. PREDICTION OF PRODUCTIVITY METHODS}

There are different methods for predicting Productivity Index $(\mathrm{PI})$ of both types of wells (Vertical wells and Horizontal wells). In this study, multilateral wells are considered as horizontal wells.

\subsection{Steady State PI}

There are different methods ${ }^{3}$ for predicting the PI for Steady state Horizontal wells. They are:

- Borisov's method.

- The Giger - Reiss - Jourdan method.

- Joshi's method.

- The Renard - Dupuy method.

\subsubsection{Borisov's method}

Borisov proposed the following expression for predicting the productivity index of a horizontal well in an isotropic reservoir, i.e., $k_{v}=k_{h}$.

$$
J_{h}=\frac{0.00708 h k_{h}}{\mu_{o} B_{o}\left[\ln \left(\frac{4 r_{e h}}{L}\right)+\left(\frac{L}{h}\right) \ln \left(\frac{h}{2 \pi r_{w}}\right)\right]}
$$

\subsubsection{The Giger - Reiss - Jourdan method}

Giger - Reiss - Jourdan proposed the following expression for predicting the productivity index of a horizontal well in an isotropic reservoir, i.e., $\mathrm{k}_{\mathrm{v}}=\mathrm{k}_{\mathrm{h}}$.

$$
J_{h}=\frac{0.00708 L k_{h}}{\mu_{o} B_{o}\left[\left(\frac{L}{h}\right) \ln (X)+\ln \left(\frac{h}{2 r_{w}}\right)\right]}
$$




$$
X=\frac{1+\sqrt{1+\left(\frac{L}{2 r_{e h}}\right)^{2}}}{L /\left(2 r_{e h}\right)}
$$

For reservoir anisotropy, he proposed the following relationships:

$$
\begin{aligned}
J_{h} & =\frac{0.00708 k_{h}}{\mu_{o} B_{o}\left[\left(\frac{1}{h}\right) \ln (X)+\left(\frac{B^{2}}{L}\right) \ln \left(\frac{h}{2 r_{w}}\right)\right]} \\
B & =\sqrt{\frac{k_{h}}{k_{v}}}
\end{aligned}
$$

\subsubsection{Joshi's method}

Joshi proposed the following expression for estimating the productivity index of a horizontal well in an isotropic reservoir:

$$
\begin{aligned}
& J_{h}=\frac{0.00708 h k_{h}}{\mu_{o} B_{o}\left[\ln (R)+\left(\frac{h}{L}\right) \ln \left(\frac{h}{2 r_{w}}\right)\right]} \\
& R=\frac{a+\sqrt{a^{2}-(L / 2)^{2}}}{(L / 2)}
\end{aligned}
$$

Here ' $a$ ' is half the major axis of the drainage ellipse and is given by:

$$
a=(L / 2)\left[0.5+\sqrt{0.25+\left(2 r_{e h} / L\right)^{4}}\right]^{0.5}
$$

For the reservoir anisotropy, he proposed following relationships with vertical permeability, $\mathrm{k}_{\mathrm{v}}$ : 


$$
\begin{aligned}
J_{h} & =\frac{0.00708 h k_{h}}{\mu_{o} B_{o}\left[\ln (R)+\left(\frac{B^{2} h}{L}\right) \ln \left(\frac{h}{2 r_{w}}\right)\right]} \\
B & =\sqrt{\frac{k_{h}}{k_{v}}} \\
R & =\frac{a+\sqrt{a^{2}-(L / 2)^{2}}}{(L / 2)}
\end{aligned}
$$

Here ' $a$ ' is half the major axis of the drainage ellipse and is given by:

$$
a=(L / 2)\left[0.5+\sqrt{0.25+\left(2 r_{e h} / L\right)^{4}}\right]^{0.5}
$$

\subsubsection{The Renard - Dupuy method}

For an isotropic reservoir, Renard and Dupuy proposed the following expression:

$$
J_{h}=\frac{0.00708 h k_{h}}{\mu_{o} B_{o}\left[\cosh ^{-1}\left(\frac{2 a}{L}\right)+\left(\frac{h}{L}\right) \ln \left(\frac{h}{2 \pi r_{w}}\right)\right]}
$$

Here ' $a$ ' is half the major axis of the drainage ellipse and is given by:

$$
a=(L / 2)\left[0.5+\sqrt{0.25+\left(2 r_{e h} / L\right)^{4}}\right]^{0.5}
$$

For anisotropic reservoirs, these authors proposed the following relationship:

$$
J_{h}=\frac{0.00708 h k_{h}}{\mu_{o} B_{o}\left[\cosh ^{-1}\left(\frac{2 a}{L}\right)+\left(\frac{B h}{L}\right) \ln \left(\frac{h}{2 \pi r_{w}^{\prime}}\right)\right]}
$$

where

$$
r_{w}^{\prime}=\frac{(1+B) r_{w}}{2 B}, \quad B=\sqrt{\frac{k_{h}}{k_{v}}}
$$




\subsection{Pseudo-Steady State PI}

There are different methods for predicting the PI for pseudo - steady state horizontal wells. Three methods are discussed below:

- Babu - Odeh method.

- Kuchuk method.

- Economides method.

\subsubsection{Babu - Odeh method ${ }^{4}$}

Babu \& Odeh presented the following equation for pseudo-steady state conditions:

$$
J_{h}=\frac{0.00708 L_{y} \sqrt{k_{x} k_{y}}}{\mu B\left[\ln \left(\frac{\sqrt{L_{x} h}}{r_{w}}\right)+\ln \left(C_{h}\right)-0.75+S_{R}+S_{d}\right]}
$$

where,

$$
\ln \left(C_{h}\right)=6.28 L_{x} / h \sqrt{k_{z} / k_{x}}\left[\frac{1}{3}-\frac{x_{o}}{L_{x}}+\left(\frac{x_{o}}{L_{x}}\right)^{2}\right]-\ln \left(\sin 180^{\circ} z_{o} h\right)-0.5 \ln \left[\left(\frac{L_{x}}{h}\right) \sqrt{k_{z} / k_{x}}\right]-1.088
$$

here $\mathrm{x}_{\mathrm{o}}$ and $\mathrm{z}_{\mathrm{o}}$ are the coordinates measuring the centre of the well in the vertical plane, $L_{x}$ and $L_{y}$ are the dimensions of the drainage area, orthogonal and parallel respectively to the horizontal well. $S_{R}$ and $S_{d}$ are the skin factors under different conditions.

\subsubsection{Kuchuk method ${ }^{4}$}

Productivity equation suggested by Kuchuk used an approximate infinite-conductivity solution. It is expressed as:

$$
J_{h}=\frac{k_{h} h /\left(70.6 \mu_{o}\right)}{F+(h / 0.5 L) \sqrt{k_{h} / k_{v}} s_{x}}
$$

where $F$ is a dimensionless function and depends upon $y_{w} /\left(2 y_{e}\right), x_{w} /\left(2 x_{e}\right), L /\left(4 x_{e}\right)$ and $\left(y_{e} / x_{e}\right)$ 
$\sqrt{k_{x} / k_{y}}$. The value of $\mathrm{s}_{\mathrm{x}}$ is calculated using the following equation:

$s_{x}=\ln \left[\left(\frac{\pi r_{w}}{h}\right)\left(1+\sqrt{\frac{k_{v}}{k_{h}}}\right) \sin \left(\frac{\pi z_{w}}{h}\right)\right]-\sqrt{\frac{k_{h}}{k_{v}}}\left(\frac{2 h}{L}\right)\left[\frac{1}{3}-\left(\frac{z_{w}}{h}\right)+\left(\frac{z_{w}}{h}\right)^{2}\right]$

\subsubsection{Economides Method ${ }^{5}$}

Economides suggested the following equation for calculating the PI:

$$
J=\frac{q_{o}}{\left(\bar{p}-p_{w f}\right)}=\frac{\bar{k} x_{e}}{887.22 B \mu\left(p_{D}+\frac{x_{e}}{2 \pi L} \sum s\right)}
$$

where,

$p_{D}=\frac{x_{e} C_{H}}{4 \pi h}+\frac{x_{e}}{2 \pi L} s_{x}$

$\sum s$ - is the summation of all damage and pseudo-skin factors.

Skin effect $s_{x}$ is:

$s_{x}=\ln \left(\frac{h}{2 \pi r_{w}}\right)-\frac{h}{6 L}+s_{e}$

where,

$s_{e}=\frac{h}{L}\left[\frac{2 z_{w}}{h}-\frac{1}{2}\left(\frac{2 z_{w}}{h}\right)^{2}-\frac{1}{2}\right]-\ln \left[\sin \left(\frac{\pi z_{w}}{h}\right)\right]$ 


\subsection{Literature Review}

\subsubsection{Analytical Solutions}

There are two main categories under which any oil or gas well is classified according to their design as a vertical well or a horizontal well. An unstimulated horizontal well can generate production rates of two to five times to that of an unstimulated vertical well at a similar pressure drawdown. Apart from this main advantage there are also few disadvantages of horizontal wells. Some of the disadvantages of horizontal wells are the less effectiveness in thicker reservoirs (>500 ft), reservoirs with low vertical permeability (relative to horizontal permeability) and in stratified reservoirs with impermeable shale barriers. Improvement of well completion and stimulation technology can overcome these disadvantages. The use of hydraulic fractures to enhance horizontal well productivity is explained by Giger et $\mathrm{al}^{6}$ and $\mathrm{Giger}^{7}$.

There have been several attempts to describe and estimate horizontal well productivity and/or injectivity indexes and several models have been used for this purpose. A widely used approximation for the well drainage is a parallelepiped model with no-flow or constant-pressure boundaries at the top or bottom, and either no-flow or infinite-acting boundaries at the sides.

One of the earliest models was introduced first by Borisov ${ }^{8}$, which assumed a constant pressure drainage ellipse whose dimensions depend on the well length. Using this configuration Joshi $^{9}$ came up with an equation, which accounted for vertical-to-horizontal permeability anisotropy. Then Economides et al., ${ }^{10}$ modified it for a wellbore in elliptical coordinates. This model does not account for either early-time or late-time phenomena nor, more importantly, actual well and reservoir configurations.

Babu \& Odeh ${ }^{11}$ used an expression, which was complicated and cumbersome to calculate, for the pressure drop at any point by integrating appropriate point source (Green's) functions in space and time. Their work assumes that the well is parallel to the y-axis of the parallelepiped model. Goode and Thambynayagam ${ }^{12}$ solved a model for horizontal well pressure transient response in Laplace space and inverted solution using a numerical inverter. Kuchuk et 
al. ${ }^{13}$ extended the Goode and Thambynayagam ${ }^{12}$ approach by including constant pressure (at the top and/or bottom) boundaries.

In general it is believed that the productivity of a horizontal well is proportional to the well length. But as the length increases, drilling and well control becomes more difficult. Apart from this, transportation of large volumes of liquid along a long horizontal borehole results in considerable pressure losses in the wellbore. Wellbore pressure loss yields a decrease in well productivity. Multilateral wells provide an alternative to drilling long single horizontal wells. There are many publications, which have discussed the flow into multilaterals. These can be grouped into three categories: productivity models ${ }^{14-17}$, transient flow models ${ }^{17-25}$ and field applications $^{26-30}$. 


\section{CHAPTER IV. APPROACH USING RESERVOIR SIMULATION}

\subsection{Numerical Simulation Models for Multilateral wells}

To evaluate the productivity index of multilateral wells, reservoir simulation software, ECLIPSE from Schlumberger, is used in this thesis. The ECLIPSE simulator is used to generate different models in this thesis with version 2005A for black oil (ECLIPSE 100). ECLIPSE 100 is a fully implicit, three-phase, three-dimensional black oil simulator. The black oil model considers the reservoir fluids consisting of reservoir oil, solvent gas and water. The reservoir oil and solvent gas components are assumed to be miscible in all proportions.

In this study, five different horizontal completions were considered. Namely:

1. Single Lateral.

2. Dual Lateral (with laterals at same depth).

3. Dual Lateral (with laterals at different depths).

4. Four Laterals (with laterals perpendicular to each other).

5. Single Vertical Well.

Additionally, four different lengths of $500 \mathrm{ft}, .1000 \mathrm{ft}$., $1500 \mathrm{ft}$., and $2000 \mathrm{ft}$. were considered for all lateral completions.

In all cases, the following wellbore configurations were used:

$\begin{array}{lll}\text { Main borehole diameter } & : & 12 \mathrm{in} . \\ \text { Casing Inner diameter } & : & 8.4 \mathrm{in} . \\ \text { Casing Outer diameter } & : & 9 \mathrm{in} . \\ \text { Casing Roughness } & : & 0.001 \mathrm{in} . \\ \text { Tubing Inner diameter } & : & 2.0 \mathrm{in} . \\ \text { Tubing Outer diameter } & : & 2.441 \mathrm{in} . \\ \text { Tubing Inner roughness } & : & 0.012 \mathrm{in} . \\ \text { Tubing Outer roughness } & : & 0.012 \mathrm{in} . \\ \text { Packer set at a vertical depth } & : & 4950 \mathrm{ft} .\end{array}$


GRID STRUCTURE:

\begin{tabular}{|c|c|c|c|}
\hline Direction & Minimum cell size & Maximum cell size & Growth factor \\
\hline $\mathrm{X}-$ direction & $1 \mathrm{ft}$. & $500 \mathrm{ft}$. & 2 \\
\hline $\mathrm{Y}-$ direction & $1 \mathrm{ft}$. & $500 \mathrm{ft}$. & 2 \\
\hline$Z-$ direction & $1 \mathrm{ft}$. & $500 \mathrm{ft}$. & 2 \\
\hline
\end{tabular}

All of the above-mentioned configurations, which were generated using ECLIPSE, are described below. All runs were conducted for 30 years.

\section{Single Lateral:}

Figure 4.1 is the schematic of a $500 \mathrm{ft}$ Single Lateral Well. Figure 4.2 shows grid structure used for the $500 \mathrm{ft}$ Single Lateral Well.

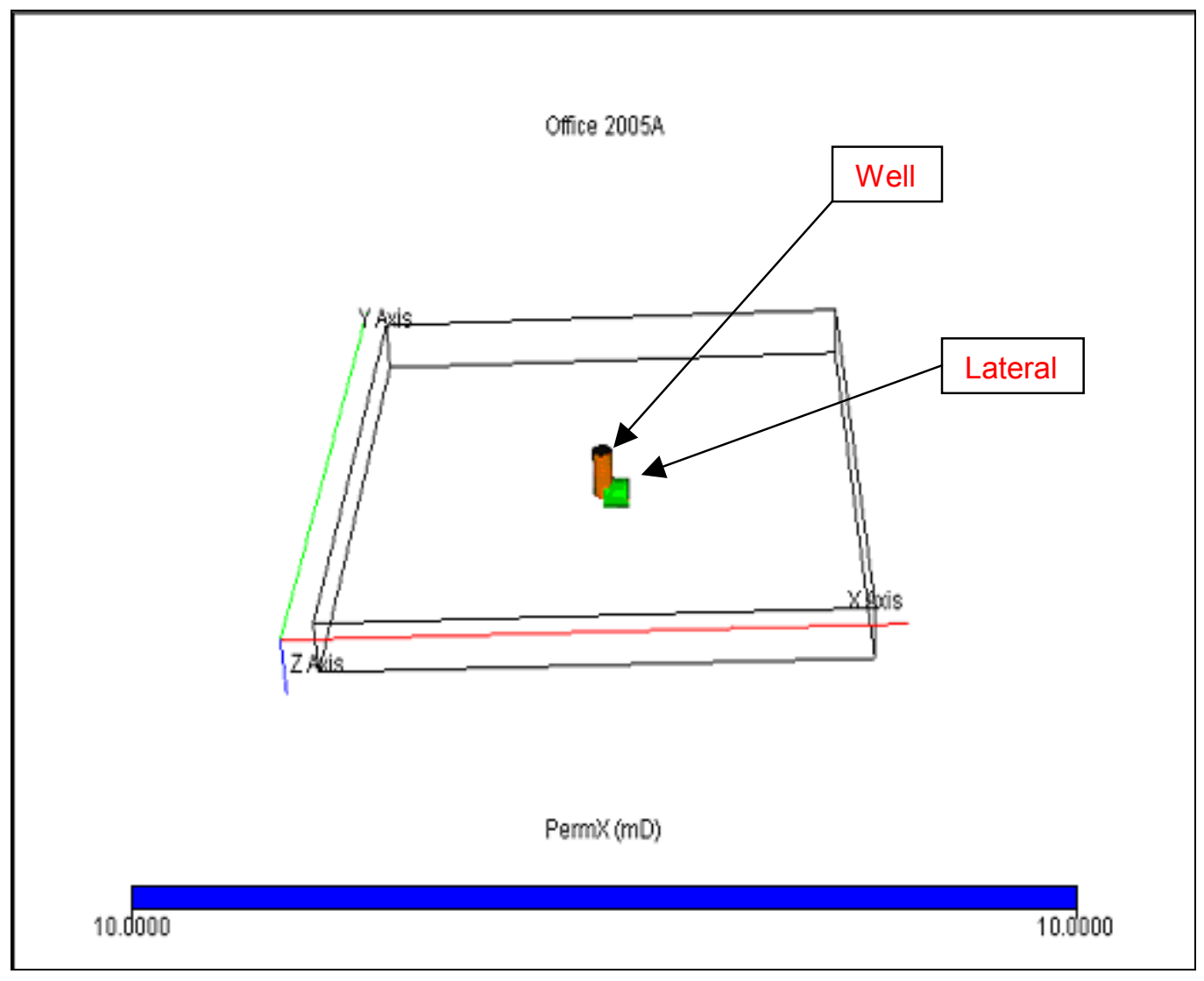

Figure 4.1: $500 \mathrm{ft}$. Single Lateral Well. 


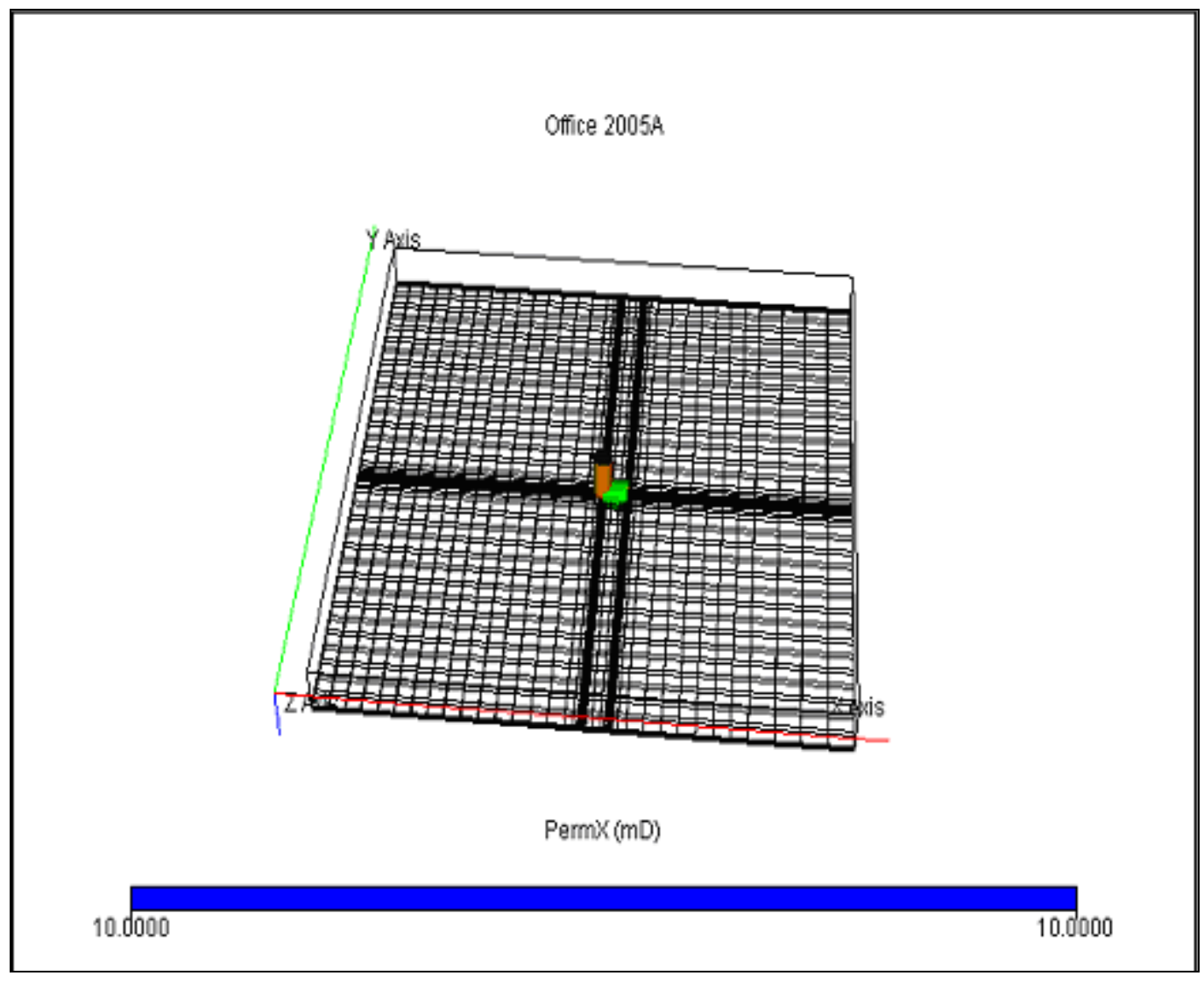

Figure 4.2: Grid structure of $500 \mathrm{ft}$. Single Lateral Well. 
Figure 4.3 is the schematic of a $1000 \mathrm{ft}$ Single Lateral Well. Figure 4.4 shows grid structure used for the $1000 \mathrm{ft}$ Single Lateral Well.

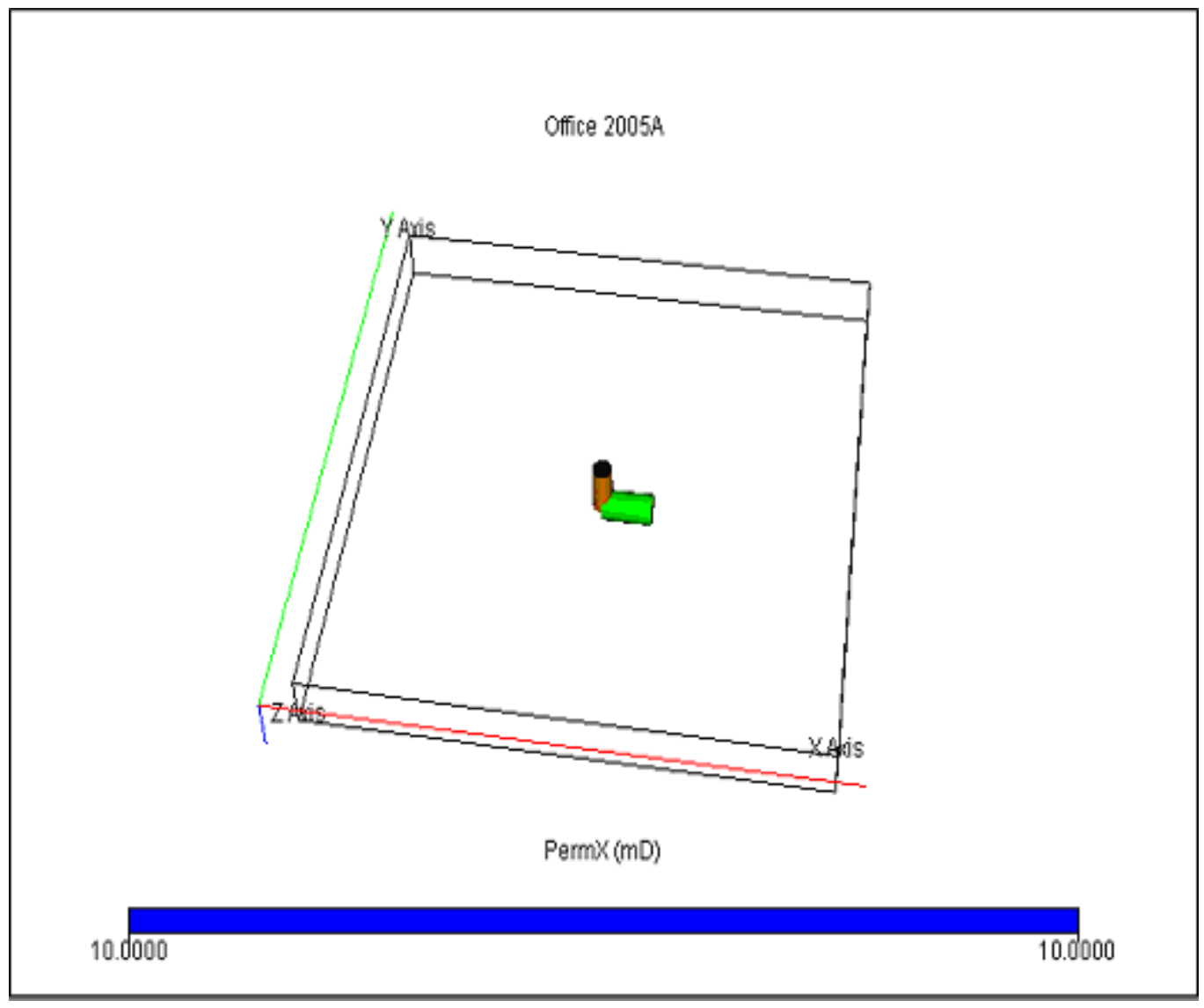

Figure 4.3: $1000 \mathrm{ft}$. Single Lateral Well. 


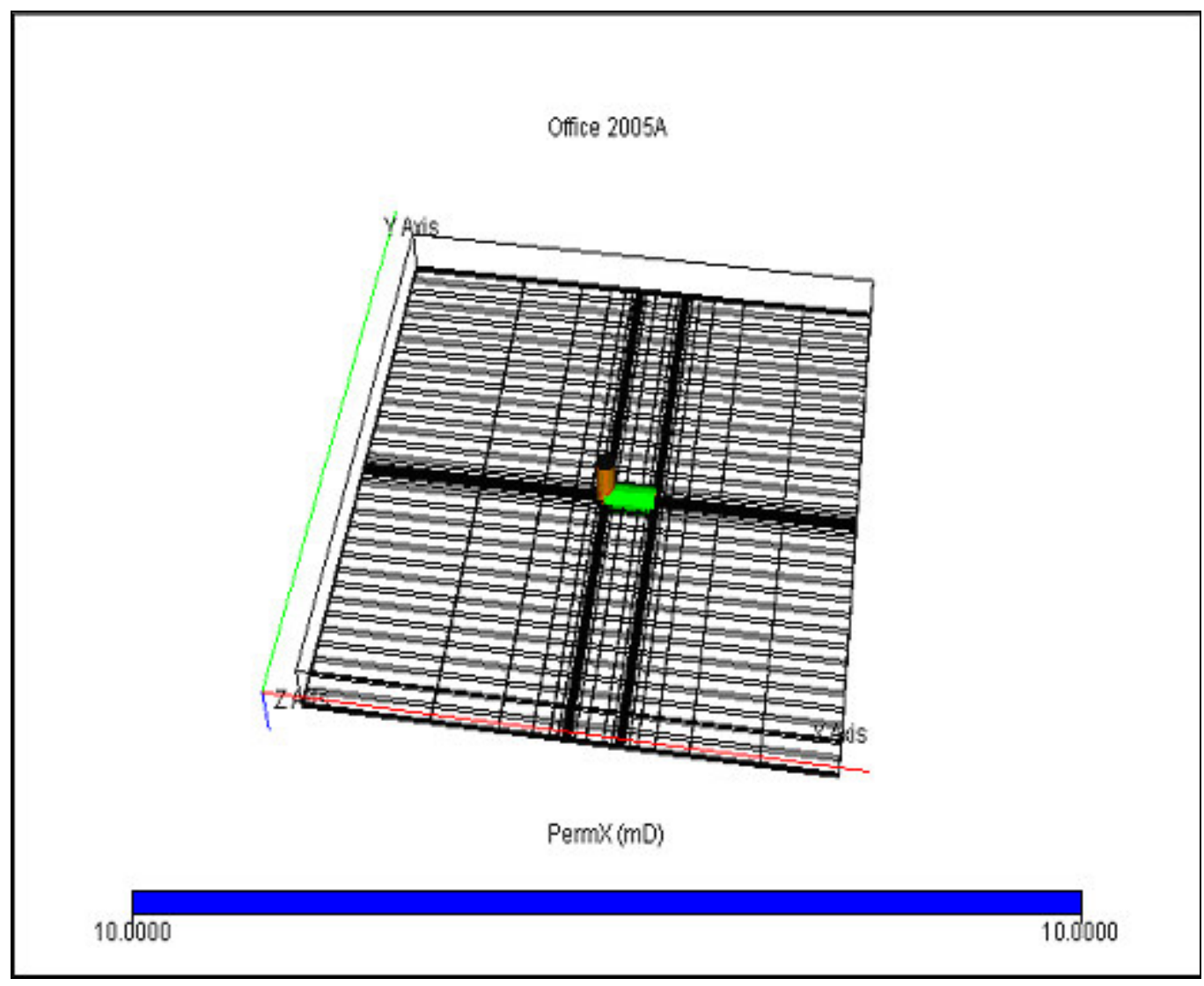

Figure 4.4: Grid structure of $1000 \mathrm{ft}$. Single Lateral Well. 
Figure 4.5 is the schematic of a $1500 \mathrm{ft}$ Single Lateral Well. Figure 4.6 shows grid structure used for the $1500 \mathrm{ft} \mathrm{Single} \mathrm{Lateral} \mathrm{Well.}$

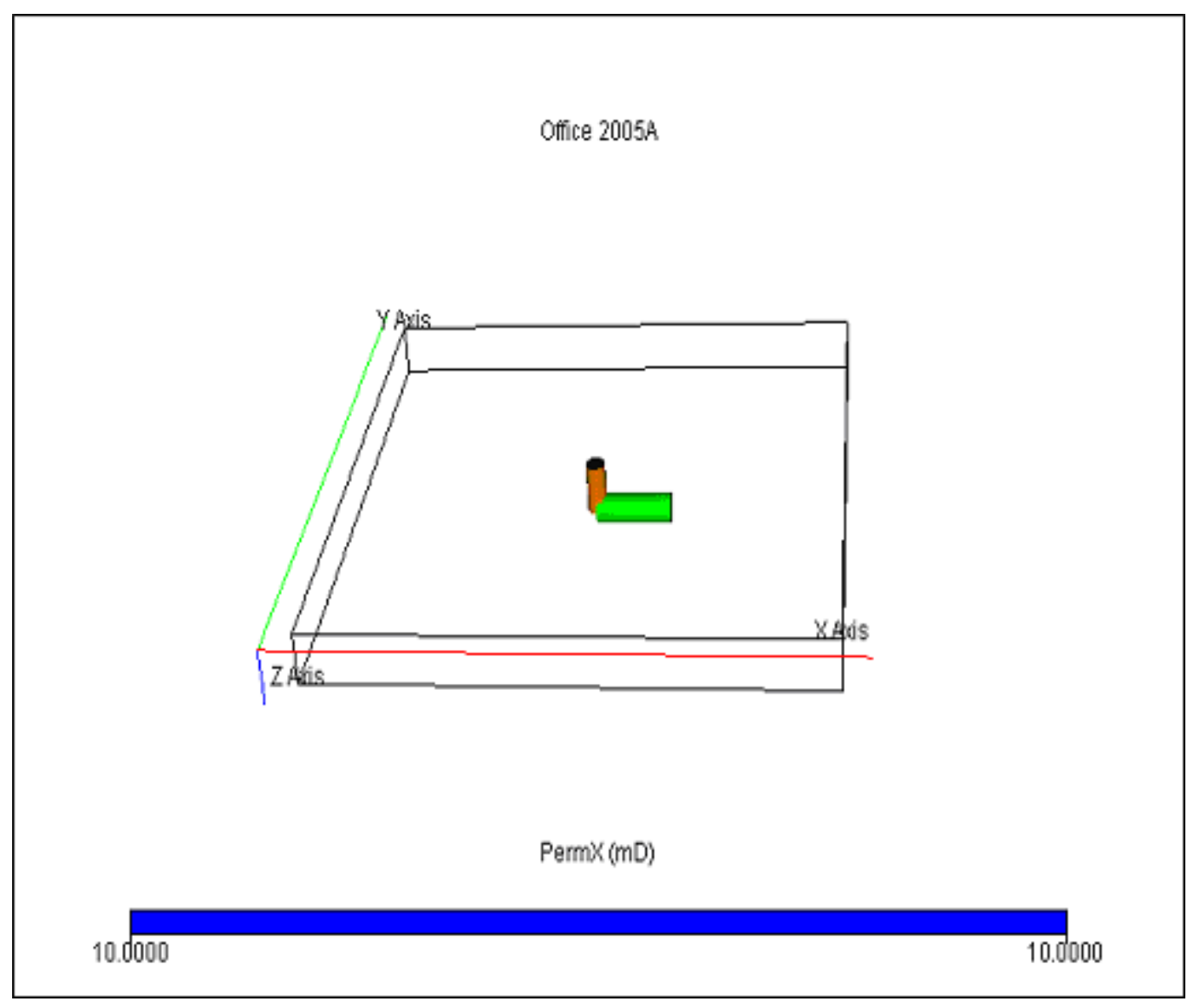

Figure 4.5: $1500 \mathrm{ft}$. Single Lateral Well. 


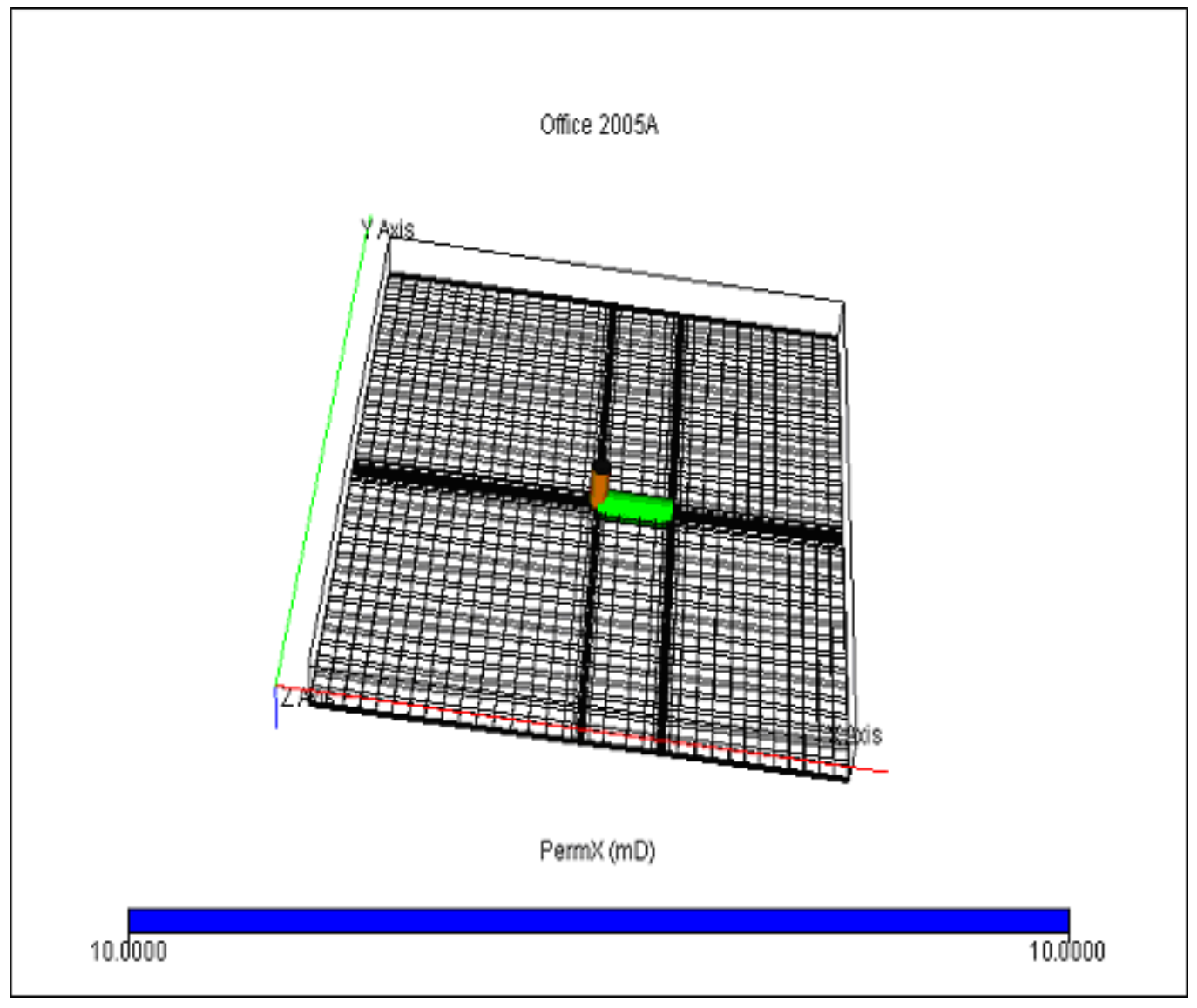

Figure 4.6: Grid structure of $1500 \mathrm{ft}$. Single Lateral Well. 
Figure 4.7 is the schematic of a $2000 \mathrm{ft}$ Single Lateral Well. Figure 4.8 shows grid structure used for the $2000 \mathrm{ft}$ Single Lateral Well.

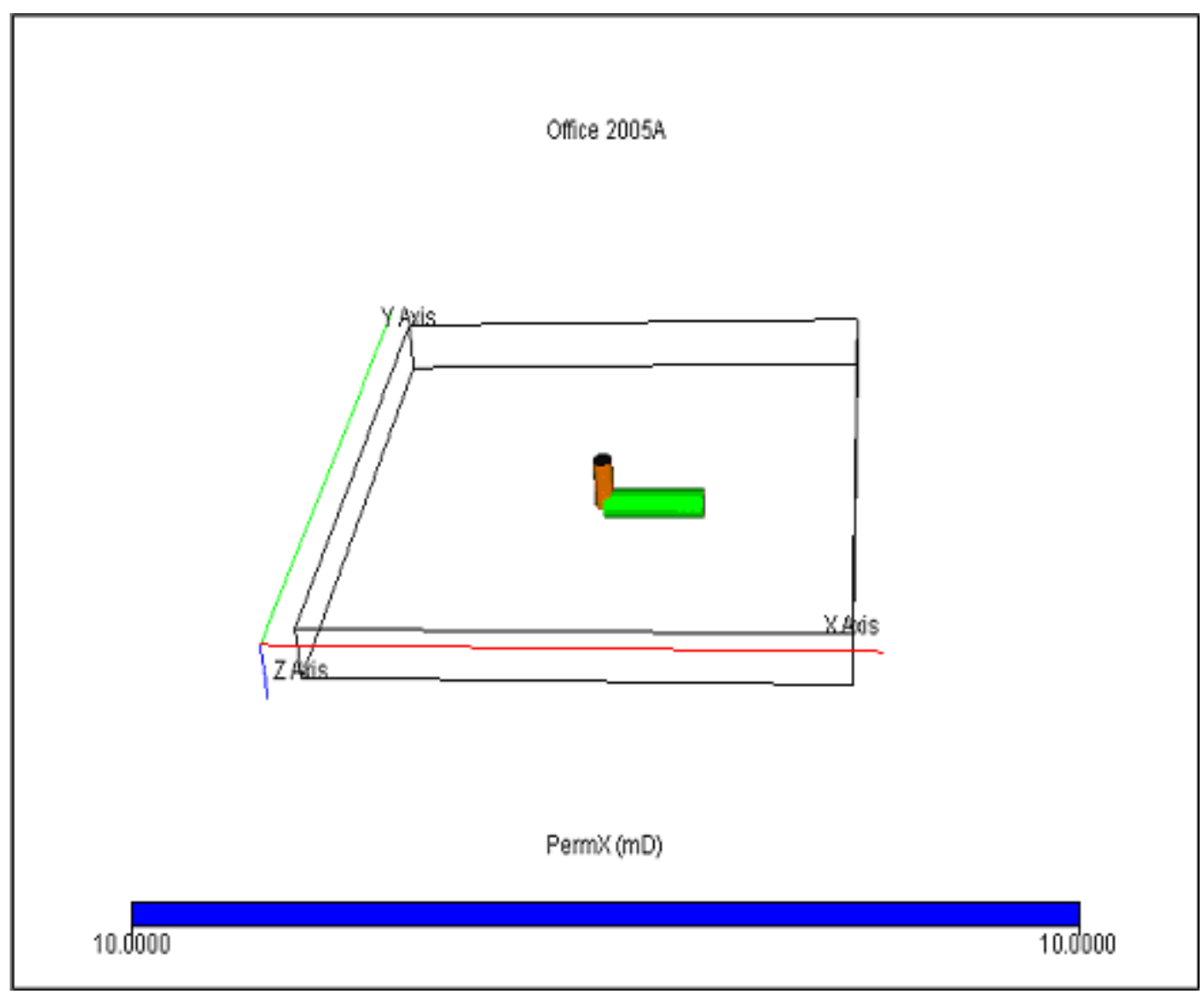

Figure 4.7: $2000 \mathrm{ft}$. Single Lateral Well. 


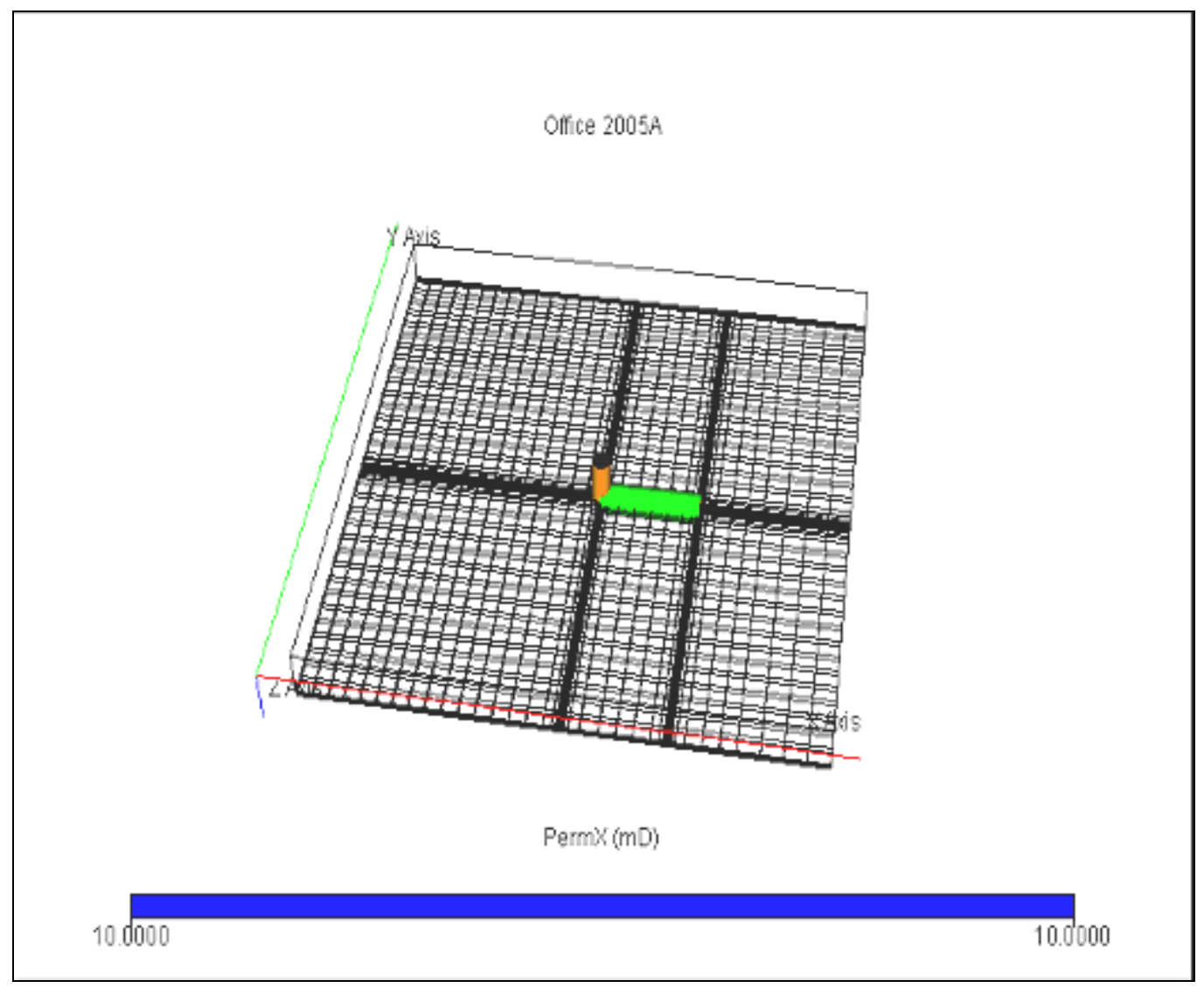

Figure 4.8: Grid structure of $2000 \mathrm{ft}$. Single Lateral Well. 


\section{Dual Lateral:}

Figure 4.9 is the schematic of a $500 \mathrm{ft}$ Dual Lateral Well and Figure 4.10 shows grid structure used for the $500 \mathrm{ft}$ Dual Lateral well.

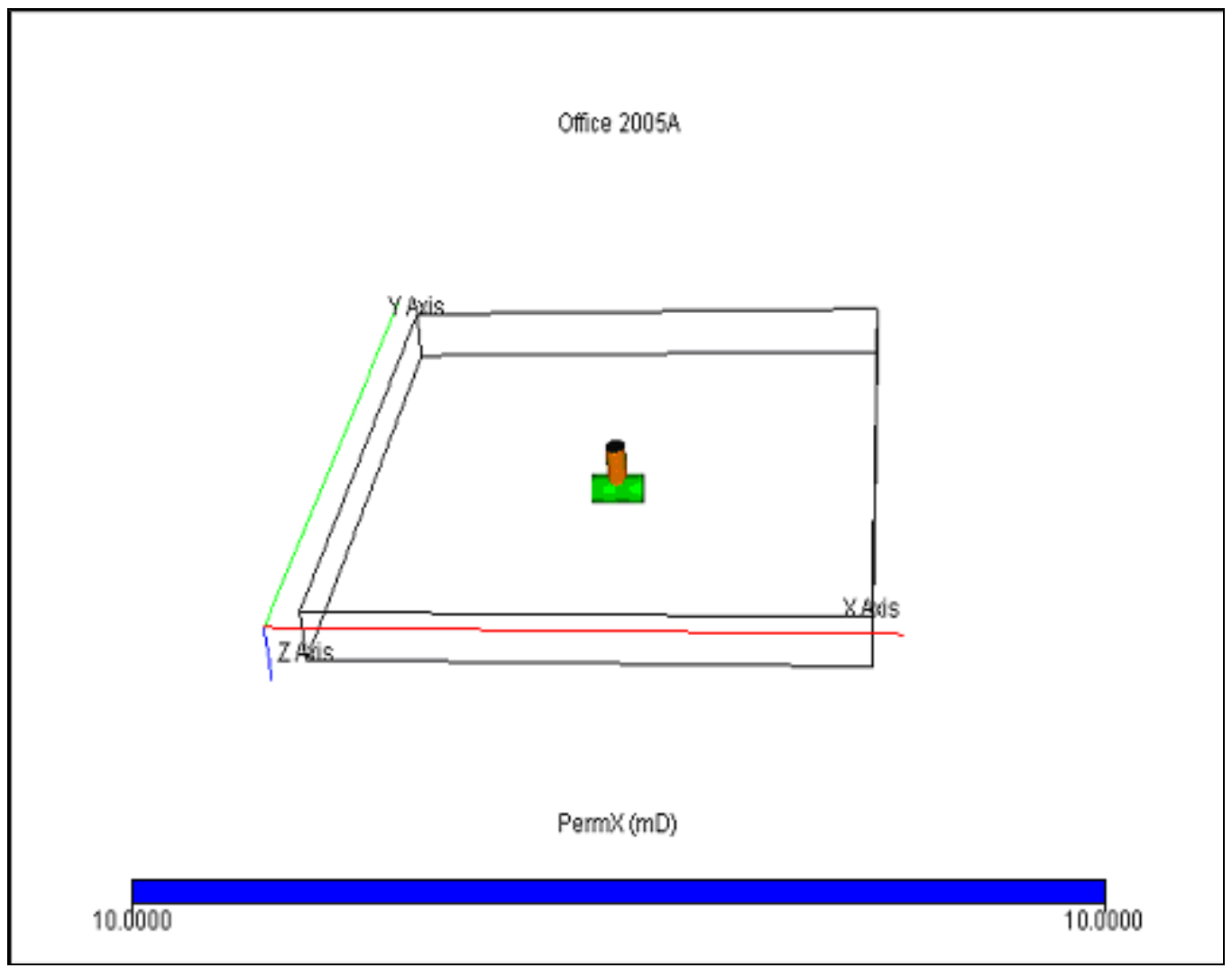

Figure 4.9: $500 \mathrm{ft}$. Dual Lateral Well. 


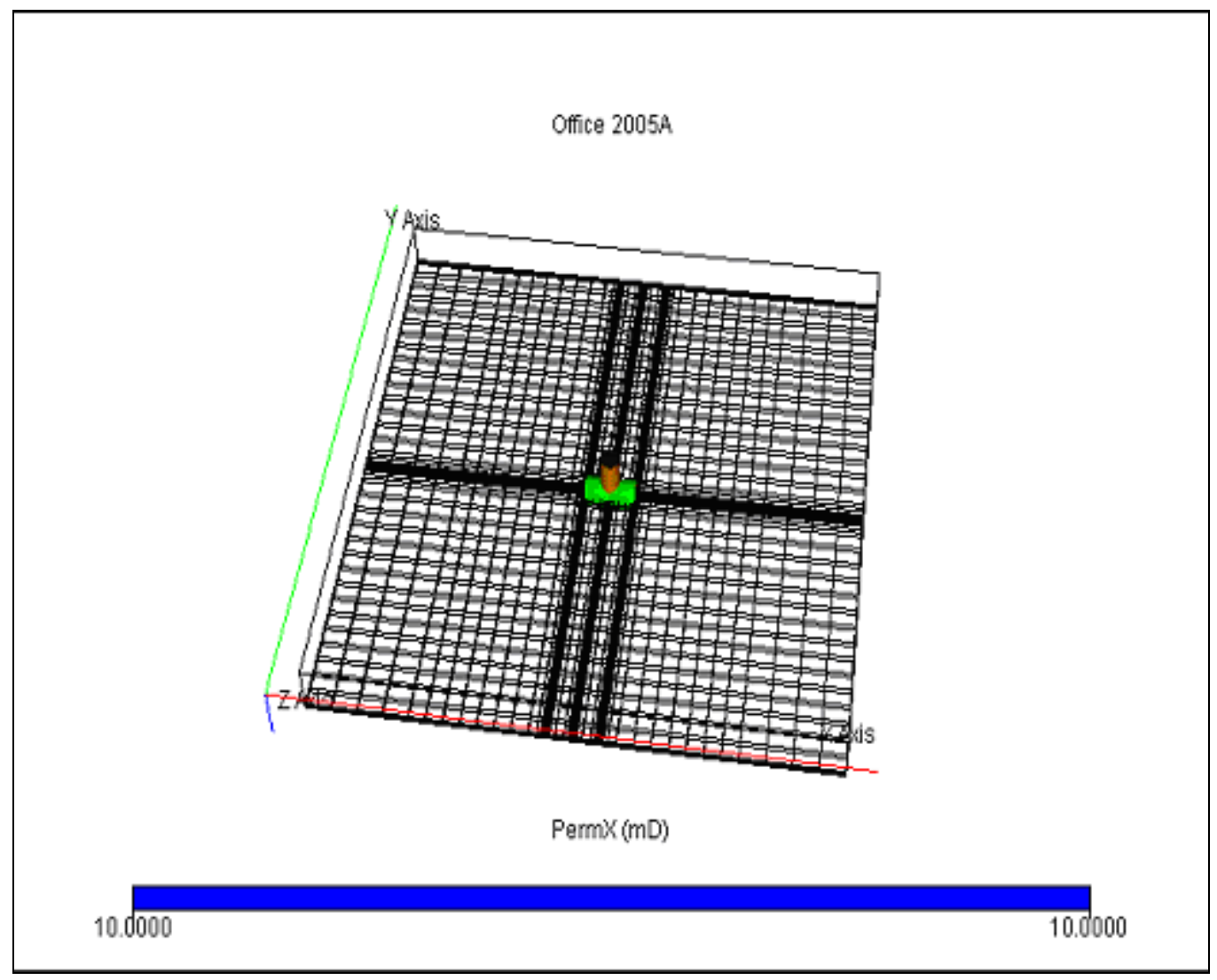

Figure 4.10: Grid structure of $500 \mathrm{ft}$. Dual Lateral Well. 
Figure 4.11 is the schematic of a $1000 \mathrm{ft}$ Dual Lateral Well and Figure 4.12 shows grid structure used for the $1000 \mathrm{ft}$ Dual Lateral well.

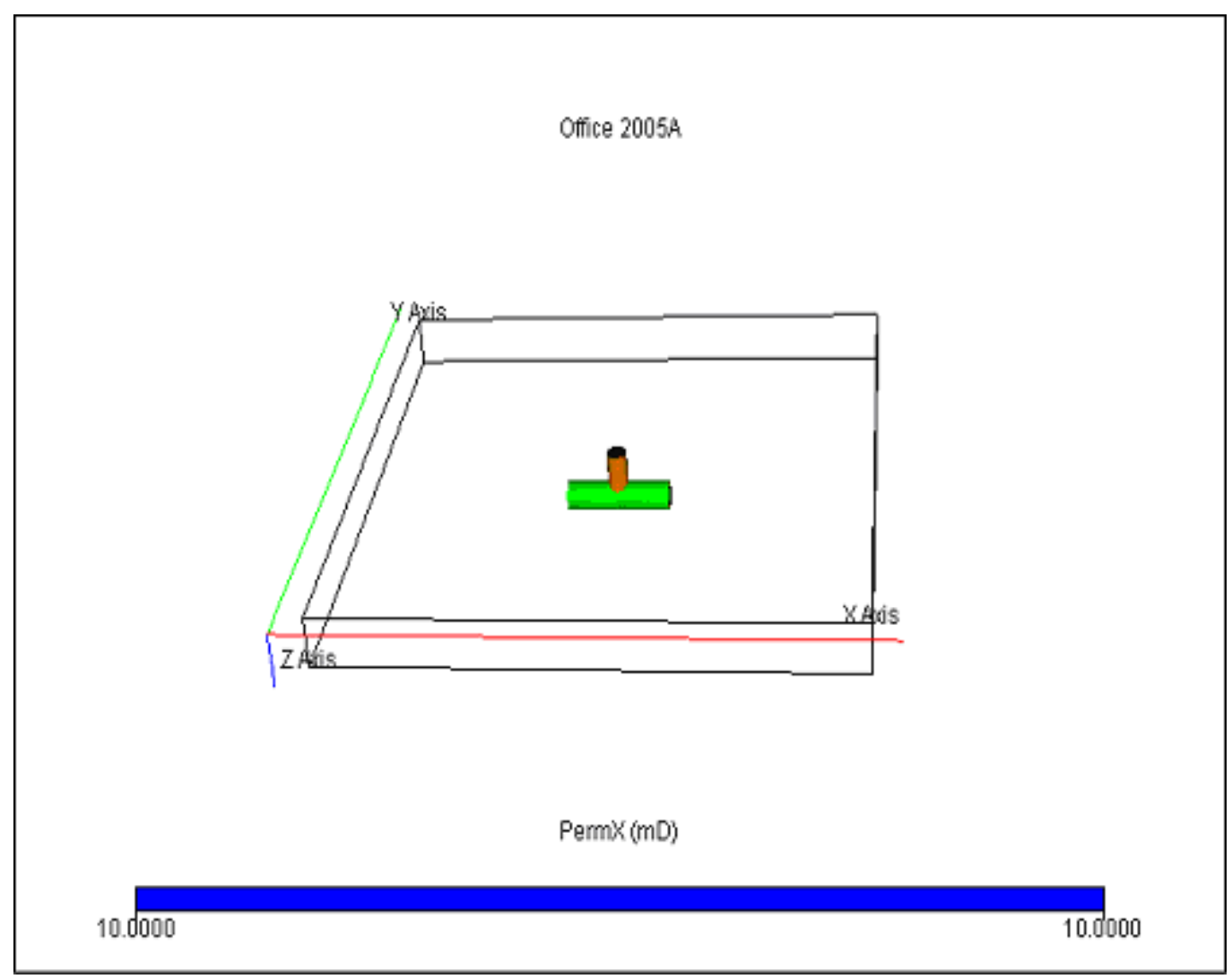

Figure 4.11: $1000 \mathrm{ft}$. Dual Lateral Well. 


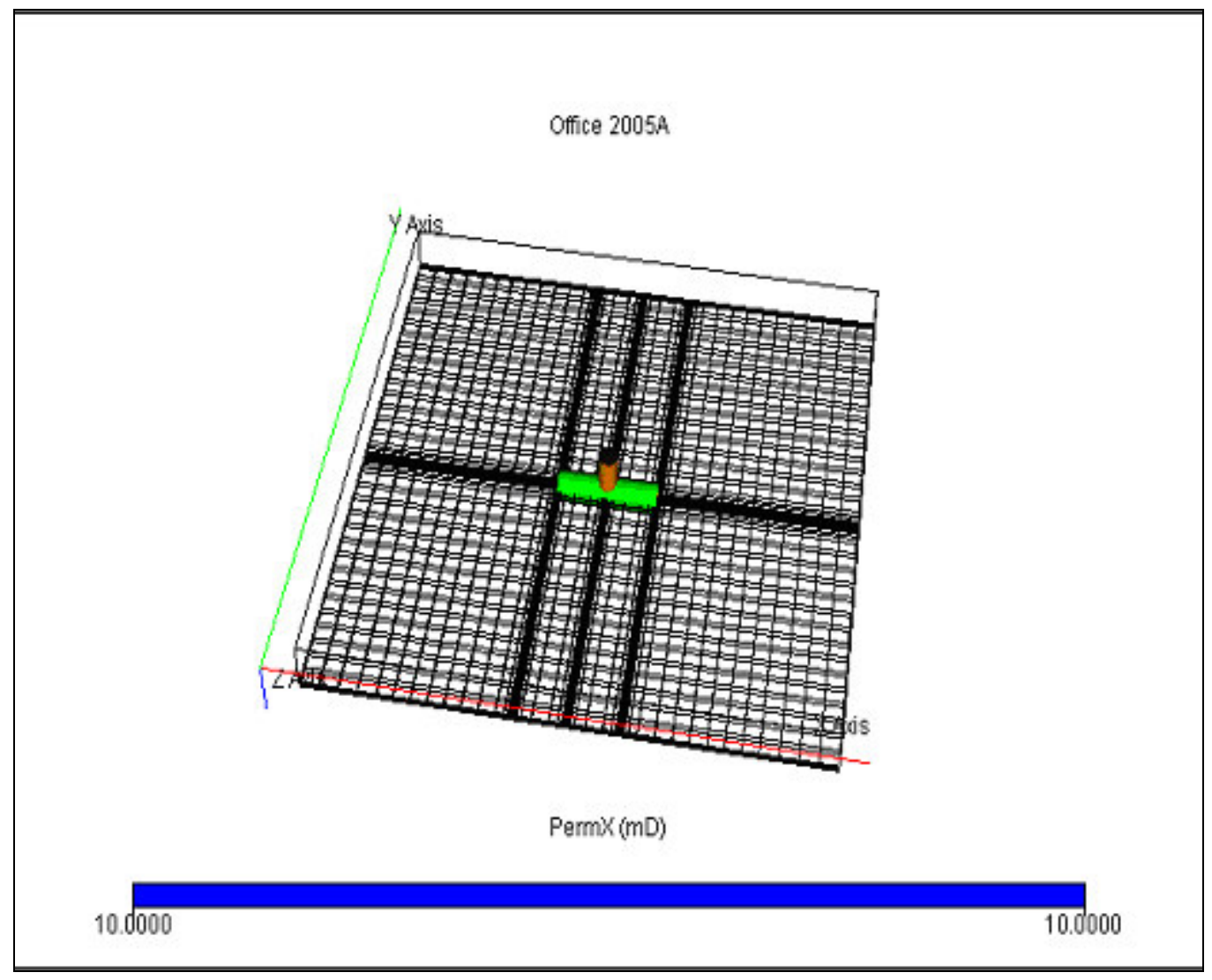

Figure 4.12: Grid structure for the1000 ft. Dual Lateral Well. 
Figure 4.13 is the schematic of a $1500 \mathrm{ft}$ Dual Lateral Well and Figure 4.14 shows grid structure used for the $1500 \mathrm{ft}$ Dual Lateral well.

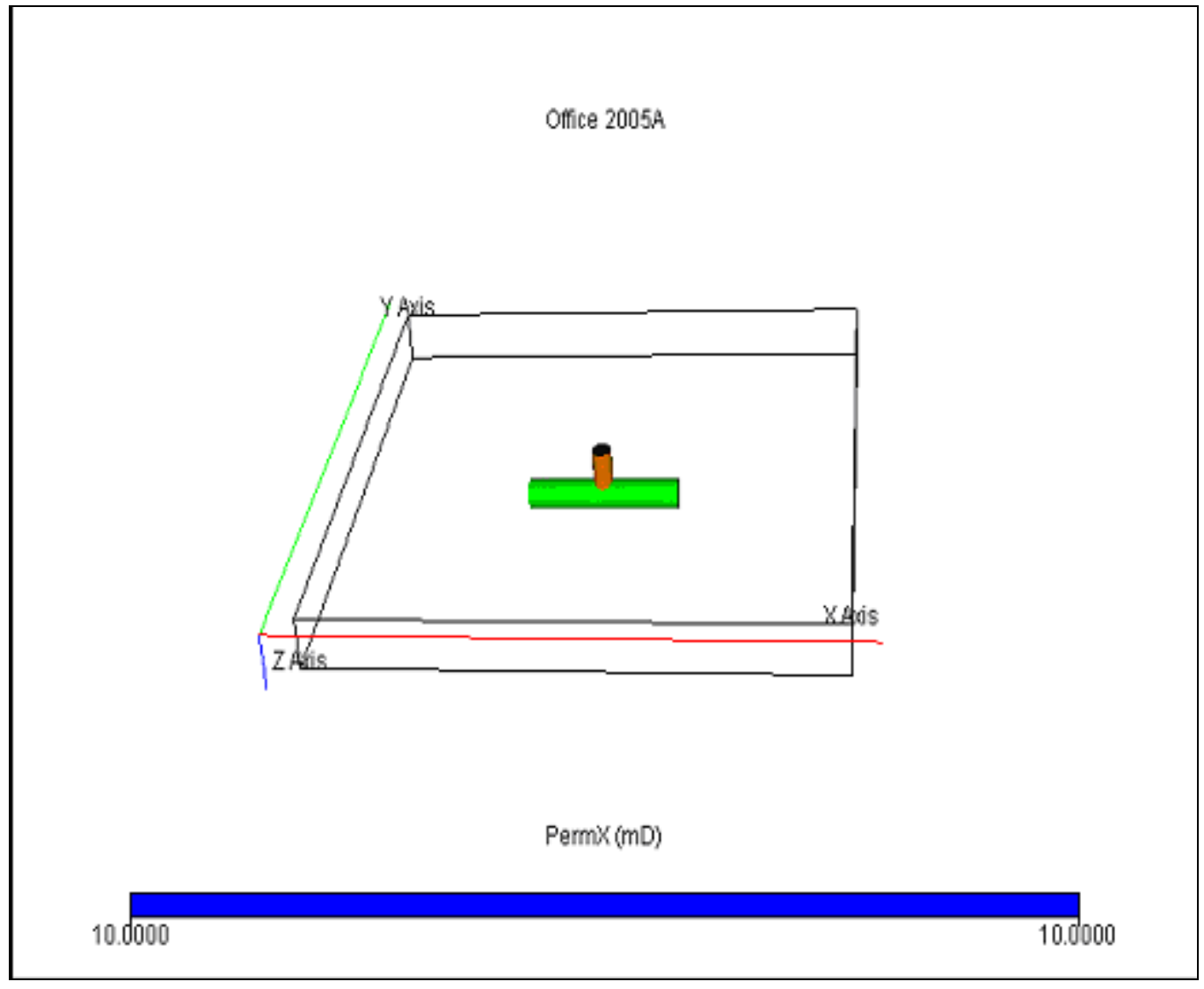

Figure 4.13: $1500 \mathrm{ft}$. Dual Lateral Well. 


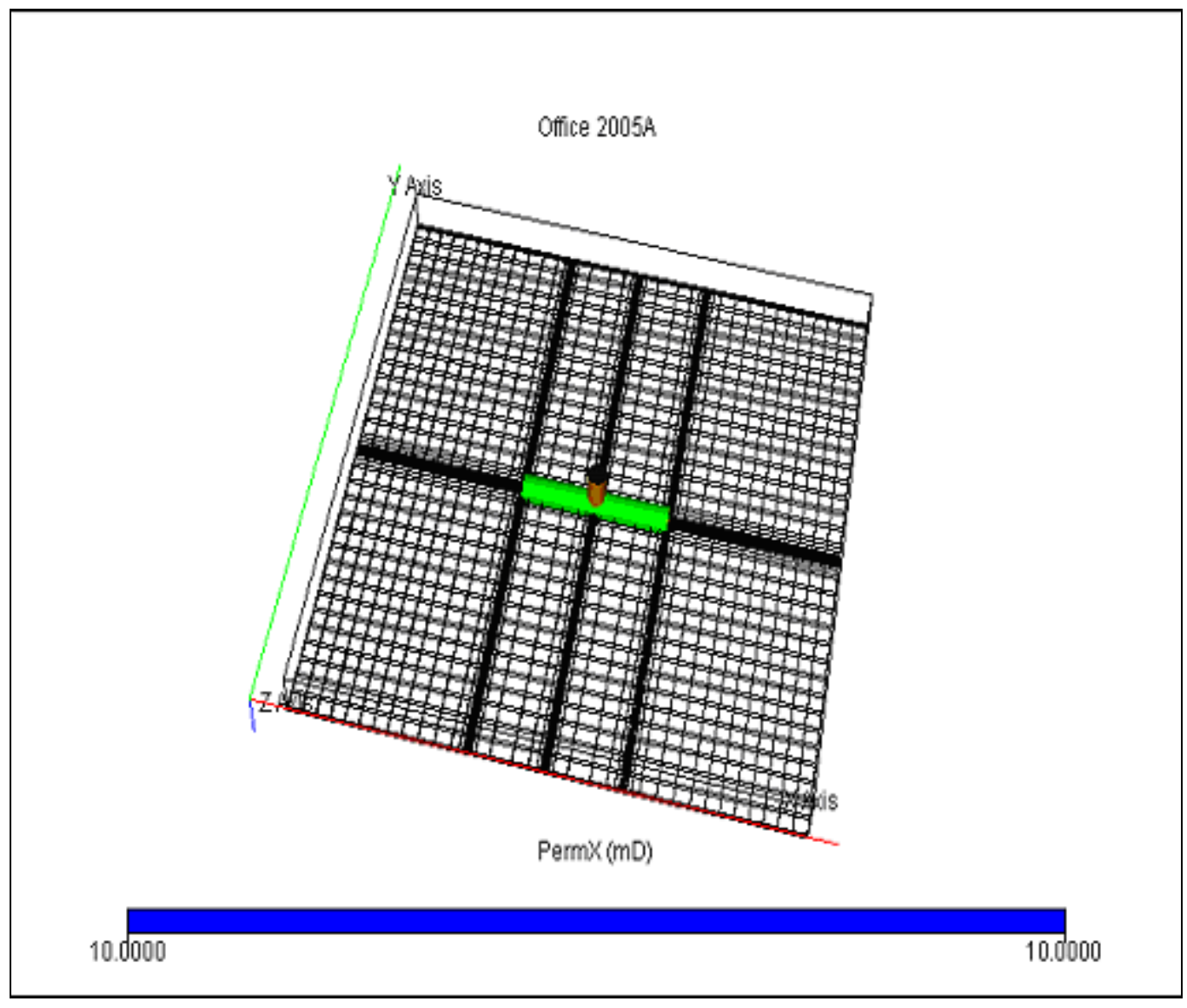

Figure 4.14: Grid structure for the $1500 \mathrm{ft}$. Dual Lateral Well. 
Figure 4.15 is the schematic of a $2000 \mathrm{ft}$ Dual Lateral Well and Figure 4.16 shows grid structure used for the $2000 \mathrm{ft}$ Dual Lateral well.

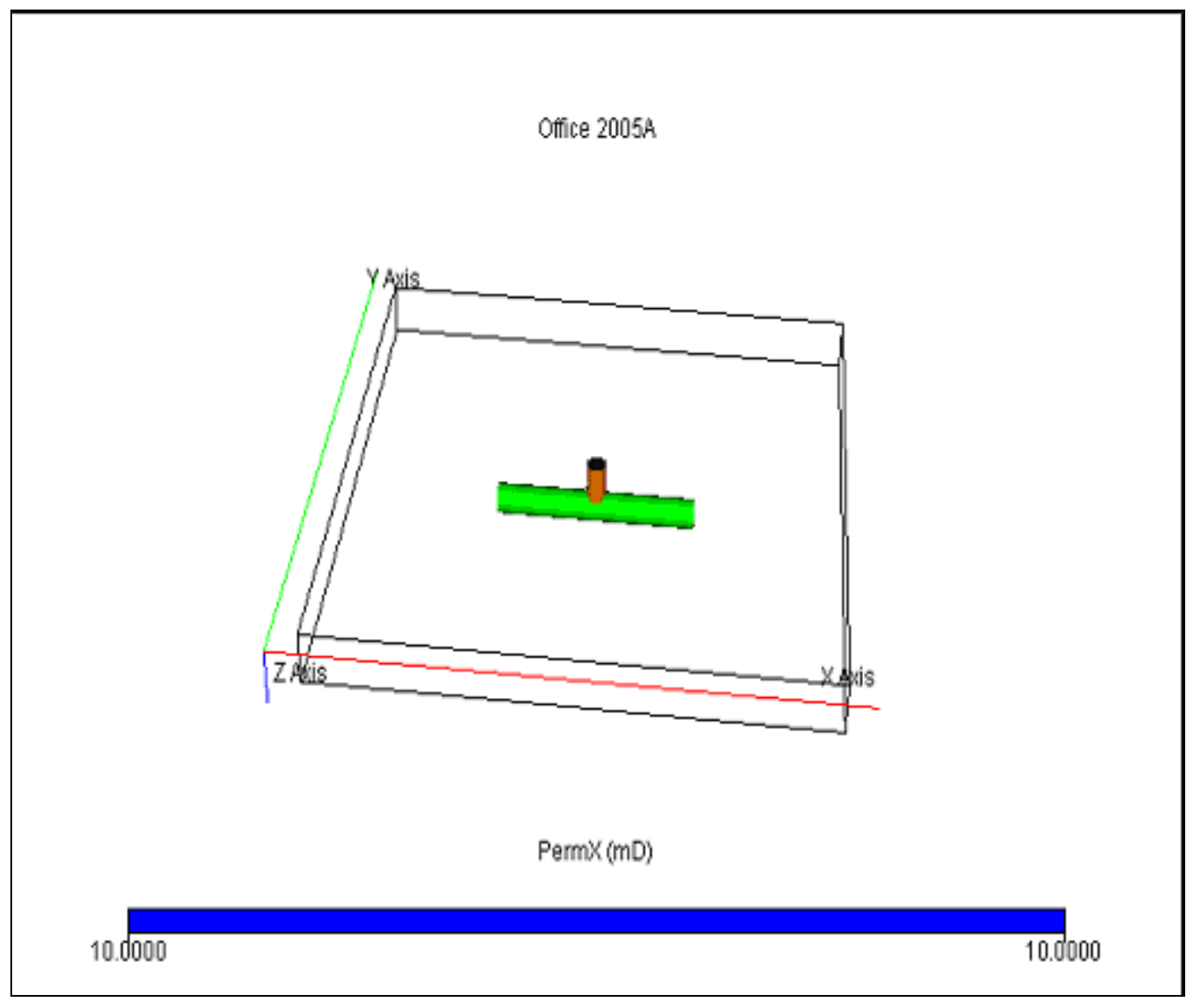

Figure 4.15: $2000 \mathrm{ft}$. Dual Lateral Well. 


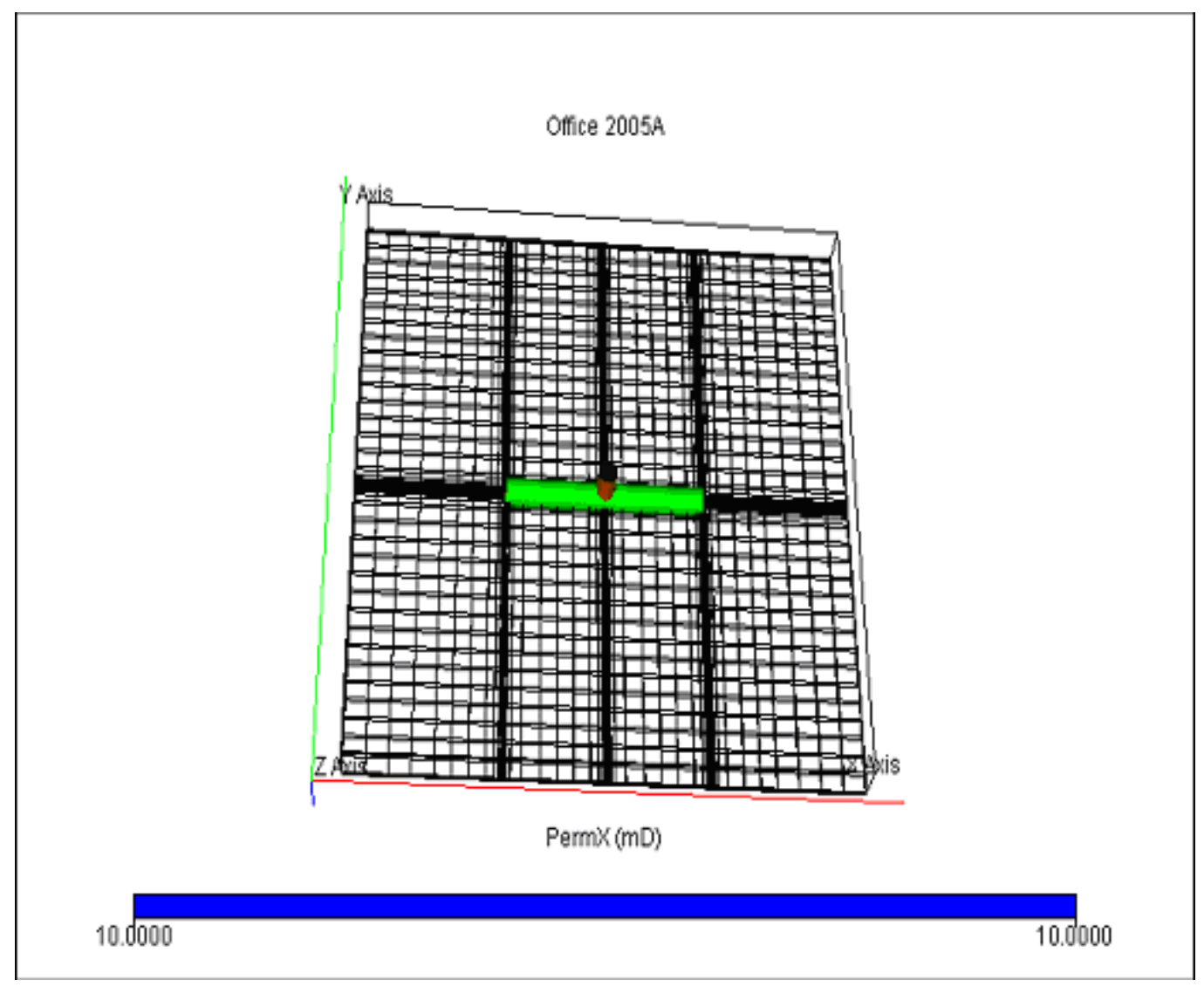

Figure 4.16: Grid structure for the $2000 \mathrm{ft}$. Dual Lateral Well. 
Dual Lateral well with laterals at different depths:

Figure 4.17 is the schematic of a $500 \mathrm{ft}$ Dual Lateral Well with laterals at different depths and Figure 4.18 shows grid structure used for this $500 \mathrm{ft}$ Dual Lateral well.

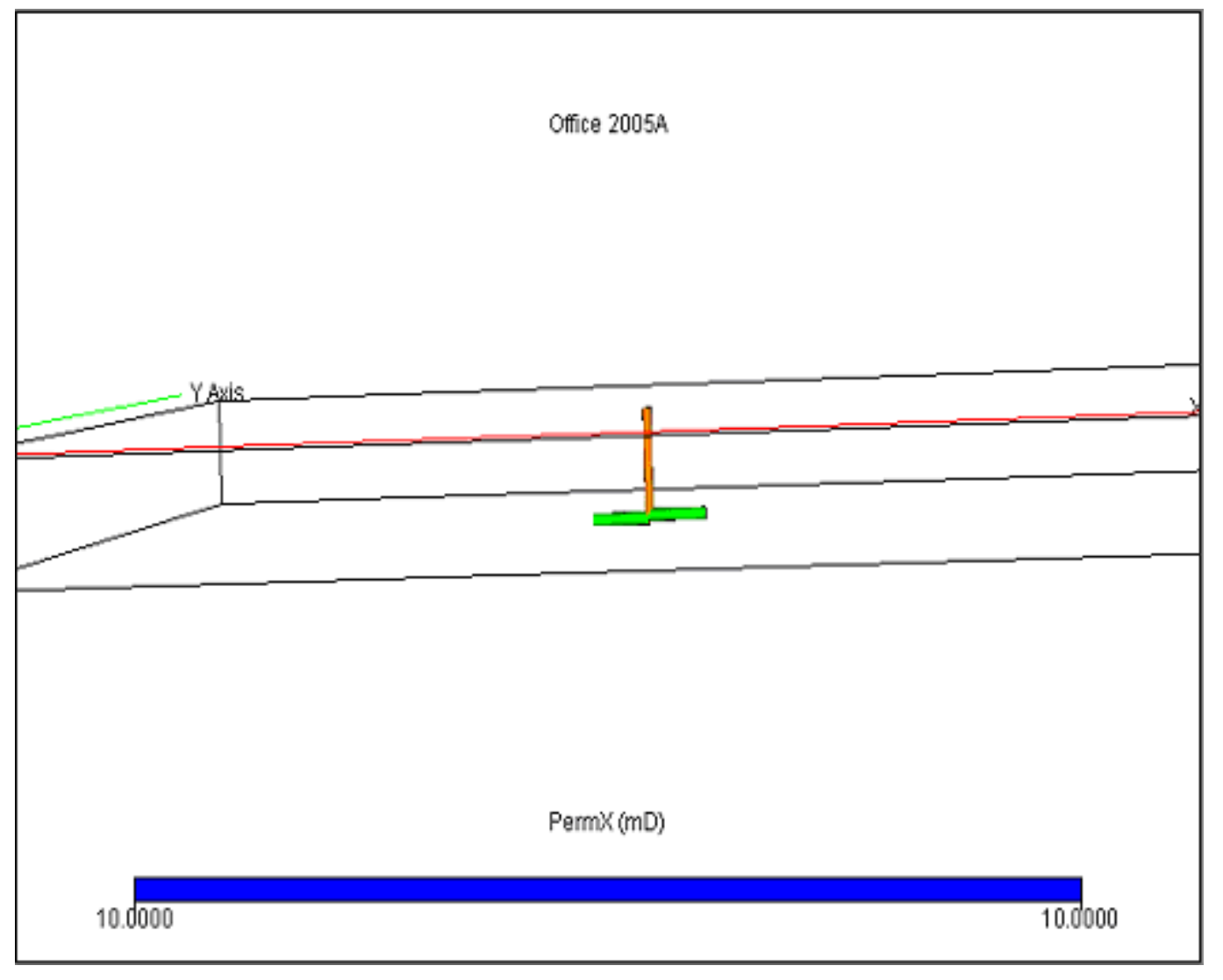

Figure 4.17: $500 \mathrm{ft}$. Dual Lateral Well with laterals at different depths. 


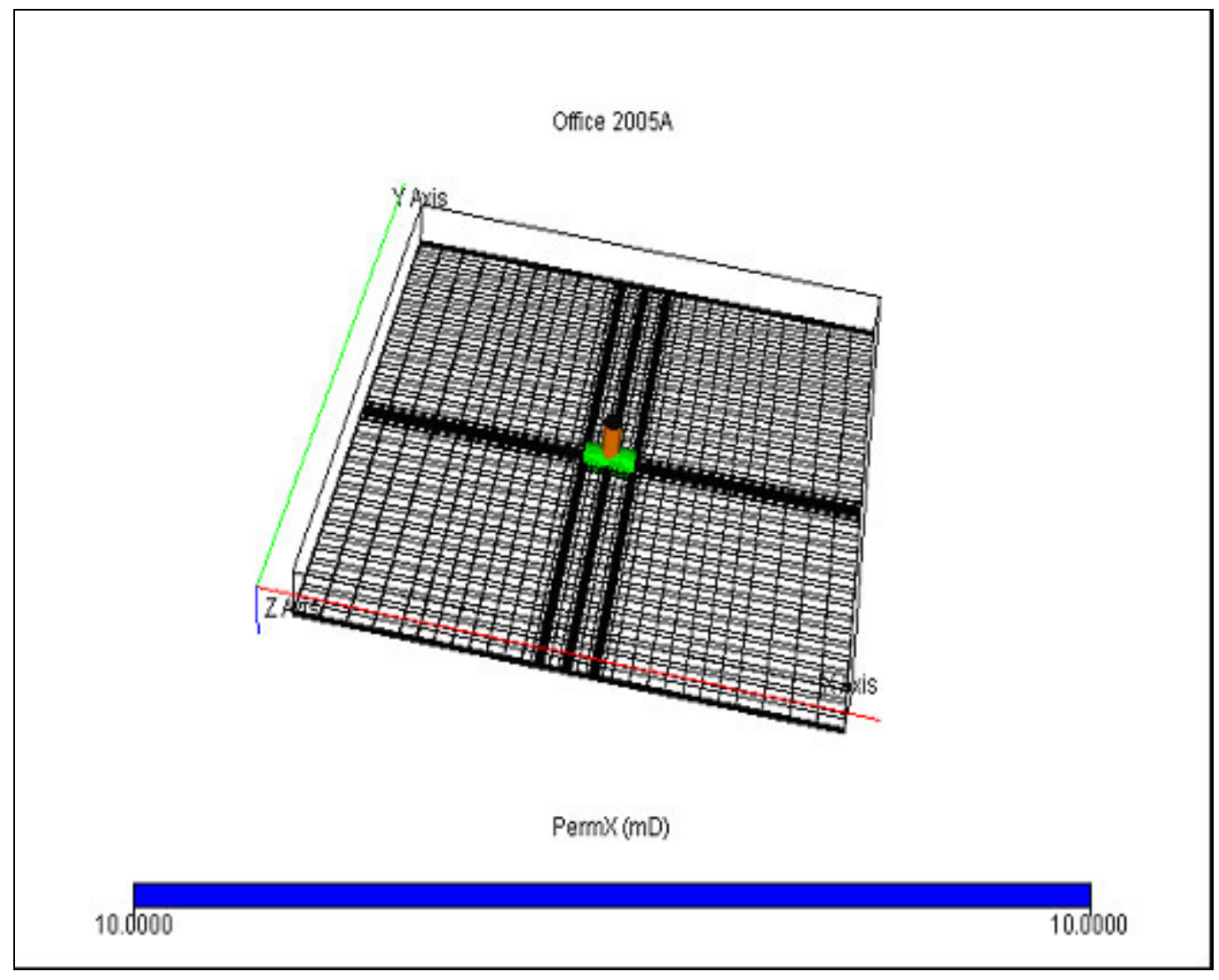

Figure 4.18: Grid structure for the $500 \mathrm{ft}$. Dual Lateral Well with laterals at different depths. 
Figure 4.19 is the schematic of a $1000 \mathrm{ft}$ Dual Lateral Well with laterals at different depths and Figure 4.20 shows grid structure used for this $1000 \mathrm{ft}$ Dual Lateral well.

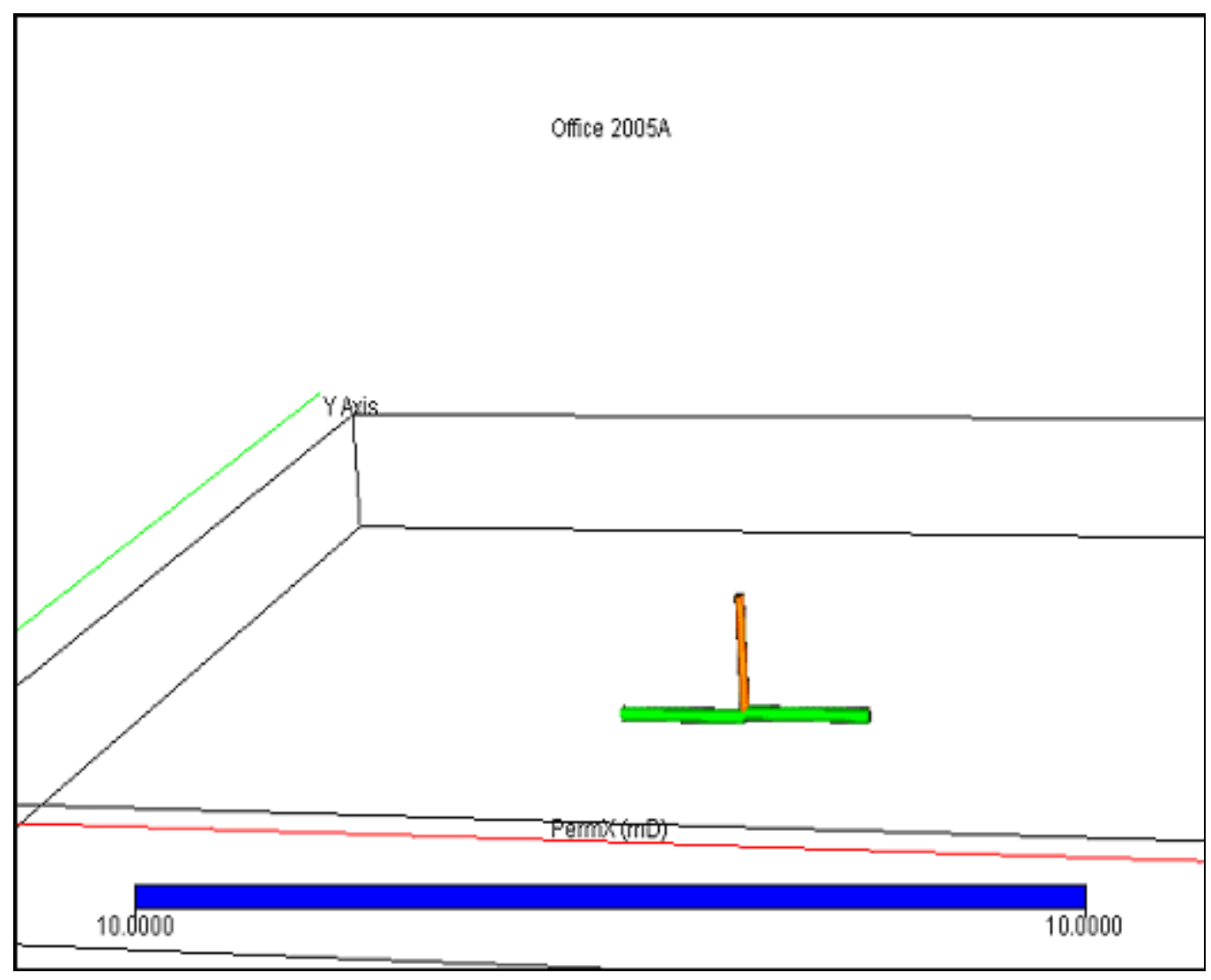

Figure 4.19: $1000 \mathrm{ft}$. Dual Lateral Well with laterals at different depths. 


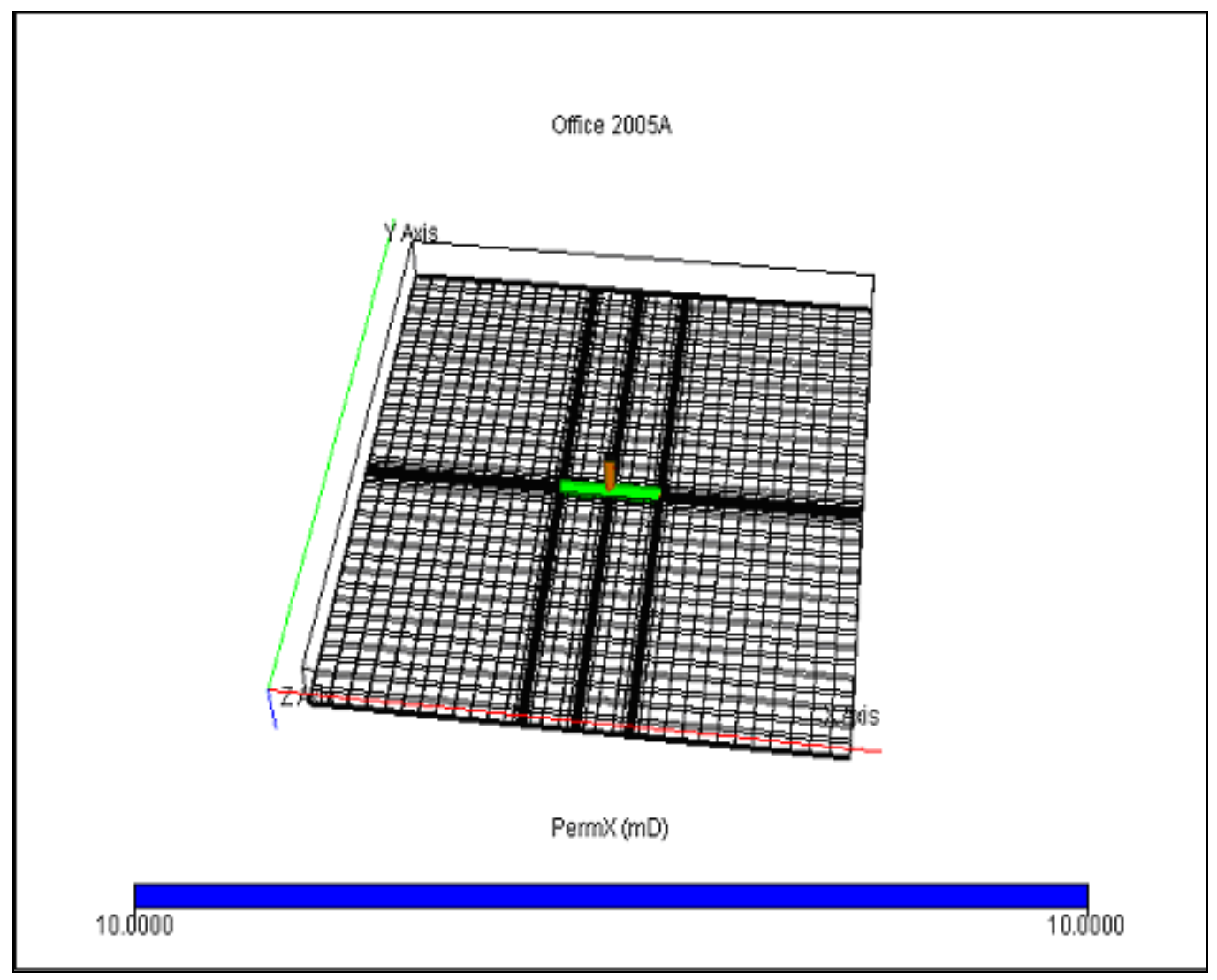

Figure 4.20: Grid structure for the $1000 \mathrm{ft}$. Dual Lateral Well with laterals at different depths. 
Figure 4.21 is the schematic of a $1500 \mathrm{ft}$ Dual Lateral Well with laterals at different depths and Figure 4.22 shows grid structure used for this $1500 \mathrm{ft}$ Dual Lateral well.

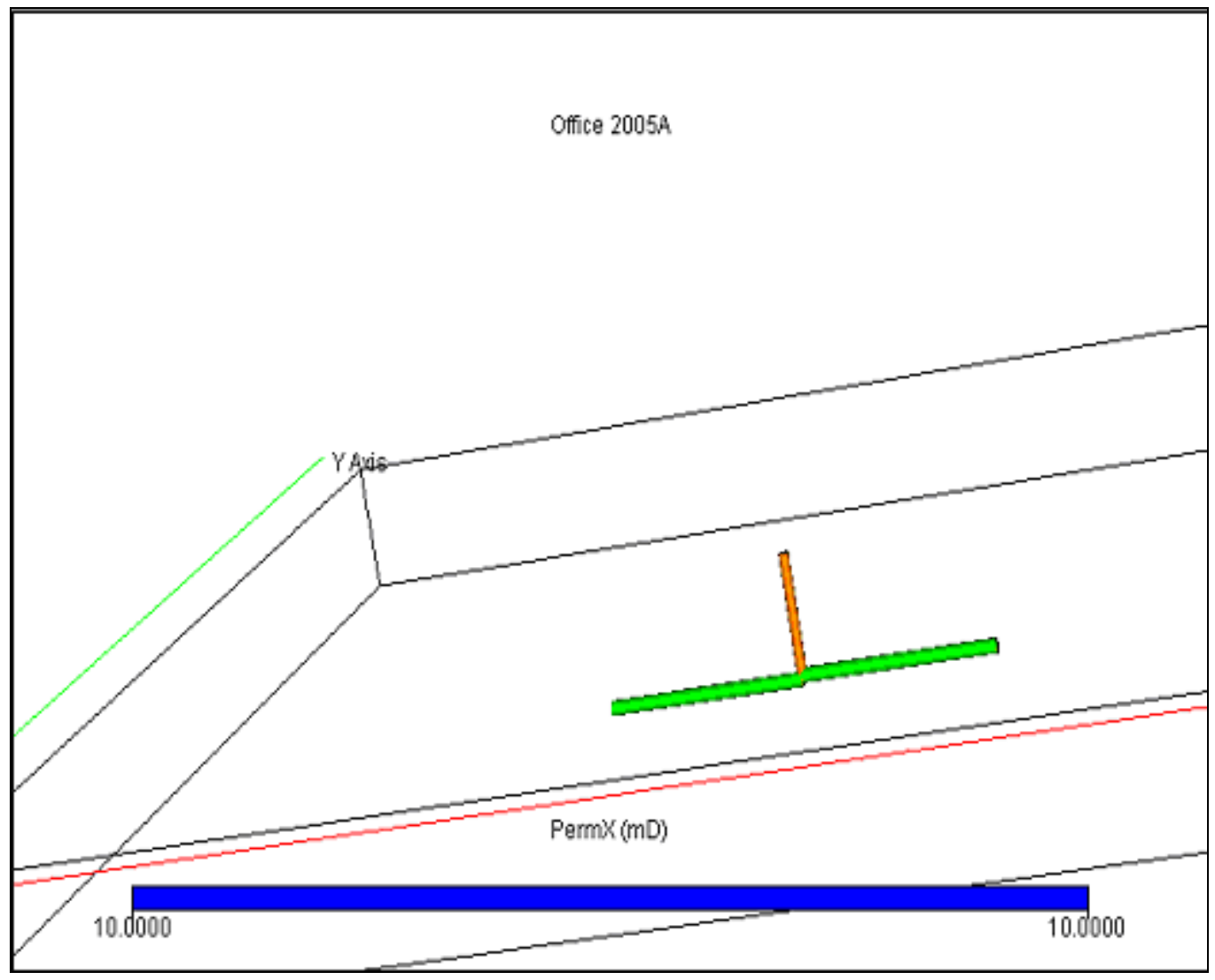

Figure 4.21: $1500 \mathrm{ft}$. Dual Lateral Well with laterals at different depths. 


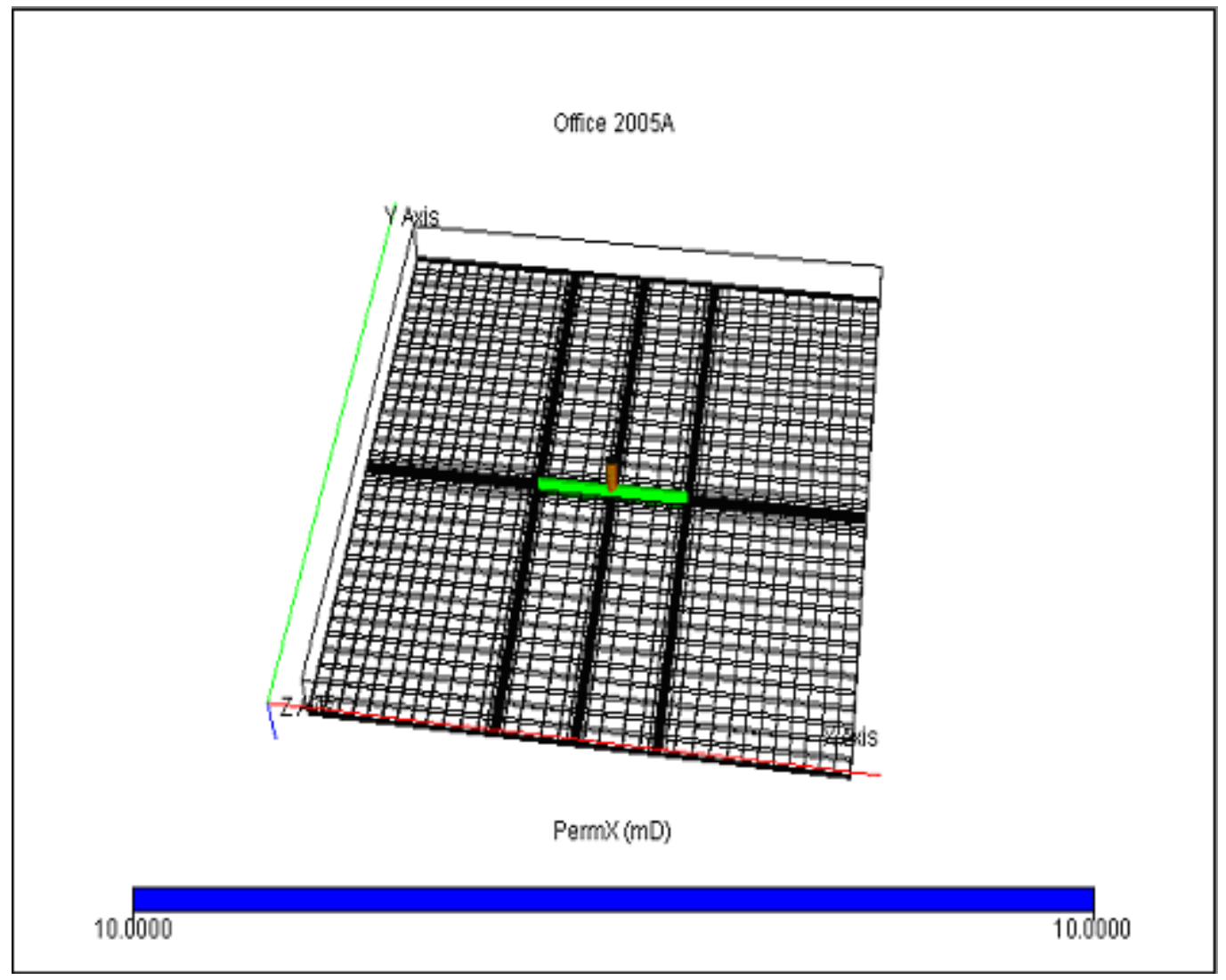

Figure 4.22: Grid structure for the $1500 \mathrm{ft}$. Dual Lateral Well with laterals at different depths. 
Figure 4.23 is the schematic of a $2000 \mathrm{ft}$ dual lateral well with laterals at different depths and Figure 4.24 shows grid structure used for this $2000 \mathrm{ft}$ Dual Lateral well.

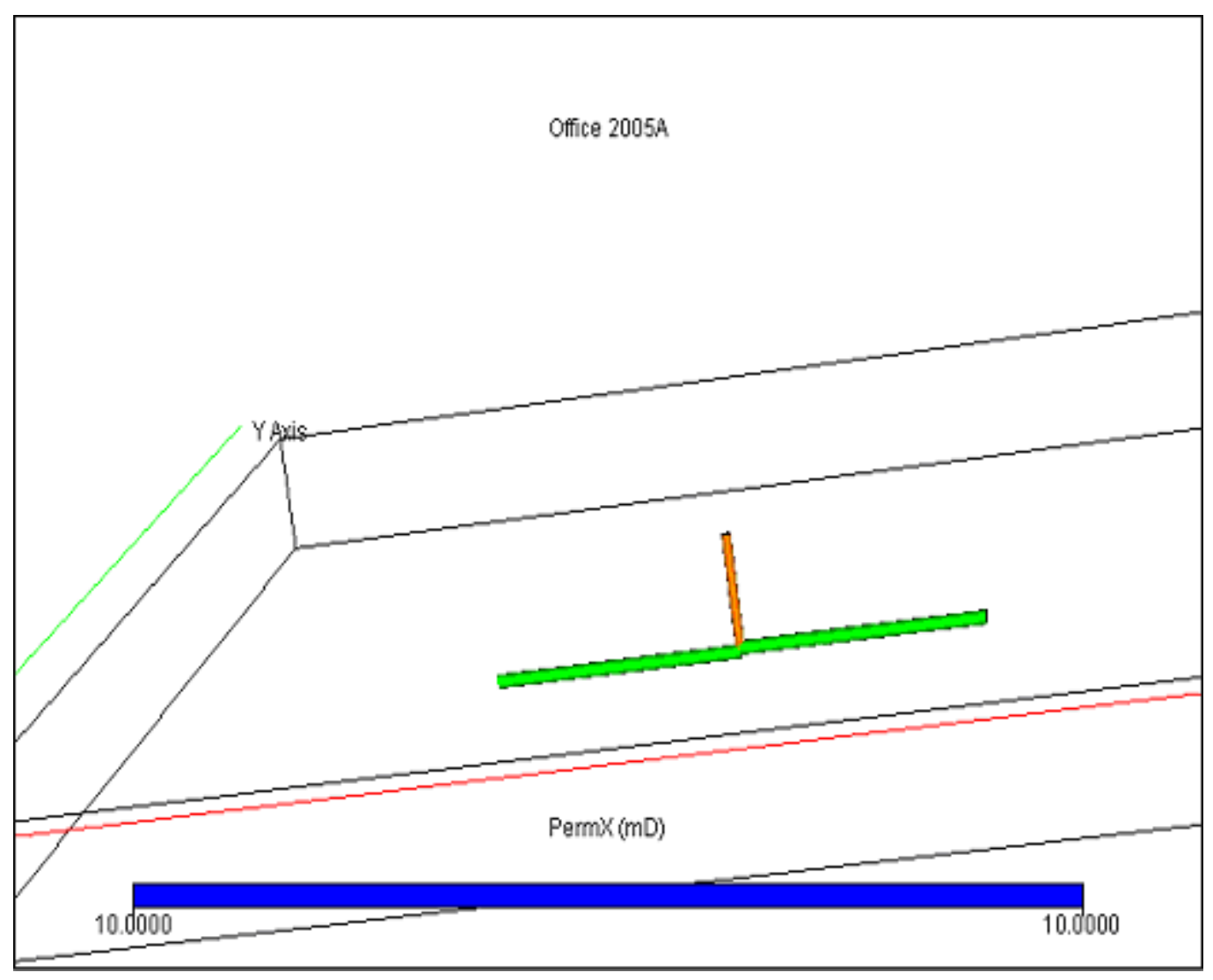

Figure 4.23: $2000 \mathrm{ft}$. Dual Lateral Well with laterals at different depths. 


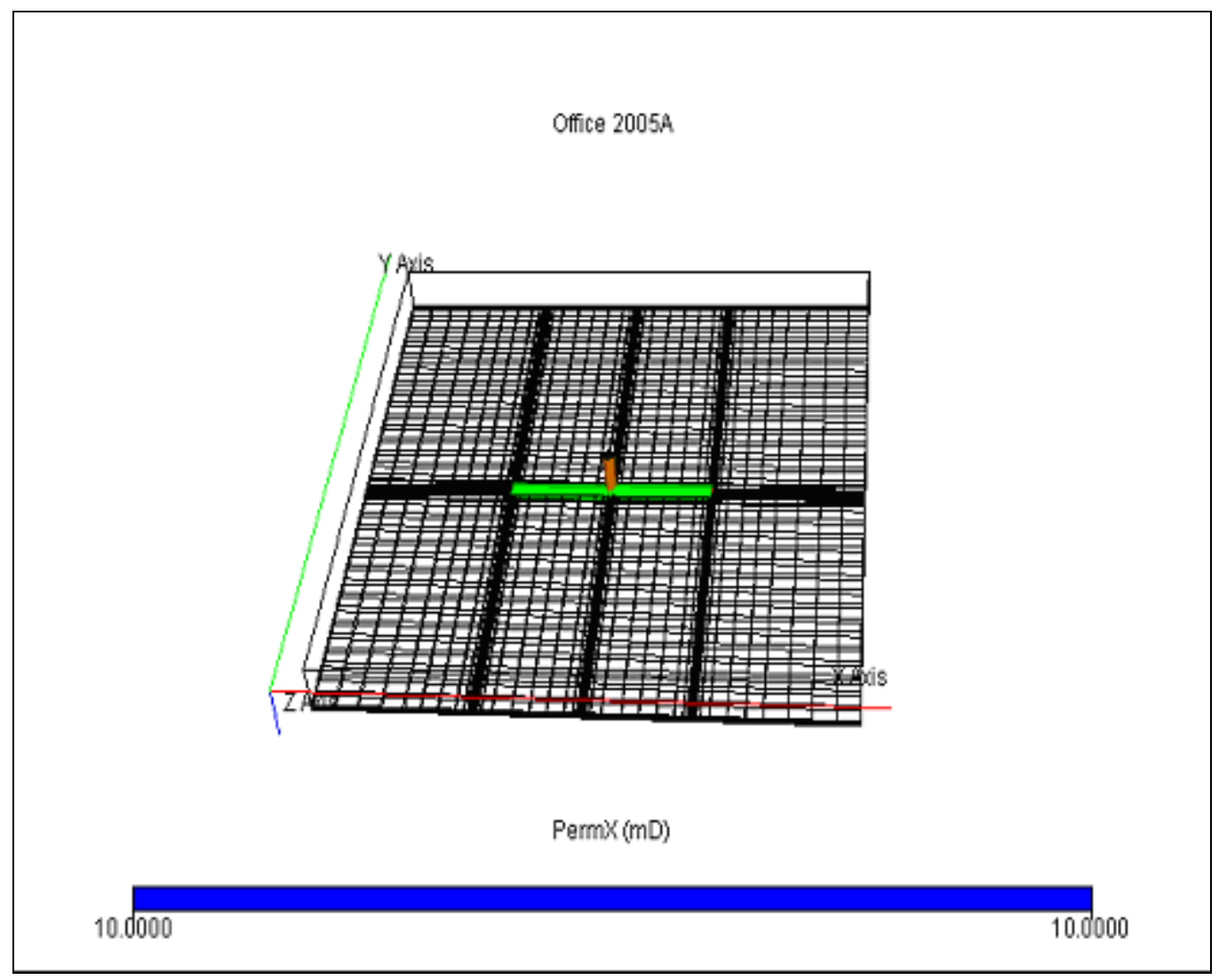

Figure 4.24: Grid structure for the $2000 \mathrm{ft}$. Dual Lateral Well with laterals at different depths. 


\section{Four Laterals:}

Figure 4.25 is the schematic of a $500 \mathrm{ft}$ four lateral well with laterals at same depths and Figure 4.26 shows grid structure used for this $500 \mathrm{ft}$ Four Lateral well.

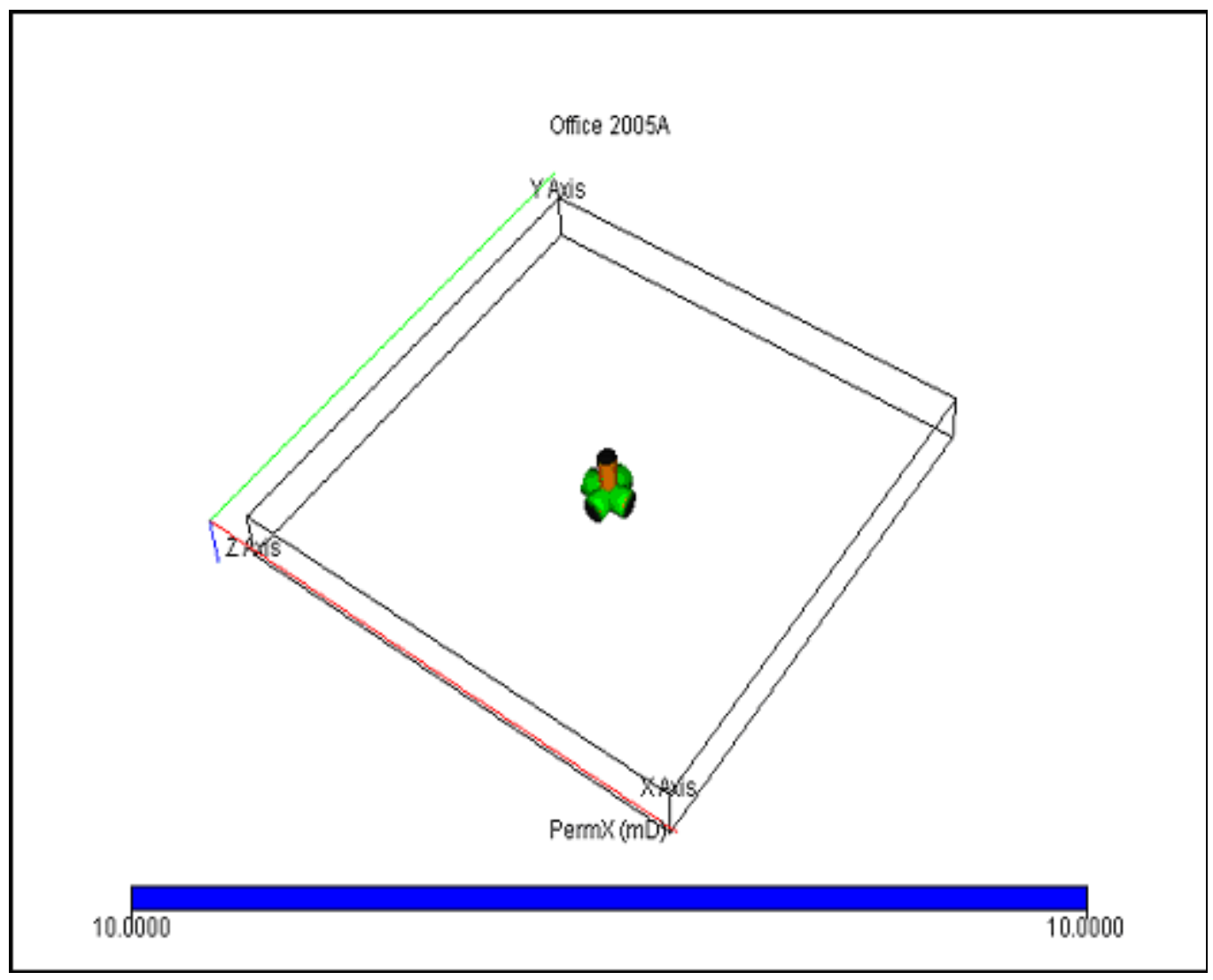

Figure 4.25: $500 \mathrm{ft.}$ 4-Laterals Well. 


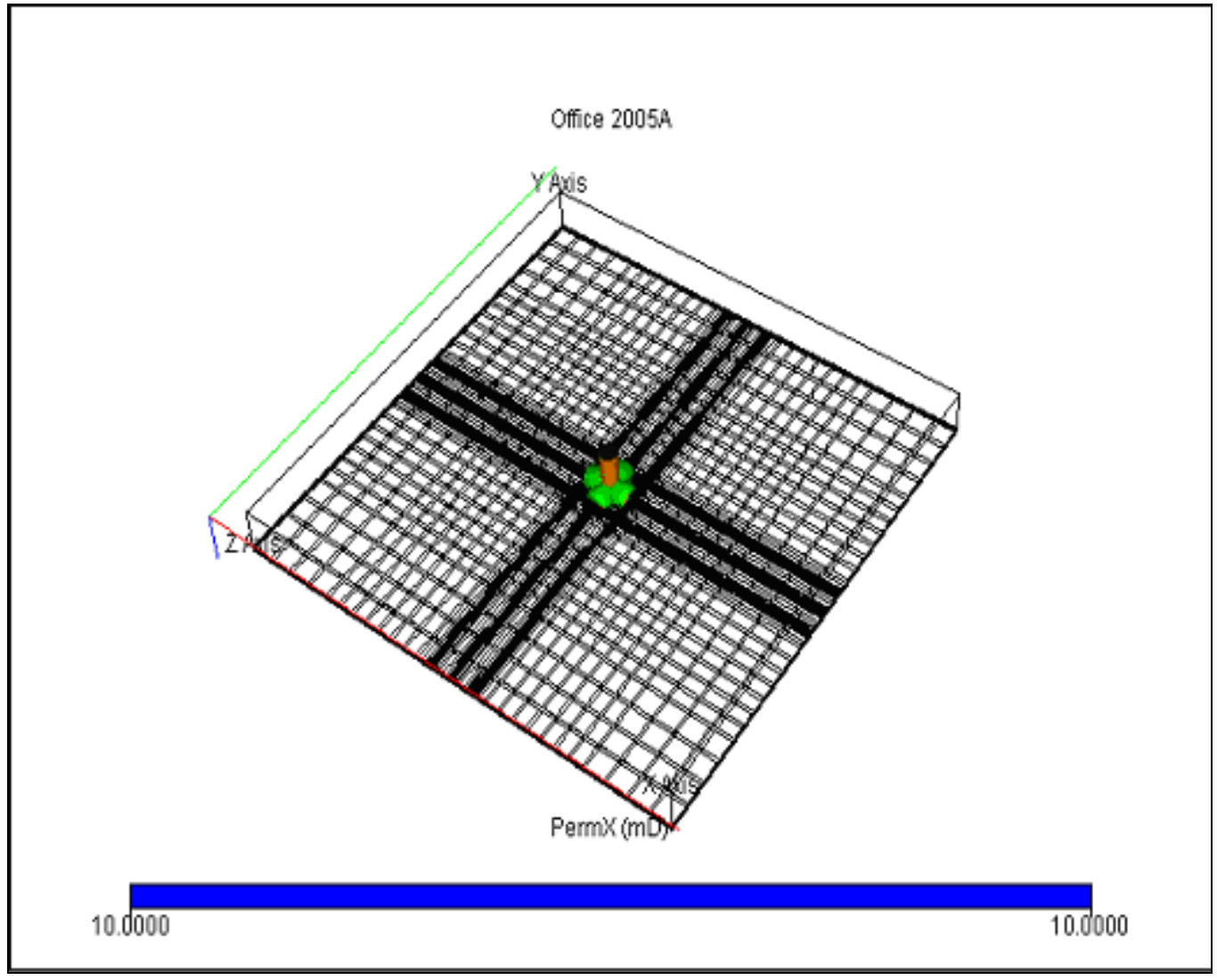

Figure 4.26: Grid structure for the $500 \mathrm{ft}$. 4-Laterals Well. 
Figure 4.27 is the schematic of a $1000 \mathrm{ft}$ four lateral well with laterals at same depths and Figure 4.28 shows grid structure used for this $1000 \mathrm{ft} \mathrm{Four} \mathrm{Lateral} \mathrm{well.}$

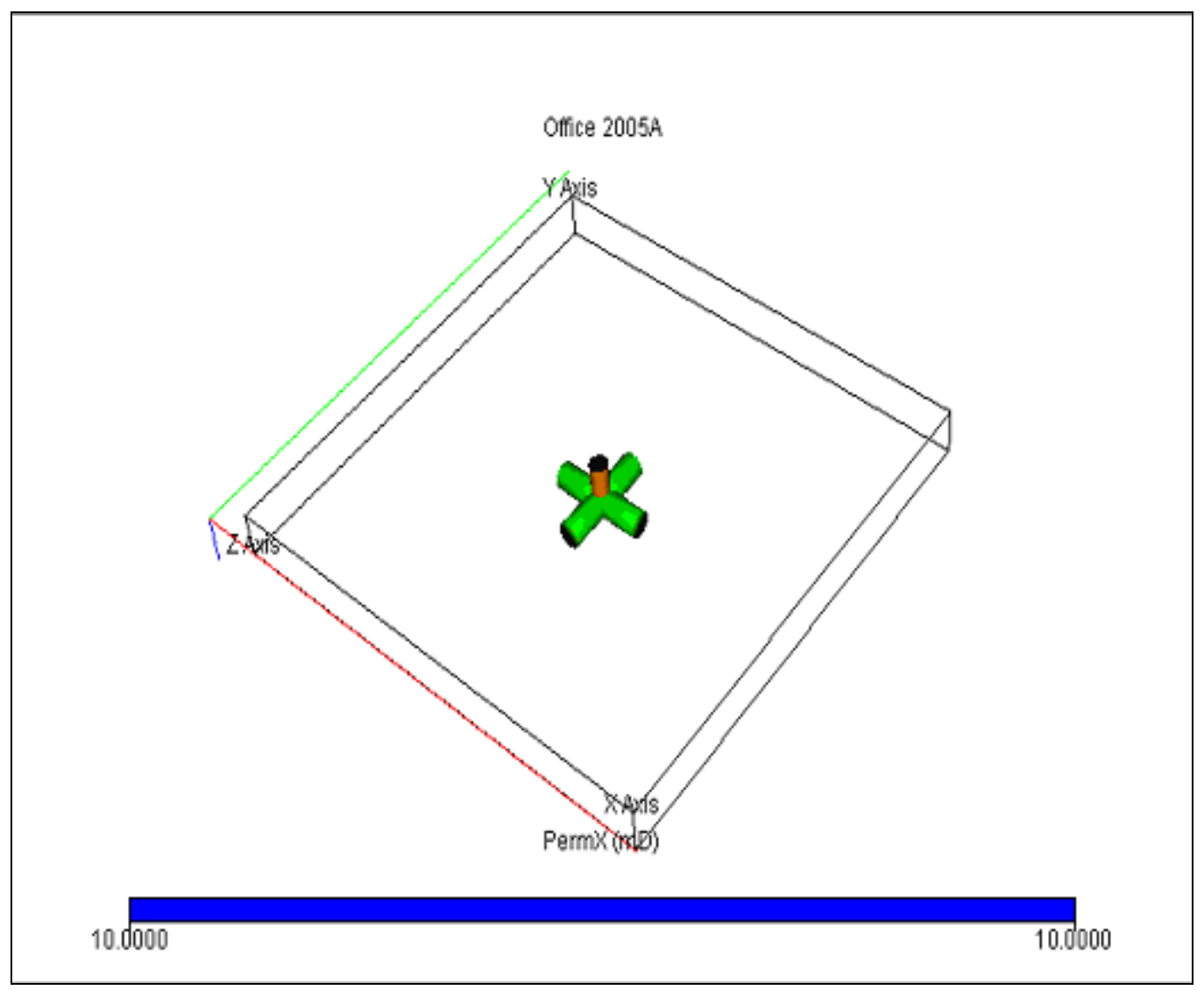

Figure 4.27: $1000 \mathrm{ft}$. 4-Laterals Well. 


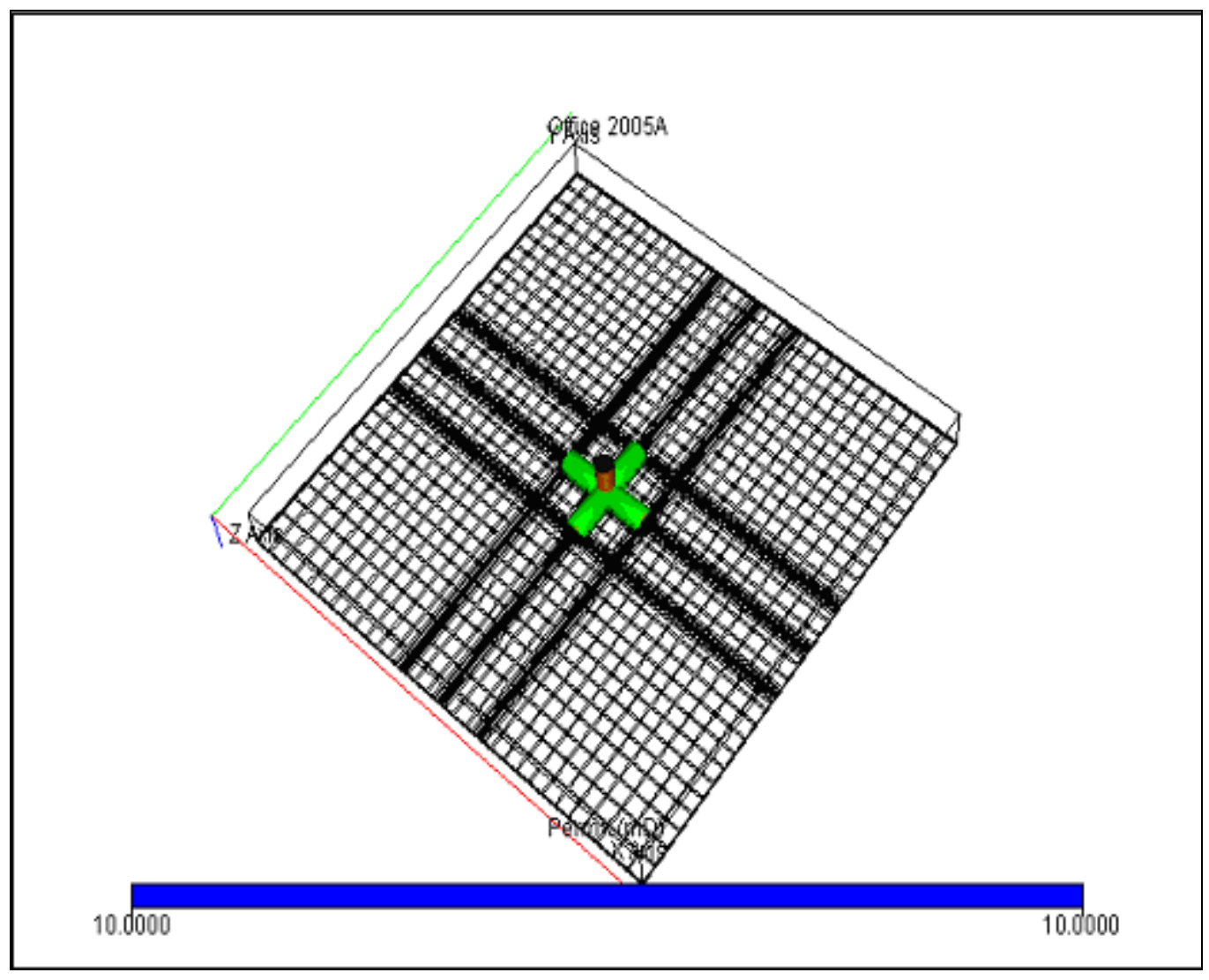

Figure 4.28: Grid structure for the $1000 \mathrm{ft}$. 4-Laterals Well. 
Figure 4.29 is the schematic of a $1500 \mathrm{ft}$ four lateral well with laterals at same depths and Figure 4.30 shows grid structure used for this $1500 \mathrm{ft}$ Four Lateral well.

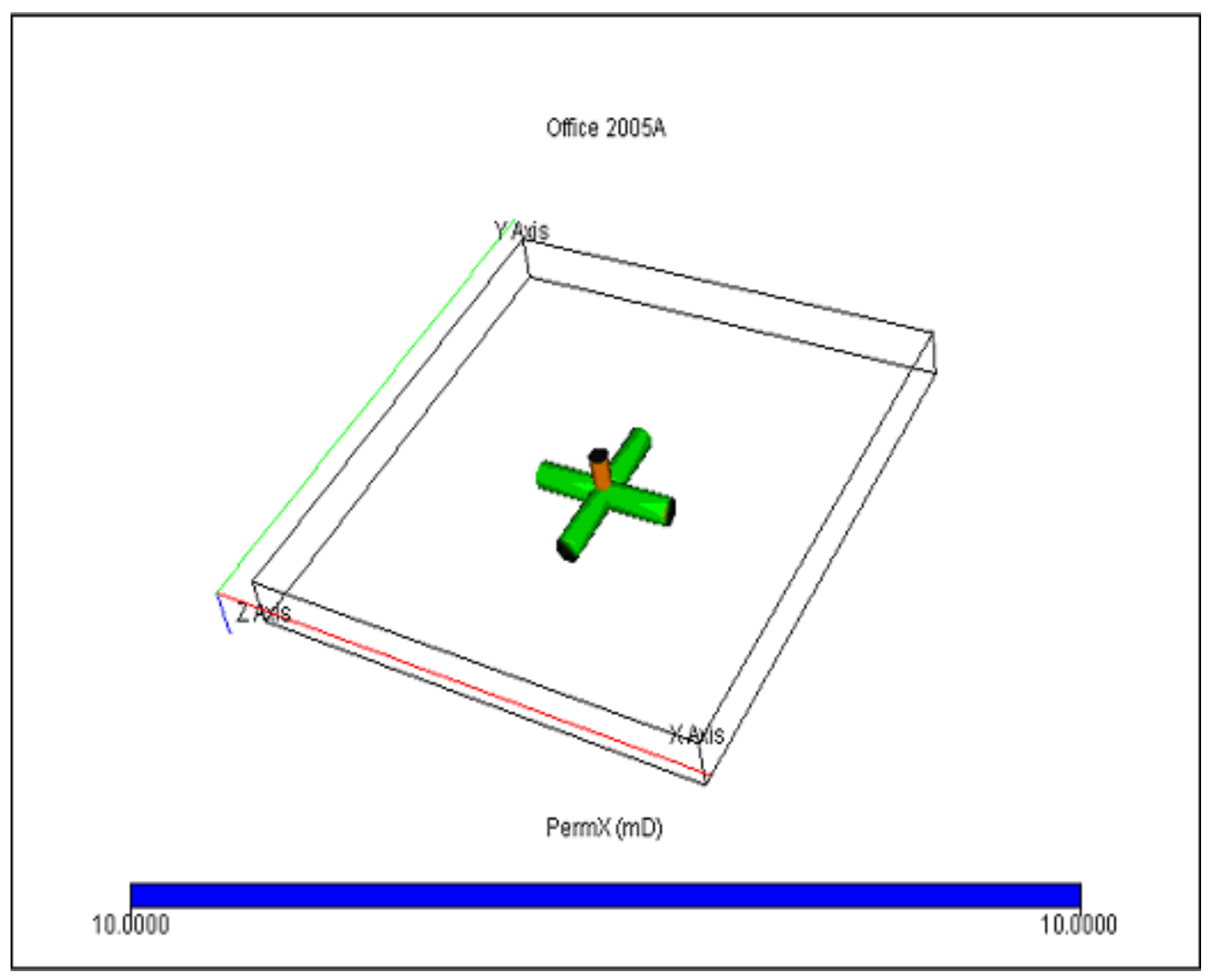

Figure 4.29: $1500 \mathrm{ft}$. 4-Laterals Well. 


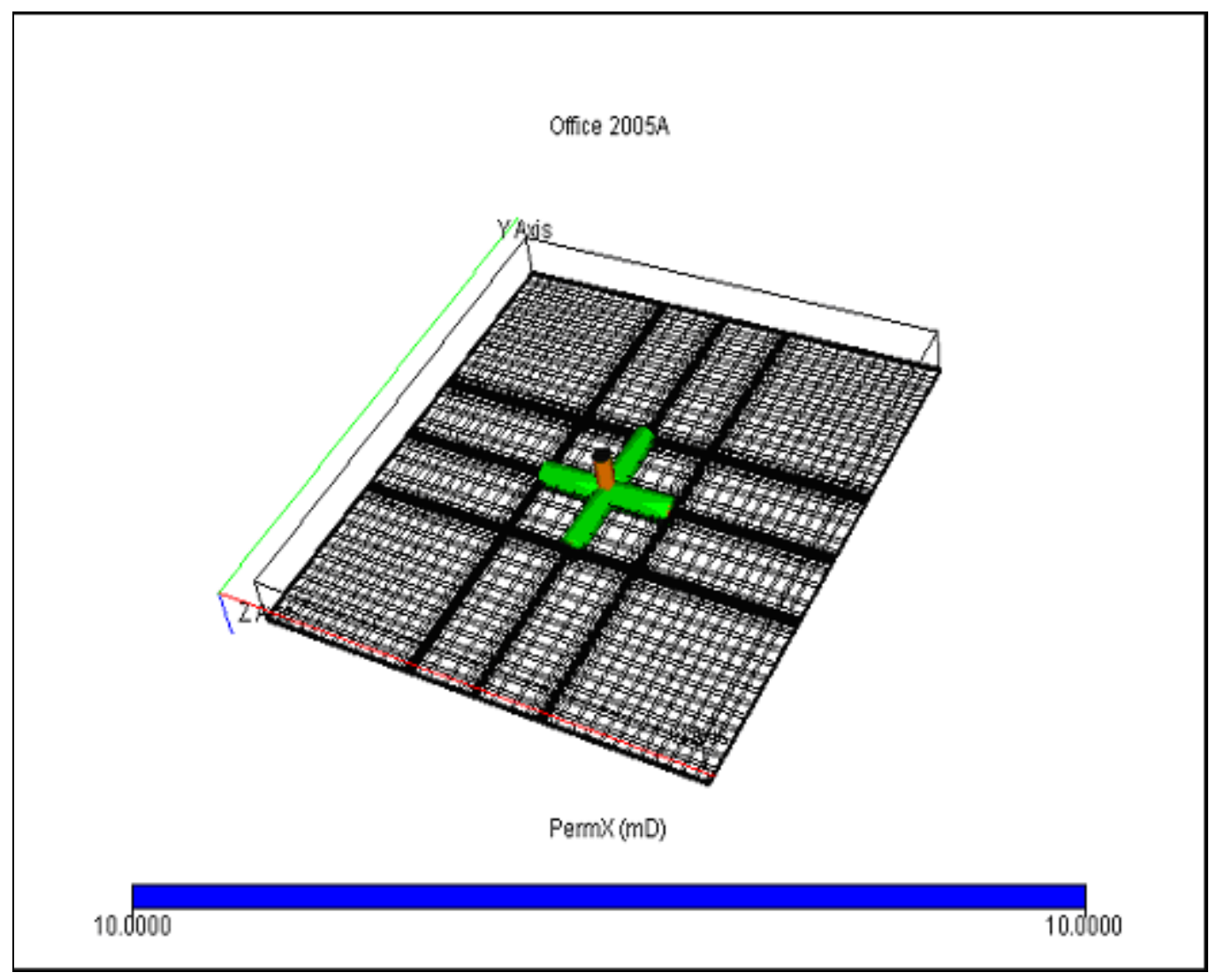

Figure 4.30: Grid structure for the $1500 \mathrm{ft}$. 4-Laterals Well. 
Figure 4.31 is the schematic of a $2000 \mathrm{ft}$ four lateral well with laterals at same depths and Figure 4.32 shows grid structure used for this $2000 \mathrm{ft}$ Four Lateral well.

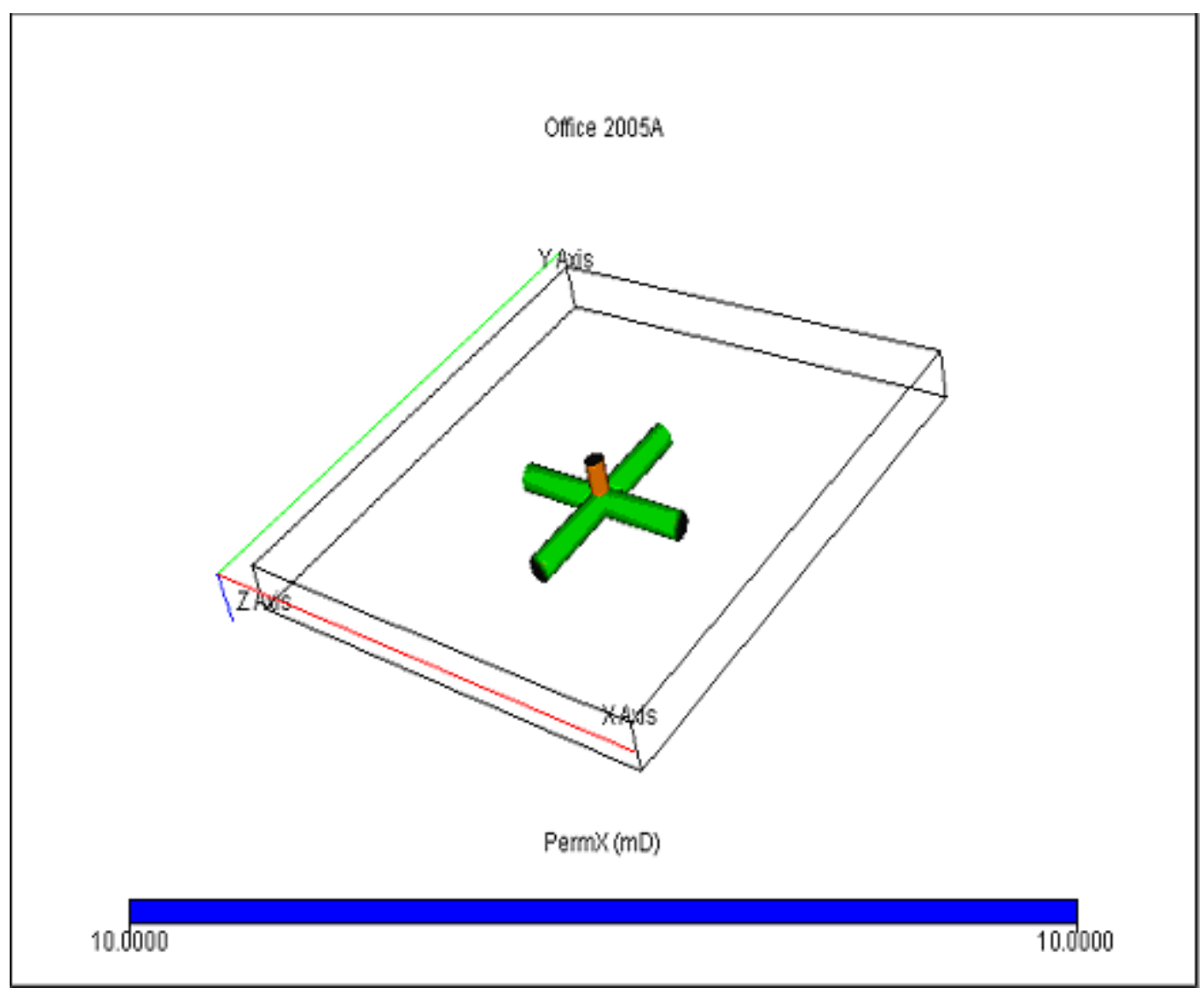

Figure 4.31: $2000 \mathrm{ft}$. 4-Laterals Well. 


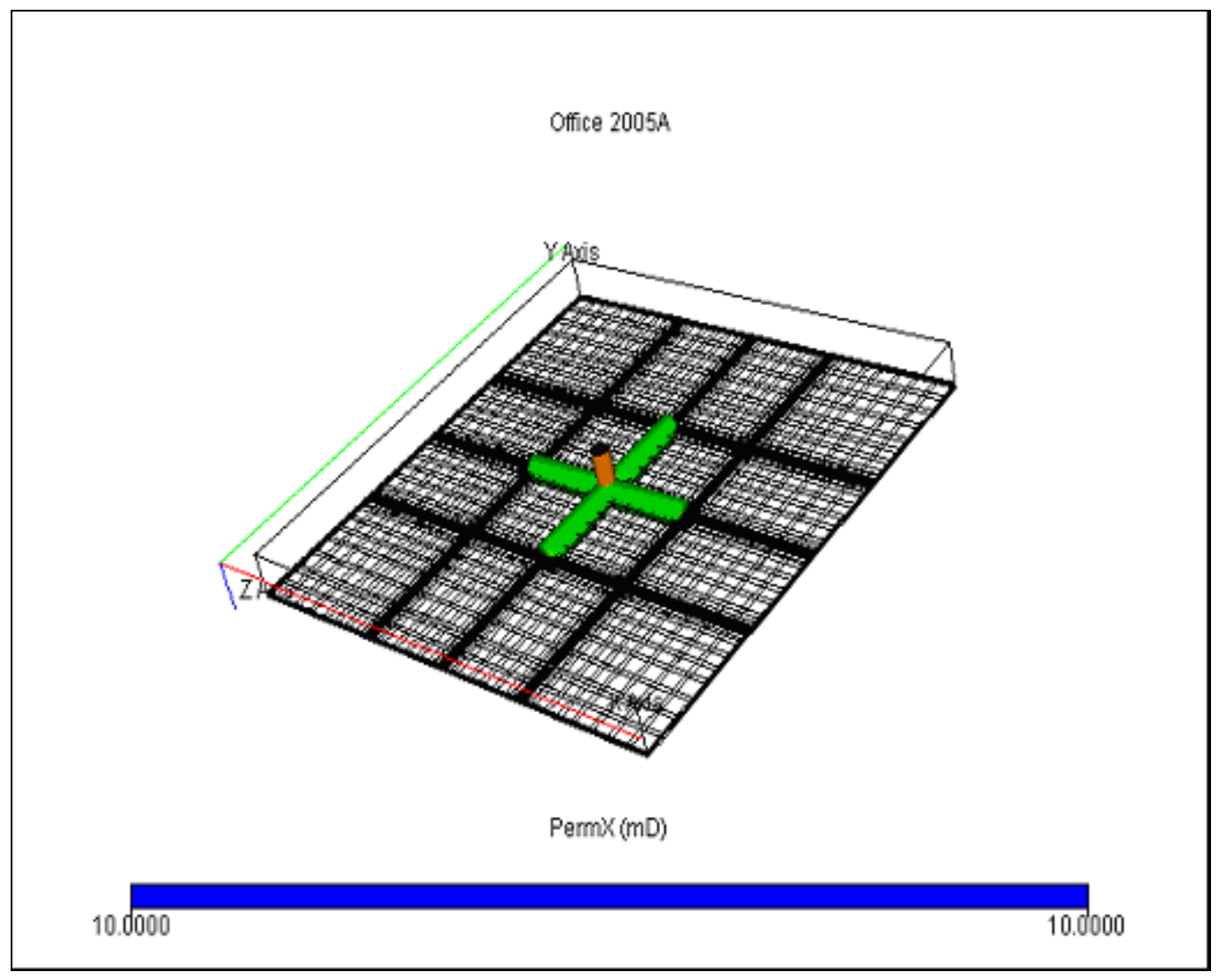

Figure 4.32: Grid structure for the $2000 \mathrm{ft}$. 4-Laterals Well. 


\section{Vertical Well:}

Figure 4.33 is the schematic of a Vertical well. Figure 4.34 shows grid structure used for this Vertical well.

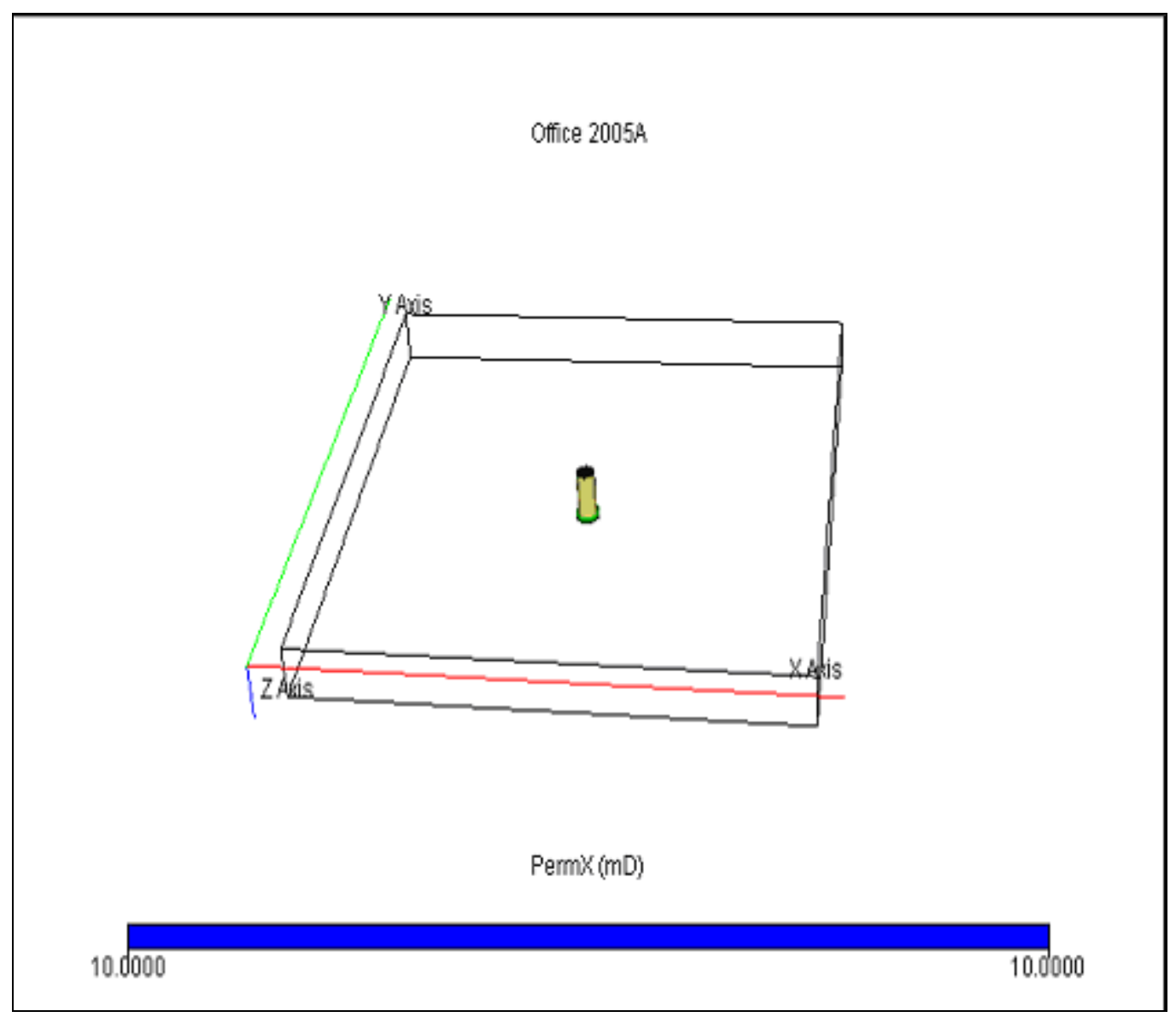

Figure 4.33: Single Vertical well. 


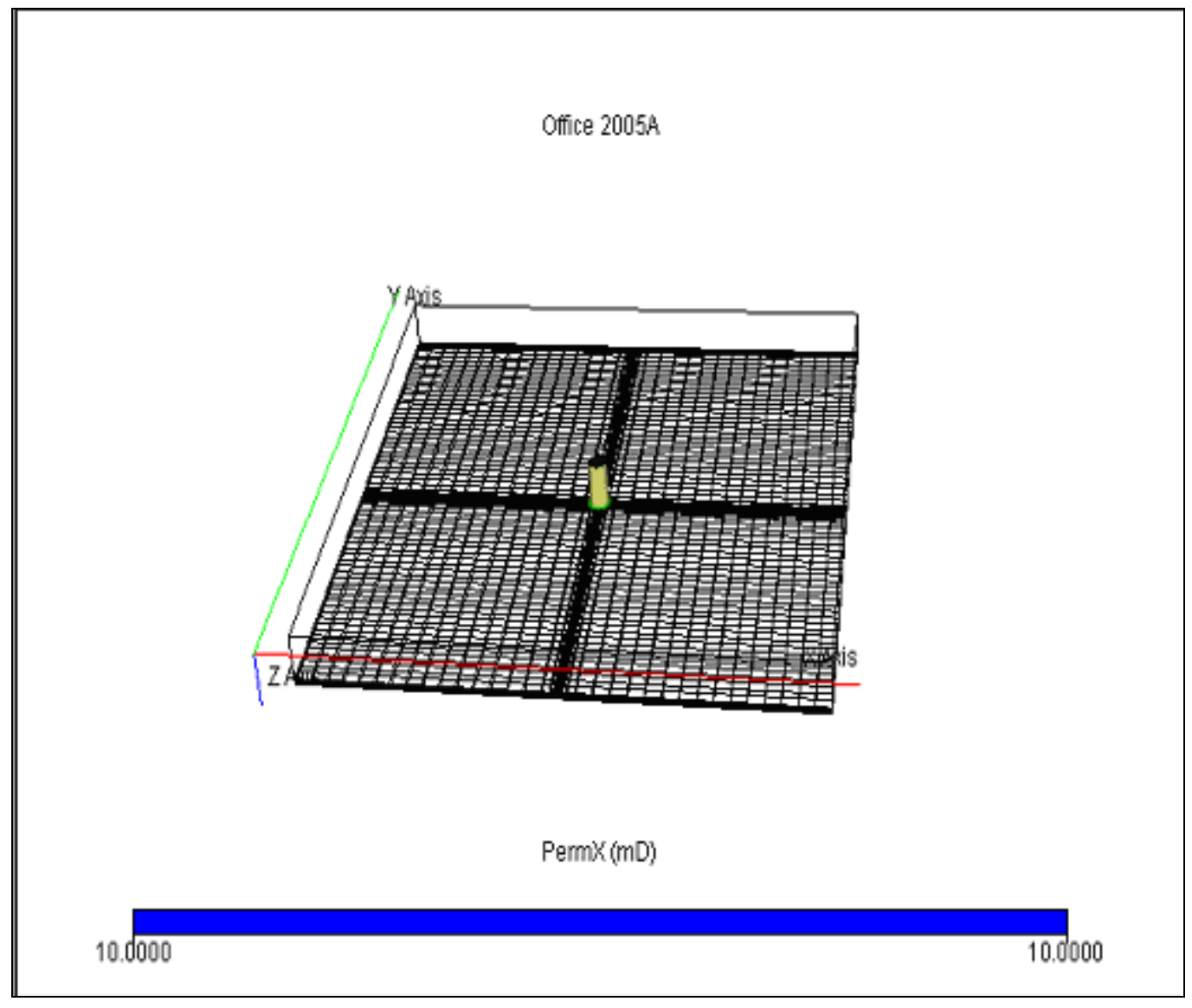

Figure 4.34: Grid structure for the Vertical Well. 


\section{CHAPTER V: RESULTS AND DISCUSSION}

For all the configurations that were described in the previous chapter had the following:

\section{Reservoir description:}

$\begin{array}{lll}\text { Length of the reservoir } & : & 10000 \mathrm{ft} . \\ \text { Width of the reservoir } & : & 10000 \mathrm{ft} . \\ \text { Thickness } & : & 100 \mathrm{ft} . \\ \text { Porosity } & : & 0.25 \\ \text { Permeability: } & : & 10 \mathrm{mD} . \\ \quad \text { X- Direction } & : & 10 \mathrm{mD} . \\ \quad \text { Y- Direction } & : & 1 \mathrm{mD} . \\ \quad \text { Z- Direction } & : & 1 \mathrm{E}-6 / \mathrm{psi} . \\ \text { Compressibility } & : & 3500 \mathrm{psia} . \\ \text { Initial reservoir pressure } & : & 5180 \mathrm{ft} .\end{array}$

\section{Fluid Properties:}

Oil density at surface

$\begin{array}{ll}: & 49.9 \mathrm{lb} / \mathrm{ft}^{3} . \\ : & 1.25 \mathrm{rb} / \mathrm{stb} . \\ : & 3 \mathrm{E}-6 / \mathrm{psi} . \\ : & 1 \mathrm{cp} . \\ : & 0.00697224 \mathrm{Mscf} / \mathrm{stb} . \\ : & 50 \mathrm{psia} . \\ : & 0.7 \\ : & 2\end{array}$

Skin

Oil formation volume factor

Oil compressibility

Oil Viscosity

Total GOR

Bubble point pressure

Runs were conducted using the above data with the configurations given in Chapter IV (with different lateral lengths), field pressure rates, field oil production rates, well bottom hole pressure and field pressure variations are tabulated. Using these values, Productivity Index, $\mathrm{J}$ for each configuration (for different lateral lengths) is calculated with the following equation: 


$$
J=\frac{q}{\Delta p}=\frac{q}{\left(p_{\text {field }}-p_{W B H P}\right)}
$$

The basic equation that governs single-phase flow of a slightly compressible fluid in a porous medium is given by:

$$
\frac{\partial^{2} p_{D}}{\partial x_{D}{ }^{2}}+\frac{\partial^{2} p_{D}}{\partial y_{D}{ }^{2}}+\frac{\partial^{2} p_{D}}{\partial z_{D}{ }^{2}}=\frac{\partial p_{D}}{\partial t_{D}} \text { (in dimensionless variables). }
$$

To convert the space coordinates or lengths to their dimensionless equivalent, they are scaled by the reservoir length in the $\mathrm{x}$-direction, $\mathrm{x}_{\mathrm{e}}$ and the following forms were used:

$x_{D}=x / x_{e}$

$y_{D}=y / x_{e}$,

$z_{D}=z / x_{e}$

The following dimensionless time is used:

$$
t_{D}=\frac{2.637 \times 10^{-4} \times k \times t}{\phi \times C_{t} \times \mu \times x_{e}^{2}},
$$

where $2.637 \times 10^{-4}$ is the conversion factor for time measured in hours, and field units for $k, x_{e}, \mu$, and $\mathrm{C}_{\mathrm{t}}$.

The dimensionless variables $p_{D}, t_{D}$ are tabulated for each configuration. Dimensionless well-bore pressure is calculated with,

$$
p_{D}=\frac{k \times h}{141.2 \times q_{t} \times \mu \times B_{o}}\left[p_{\text {field }}-p_{\text {WBHP }}\right]
$$

After calculating the dimensionless pressure and time differences, dimensionless pressure derivative values are calculated and tabulated for all the configurations. The pressure derivative is given by:

$$
\left(d p_{D} / d t_{D}\right) t_{D}
$$


Using above values, different plots are generated to check the variation of productivity index with respect to time and dimensionless pressure derivative with respect to dimensionless time. The plots are prepared for the following configurations:

1. Single lateral well.

2. Dual lateral well.

3. Dual Lateral well with laterals at different depths.

4. Four lateral well.

5. Single Vertical Well.

Lateral lengths of $500 \mathrm{ft}, 1000 \mathrm{ft}, 1500 \mathrm{ft}, 2000 \mathrm{ft}$ are considered for all these configurations.

\section{Single Lateral Well:}

The results for the $500 \mathrm{ft}$. single lateral well for productivity index values are presented in Figure 5.1. As shown in Figure 5.1 the productivity index value shows a linear trend for 10 years 9 months. Compared to a vertical well completed in the same reservoir the productivity values are $57 \%$ greater indicating a larger production. 


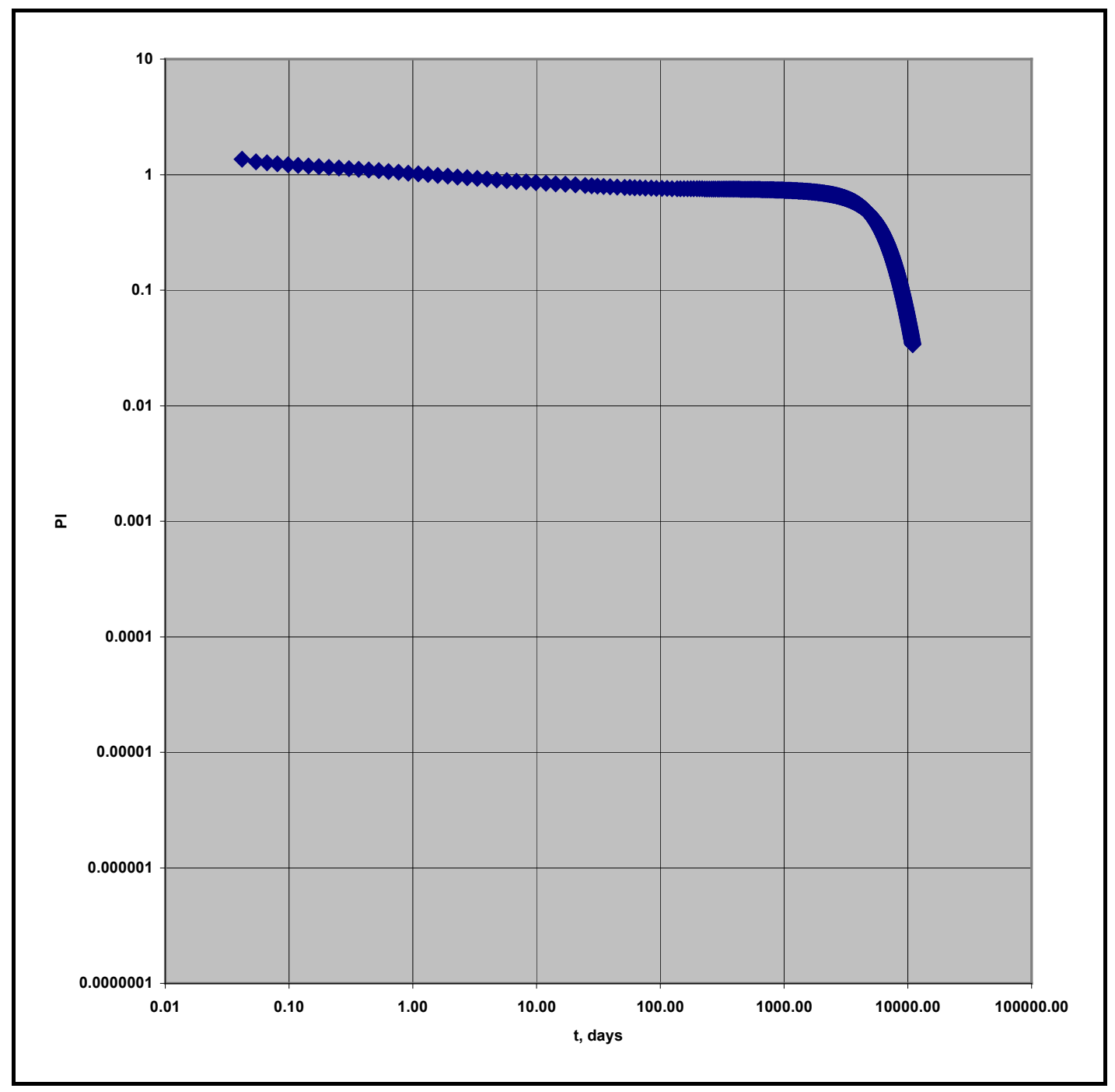

Figure 5.1: Variation of Productivity Index with time for a Single lateral well with $500 \mathrm{ft}$ lateral length. 
Figure 5.2 shows the variation of dimensionless pressure and its derivative with dimensionless time for a Single lateral well with $500 \mathrm{ft}$ lateral length.

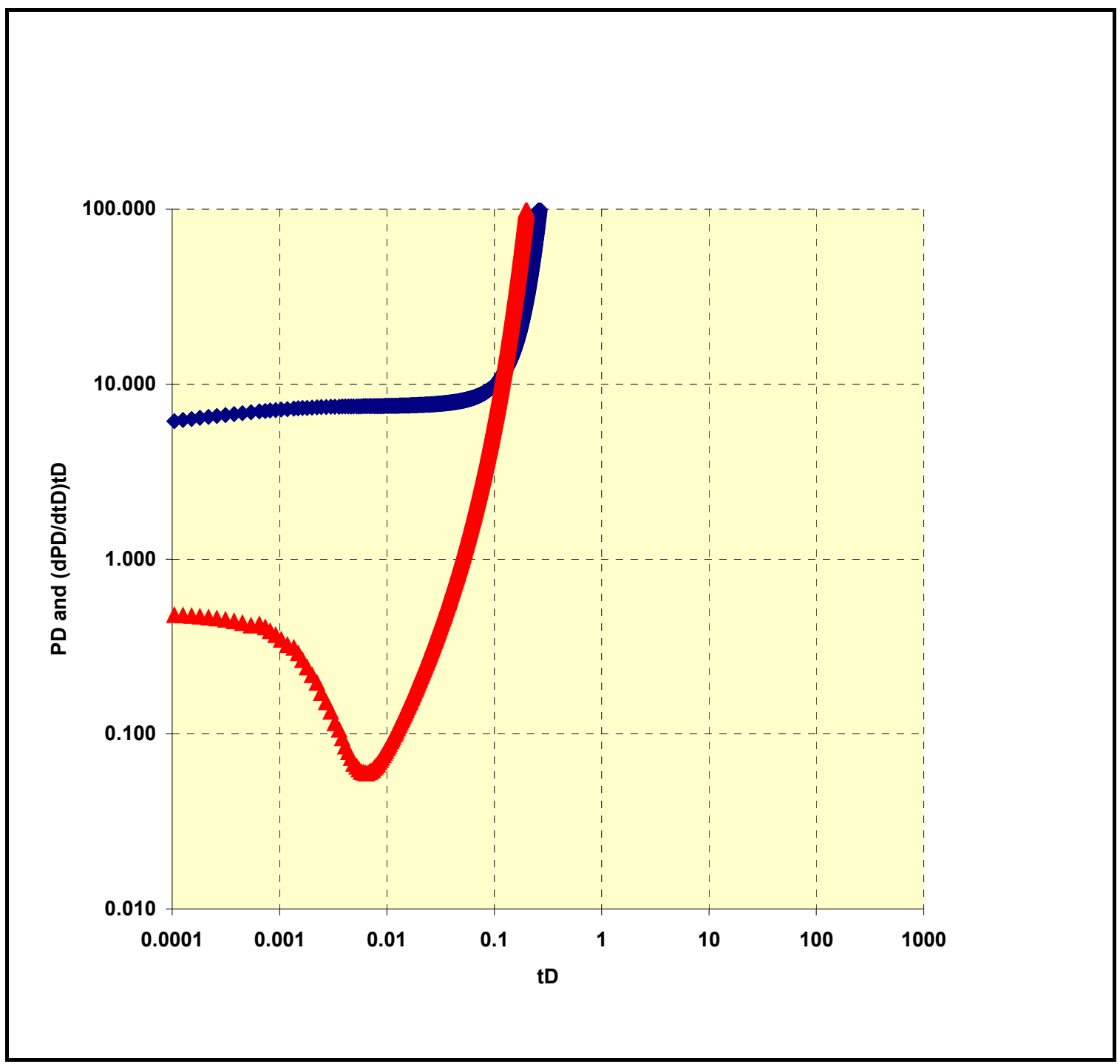

Figure 5.2: Variation of dimensionless pressure and its derivative with dimensionless time for a Single lateral well with $\mathbf{5 0 0} \mathrm{ft}$ lateral length. 
The results for the $1000 \mathrm{ft}$. single lateral well for productivity index values are presented in Figure 5.3. As shown in Figure 5.3 the productivity index value shows a linear trend for 5 years 5 months. Compared to a vertical well completed in the same reservoir the productivity values are $50 \%$ greater indicating a larger production.

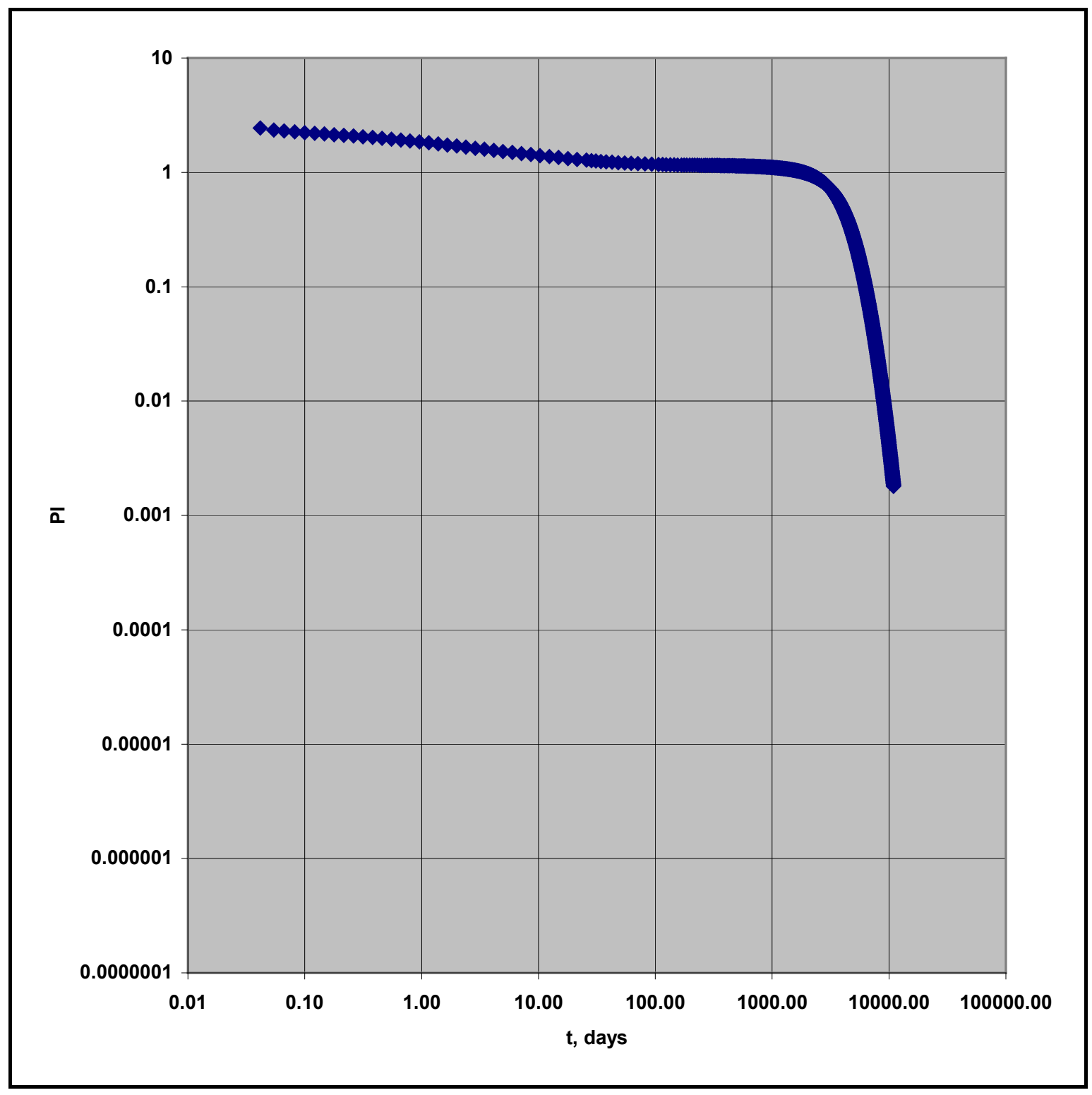

Figure 5.3 Variation of Productivity Index with time for a Single lateral well with $1000 \mathrm{ft}$ lateral length. 
Figure 5.4 shows the variation of dimensionless pressure and its derivative with dimensionless time for a Single lateral well with $1000 \mathrm{ft}$ lateral length.

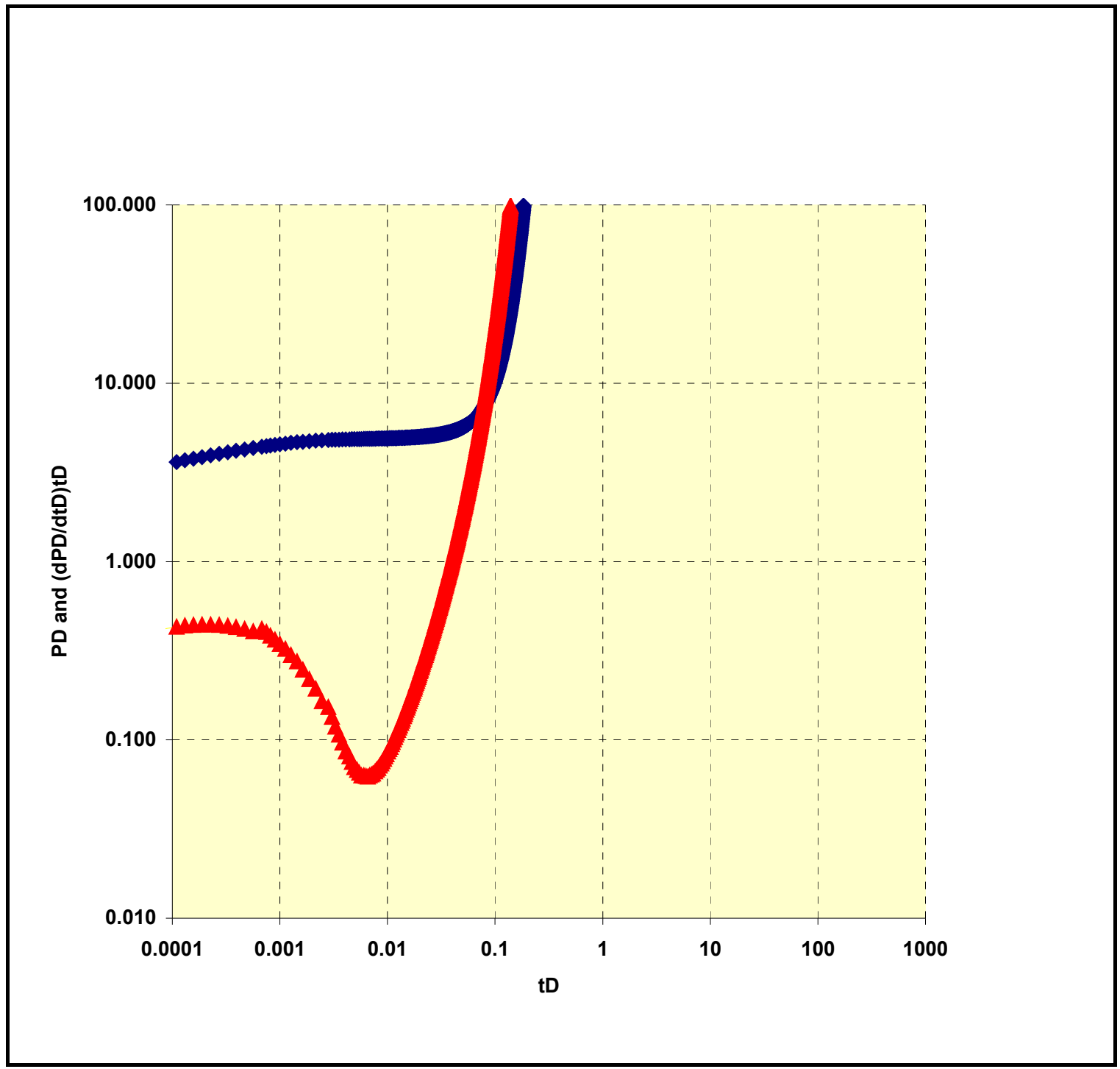

Figure 5.4: Variation of dimensionless pressure and its derivative with dimensionless time for a Single lateral well with $1000 \mathrm{ft}$ lateral length. 
The results for the $1500 \mathrm{ft}$. single lateral well for productivity index values are presented in Figure 5.5. As shown in Figure 5.5 the productivity index value shows a linear trend for 2 years 7 months. Compared to a vertical well completed in the same reservoir the productivity values are $50 \%$ greater indicating a larger production.

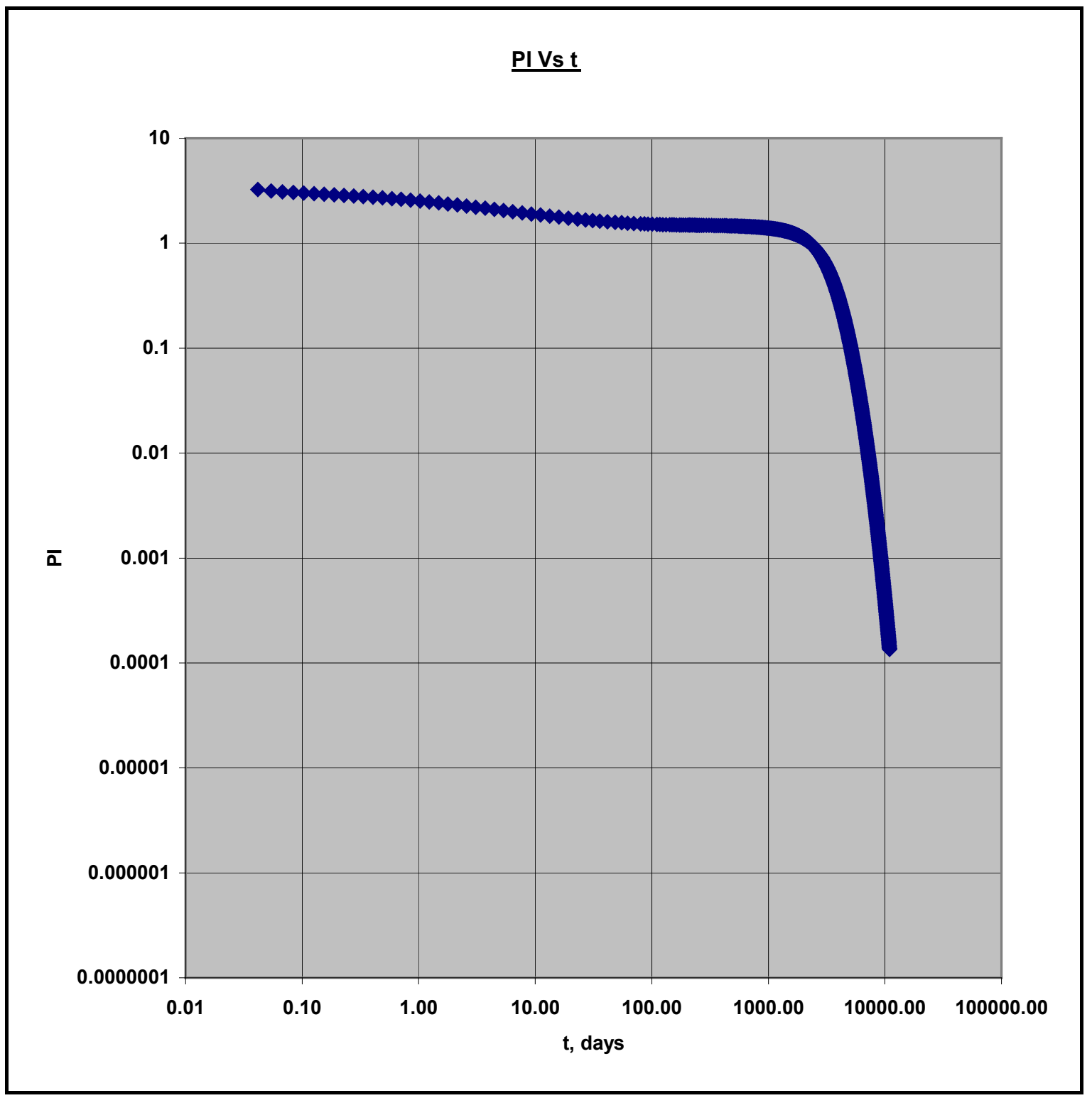

Figure 5.5 Variation of Productivity Index with time for a Single lateral well with $1500 \mathrm{ft}$ lateral length. 
Figure 5.6 shows the variation of dimensionless pressure and its derivative with dimensionless time for a Single lateral well with $1500 \mathrm{ft}$ lateral length.

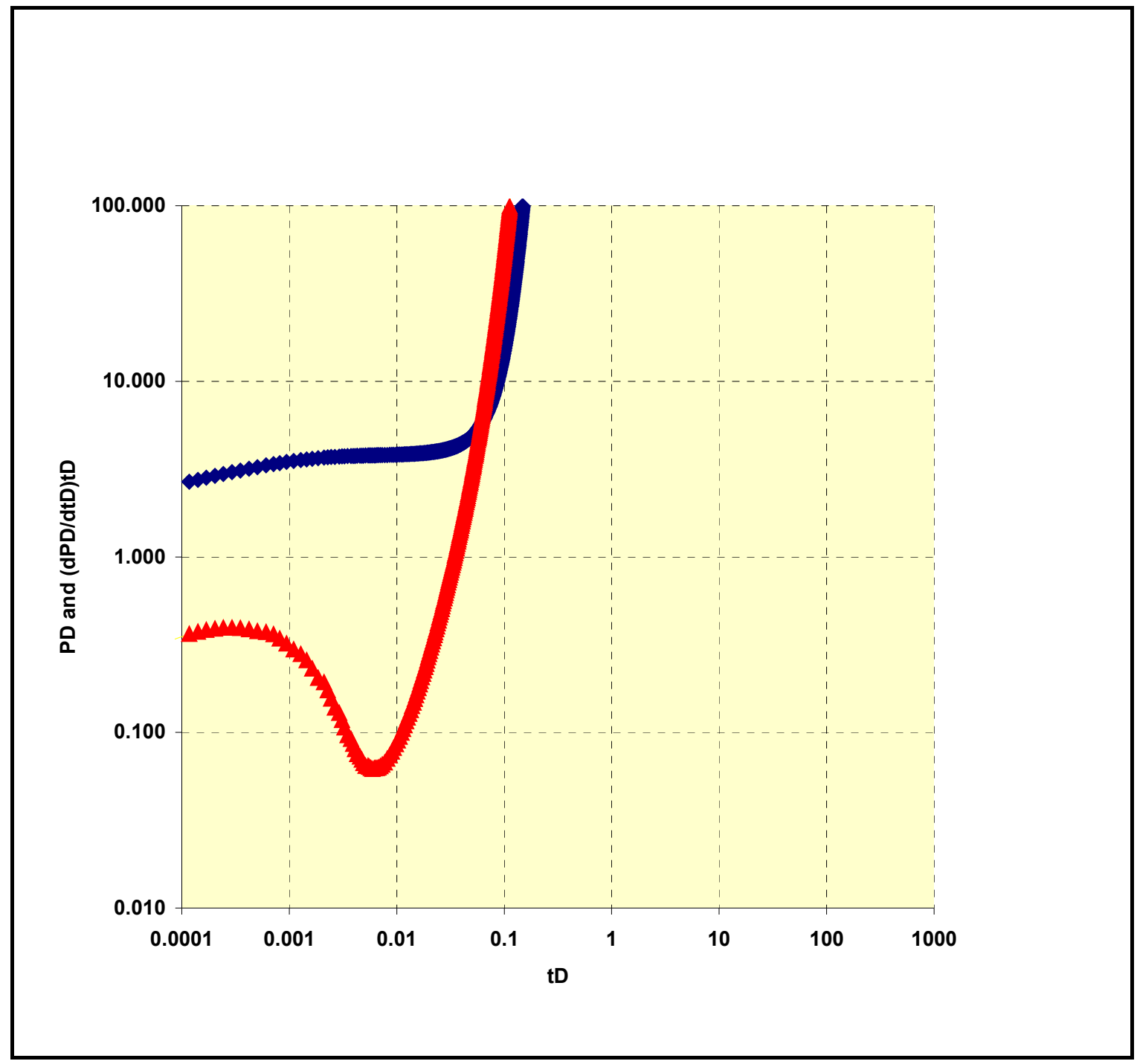

Figure 5.6: Variation of dimensionless pressure and its derivative with dimensionless time for a Single lateral well with $1500 \mathrm{ft}$ lateral length. 
The results for the $2000 \mathrm{ft}$. single lateral well for productivity index values are presented in Figure 5.7. As shown in Figure 5.7 the productivity index value shows a linear trend for 1 year 9 months. Compared to a vertical well completed in the same reservoir the productivity values are $46 \%$ greater indicating a larger production.

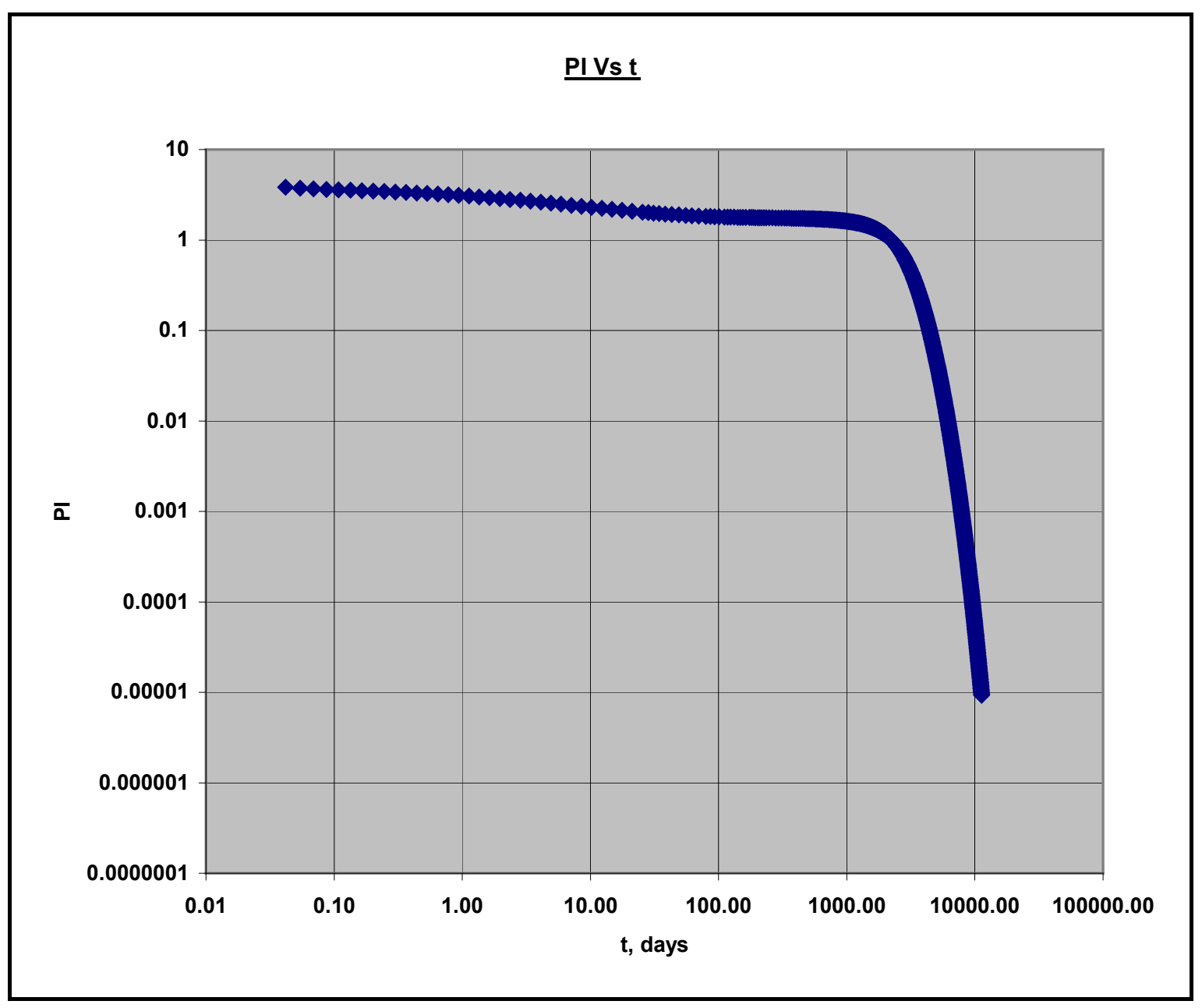

Figure 5.7: Variation of Productivity Index with time for a Single lateral well with $2000 \mathrm{ft}$ lateral length. 
Figure 5.8 shows the variation of dimensionless pressure and its derivative with dimensionless time for a Single lateral well with $2000 \mathrm{ft}$ lateral length.

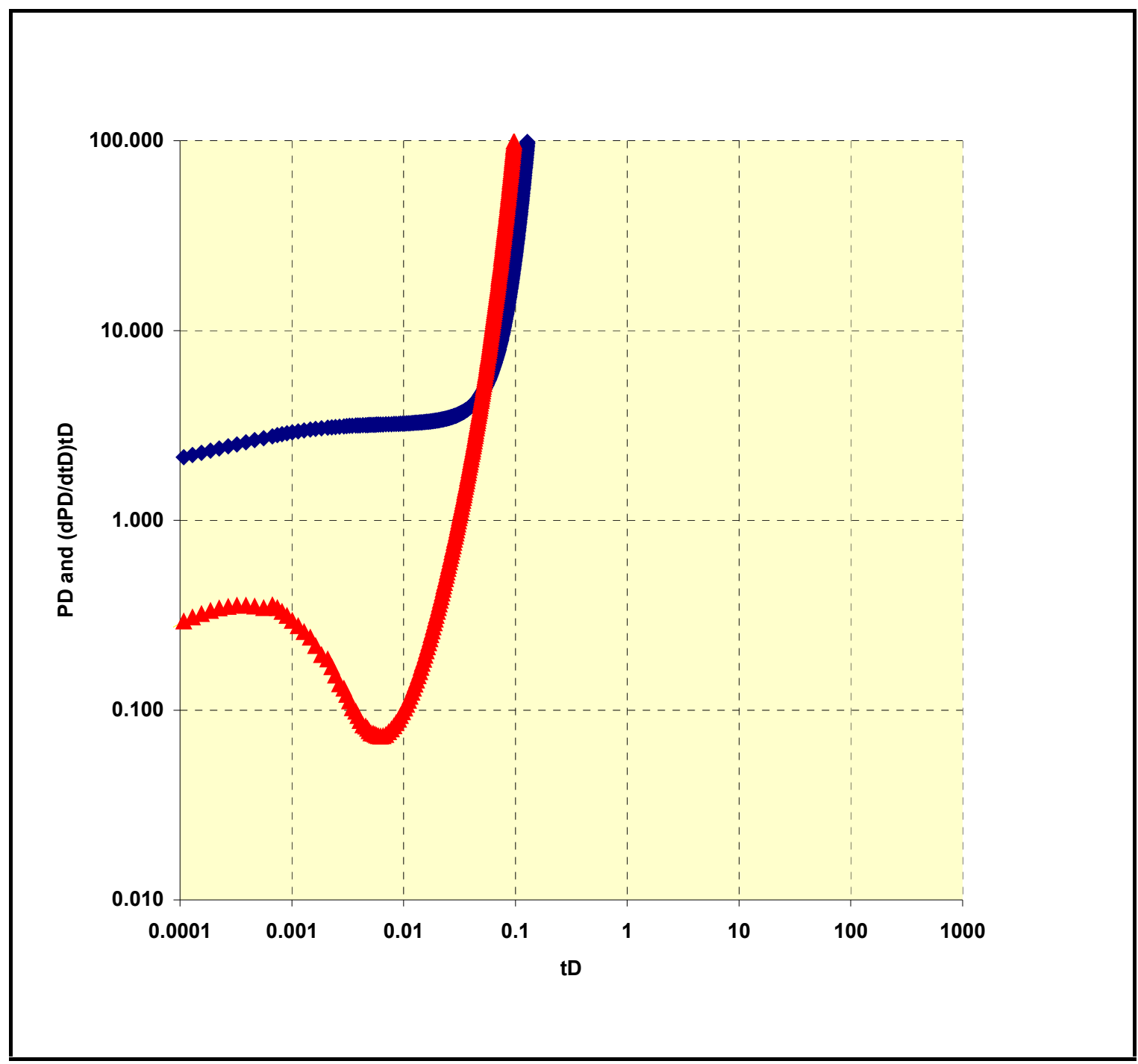

Figure 5.8: Variation of dimensionless pressure and its derivative with dimensionless time for a Single lateral well with $2000 \mathrm{ft}$ lateral length. 
Dual Lateral Well with Laterals at same height:

The results for the $500 \mathrm{ft}$. Dual Lateral (laterals at same depth) well for productivity index values are presented in Figure 5.9. As shown in Figure 5.9 the productivity index value shows a linear trend for 4 years 1 month. Compared to a vertical well completed in the same reservoir the productivity values are $49 \%$ greater indicating a larger production.

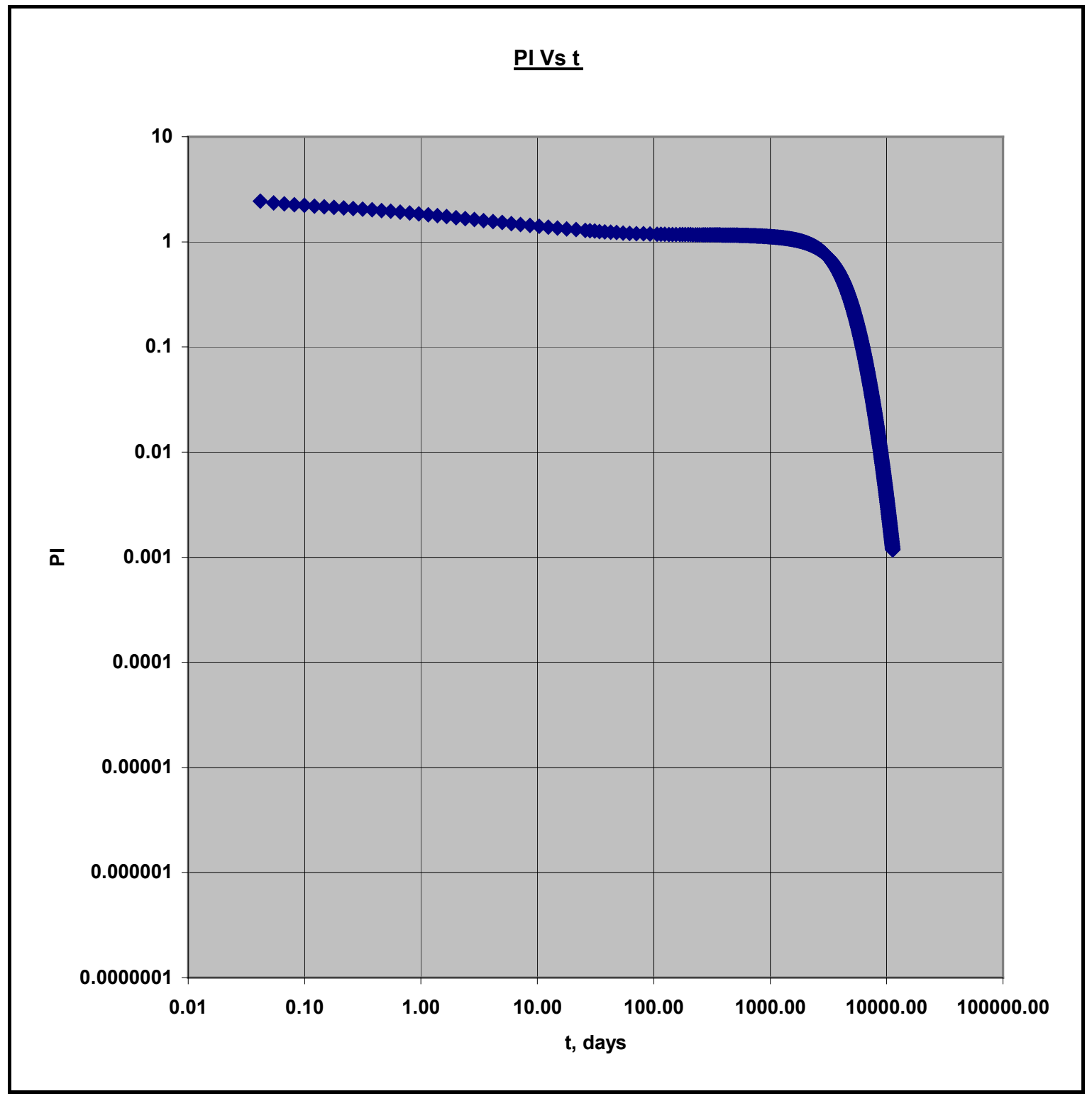

Figure 5.9: Variation of Productivity Index with time for a Dual Lateral well with $500 \mathrm{ft}$ lateral lengths, which are at the same depth. 
Figure 5.10 shows the variation of dimensionless pressure and its derivative with dimensionless time for a Dual Lateral well with $500 \mathrm{ft}$ lateral length, which are at same depth.

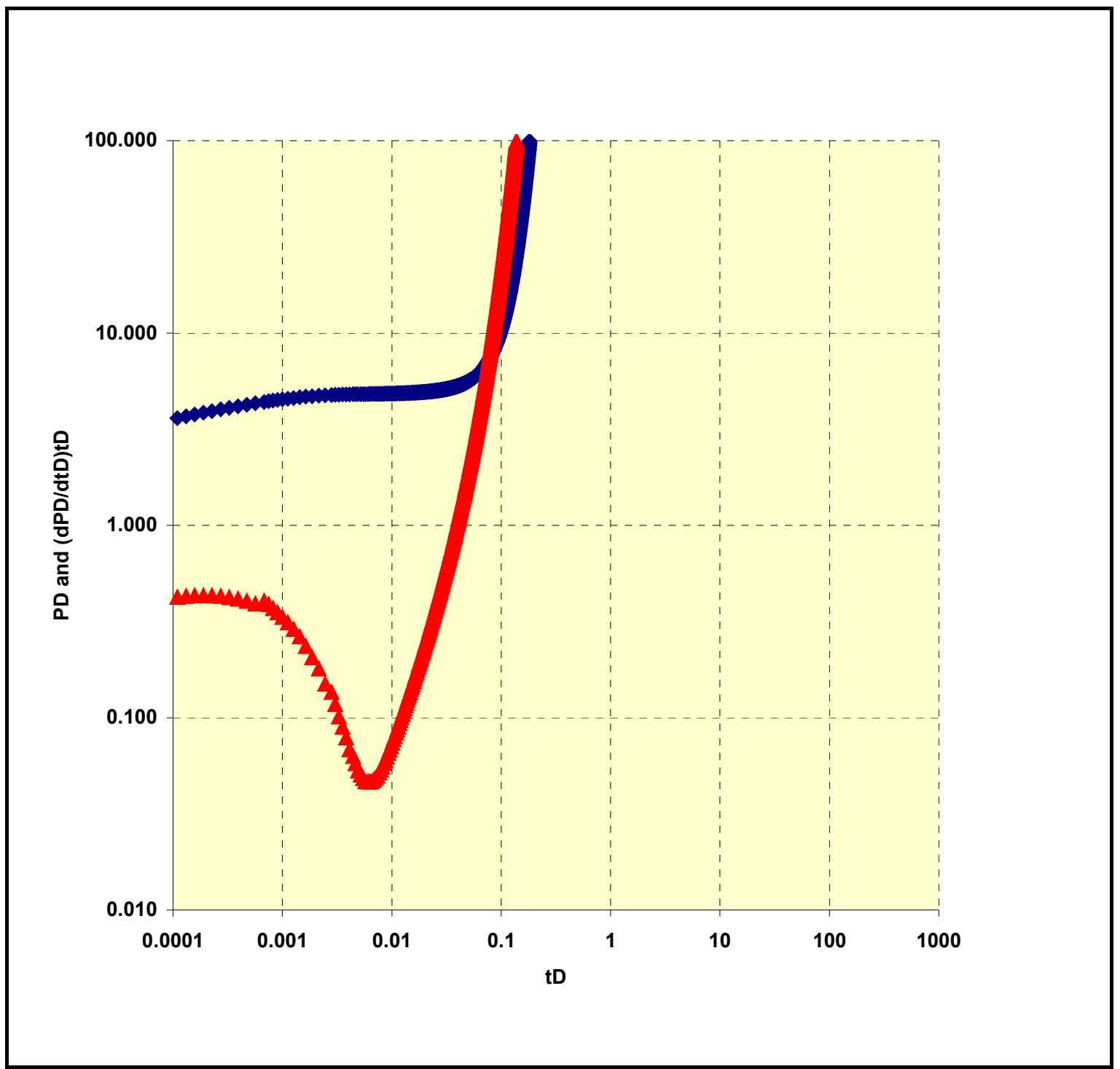

Figure 5.10: Variation of dimensionless pressure and its derivative with dimensionless time for a Dual Lateral well with $\mathbf{5 0 0} \mathrm{ft}$ lateral lengths, which are at the same depth. 
The results for the $1000 \mathrm{ft}$. Dual Lateral (laterals at same depth) well for productivity index values are presented in Figure 5.11. As shown in Figure 5.11 the productivity index value shows a linear trend for 2 years 7 month. Compared to a vertical well completed in the same reservoir the productivity values are $46 \%$ greater indicating a larger production.

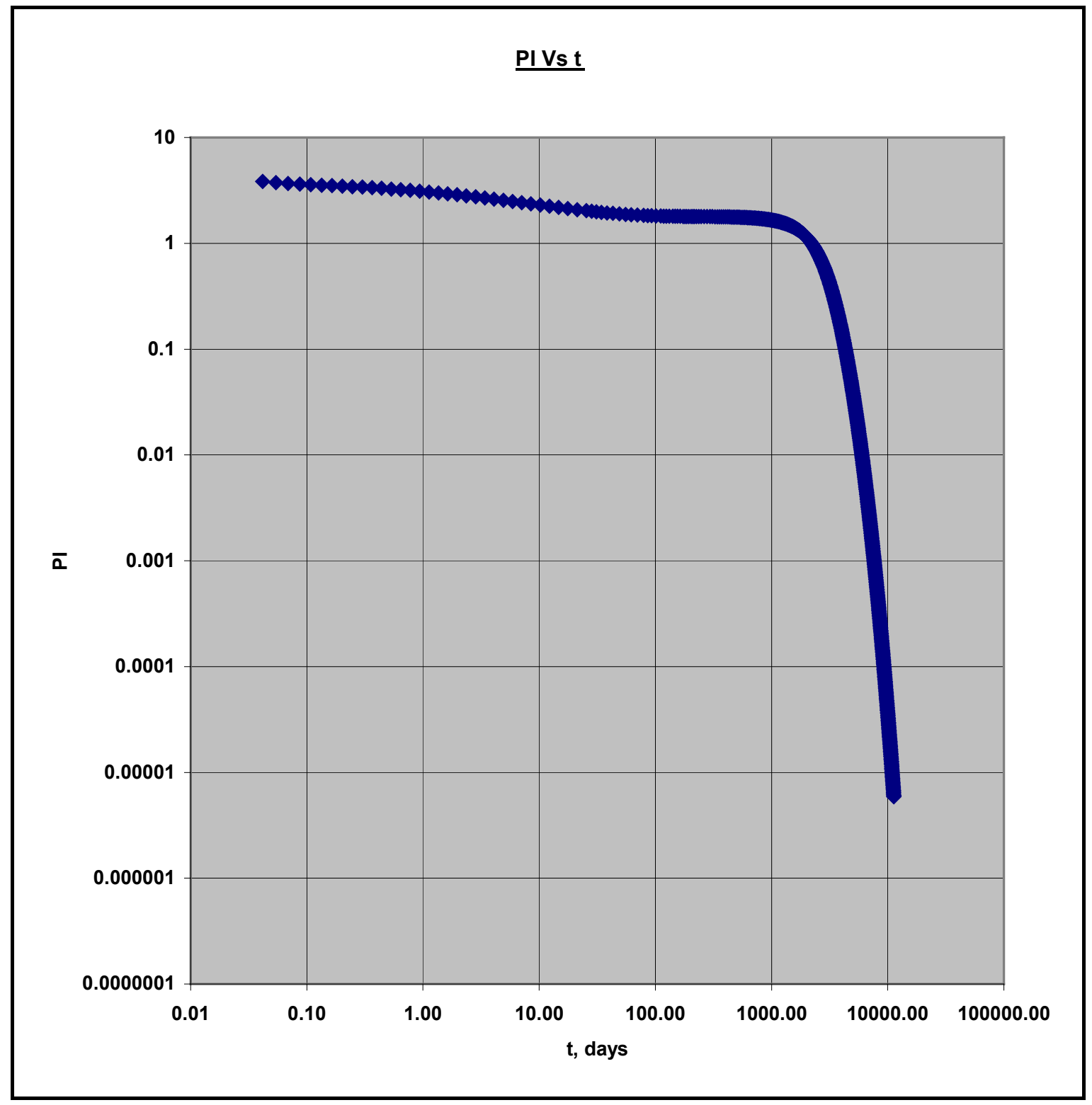

Figure 5.11 Variation of Productivity Index with time for a Dual Lateral well with $1000 \mathrm{ft}$ lateral lengths, which are at the same depth. 
Figure 5.12 shows the variation of dimensionless pressure and its derivative with dimensionless time for a Dual Lateral well with $1000 \mathrm{ft}$ lateral length, which are at same depth.

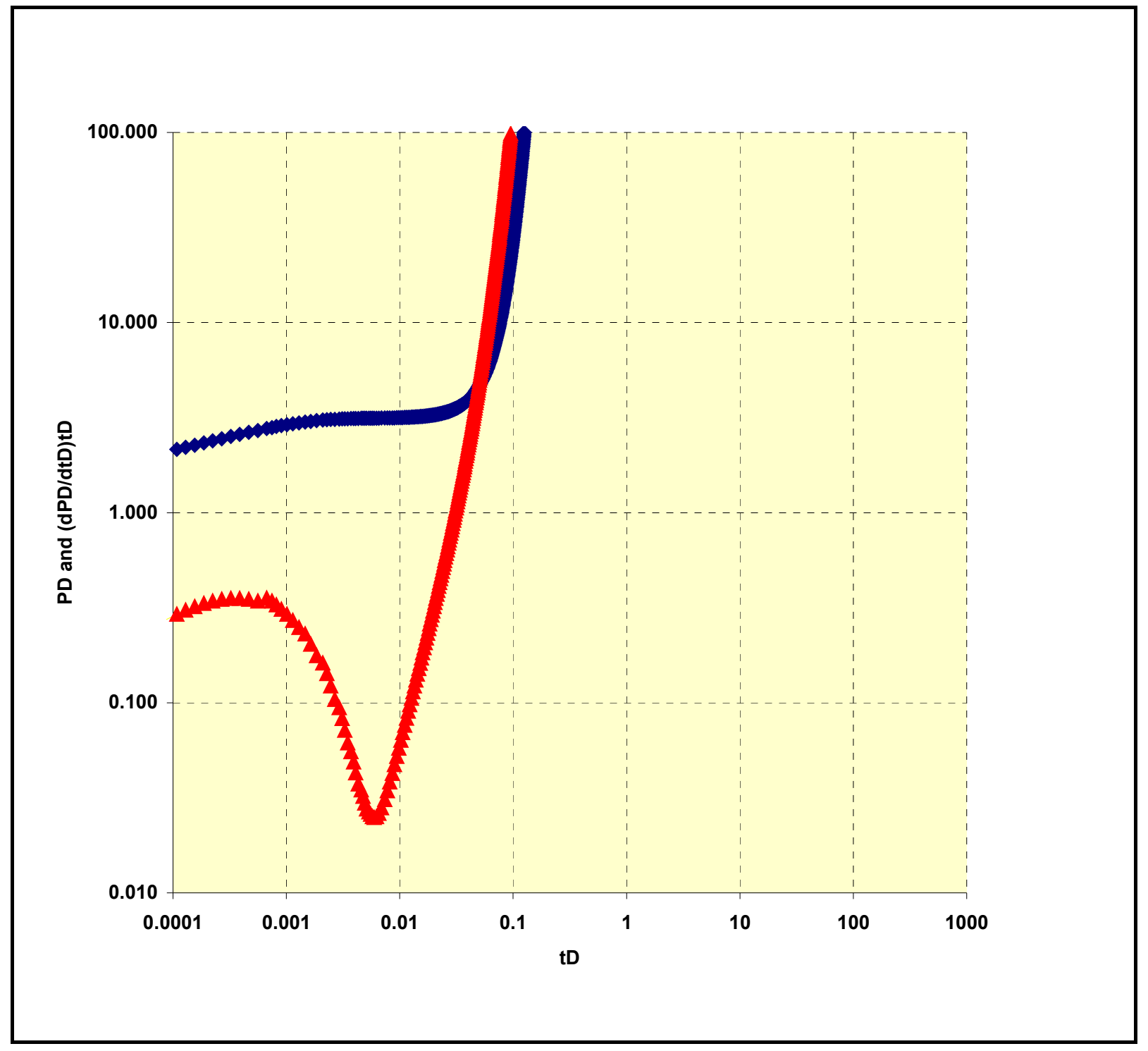

Figure 5.12: Variation of dimensionless pressure and its derivative with dimensionless time for a Dual Lateral well with $1000 \mathrm{ft}$ lateral lengths, which are at the same depth. 
The results for the $1500 \mathrm{ft}$. Dual Lateral (laterals at same depth) well for productivity index values are presented in Figure 5.13. As shown in Figure 5.13 the productivity index value shows a linear trend for 1 year 9 months and decreases to zero at the end of a dimensionless time of 11000 days. Compared to a vertical well completed in the same reservoir the productivity values are $43 \%$ greater indicating a larger production.

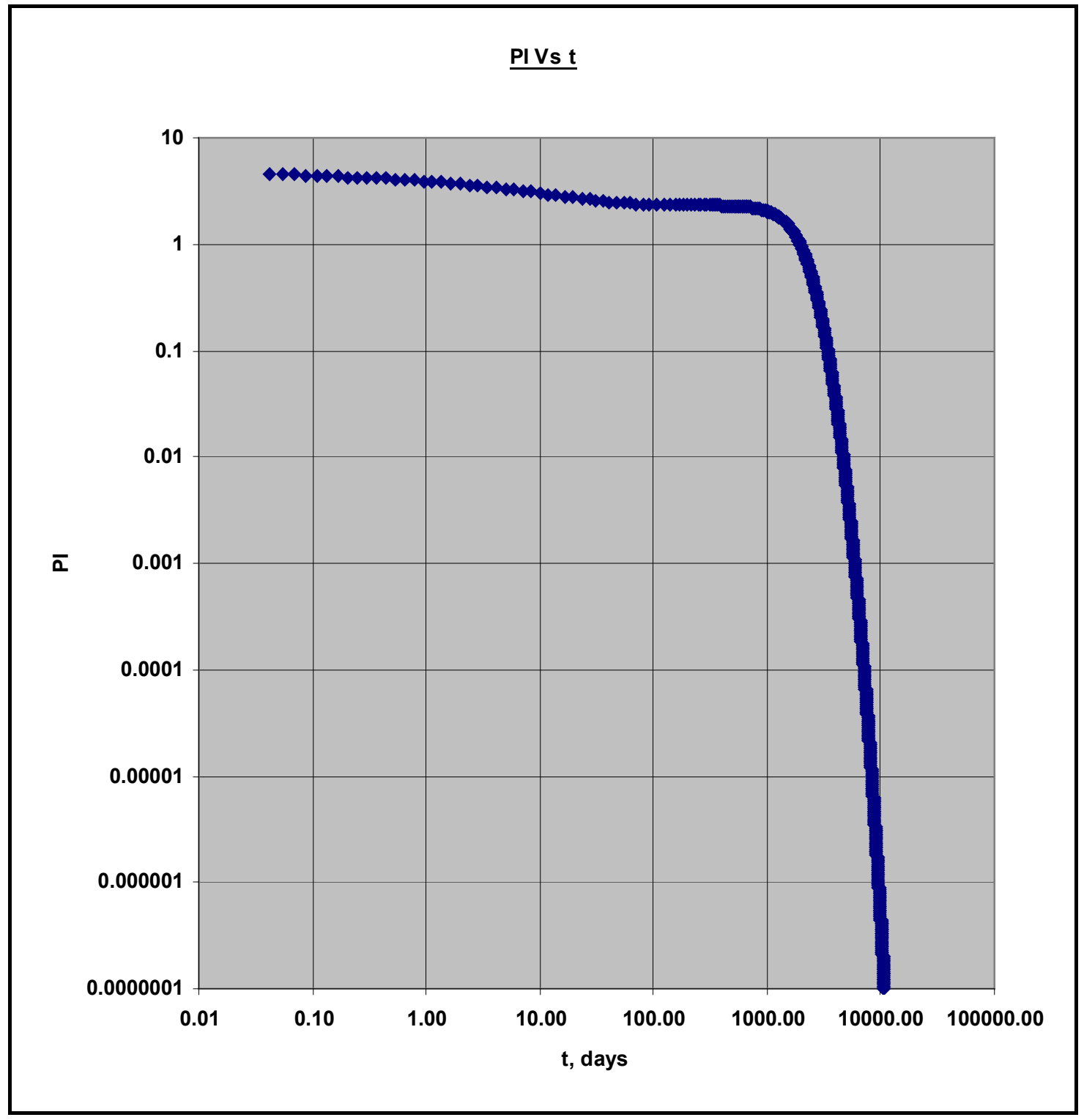

Figure 5.13: Variation of Productivity Index with time for a Dual Lateral well with $1500 \mathrm{ft}$ lateral lengths, which are at the same depth. 
Figure 5.14 shows the variation of dimensionless pressure and its derivative with dimensionless time for a Dual Lateral well with $1500 \mathrm{ft}$ lateral length, which are at same depth.

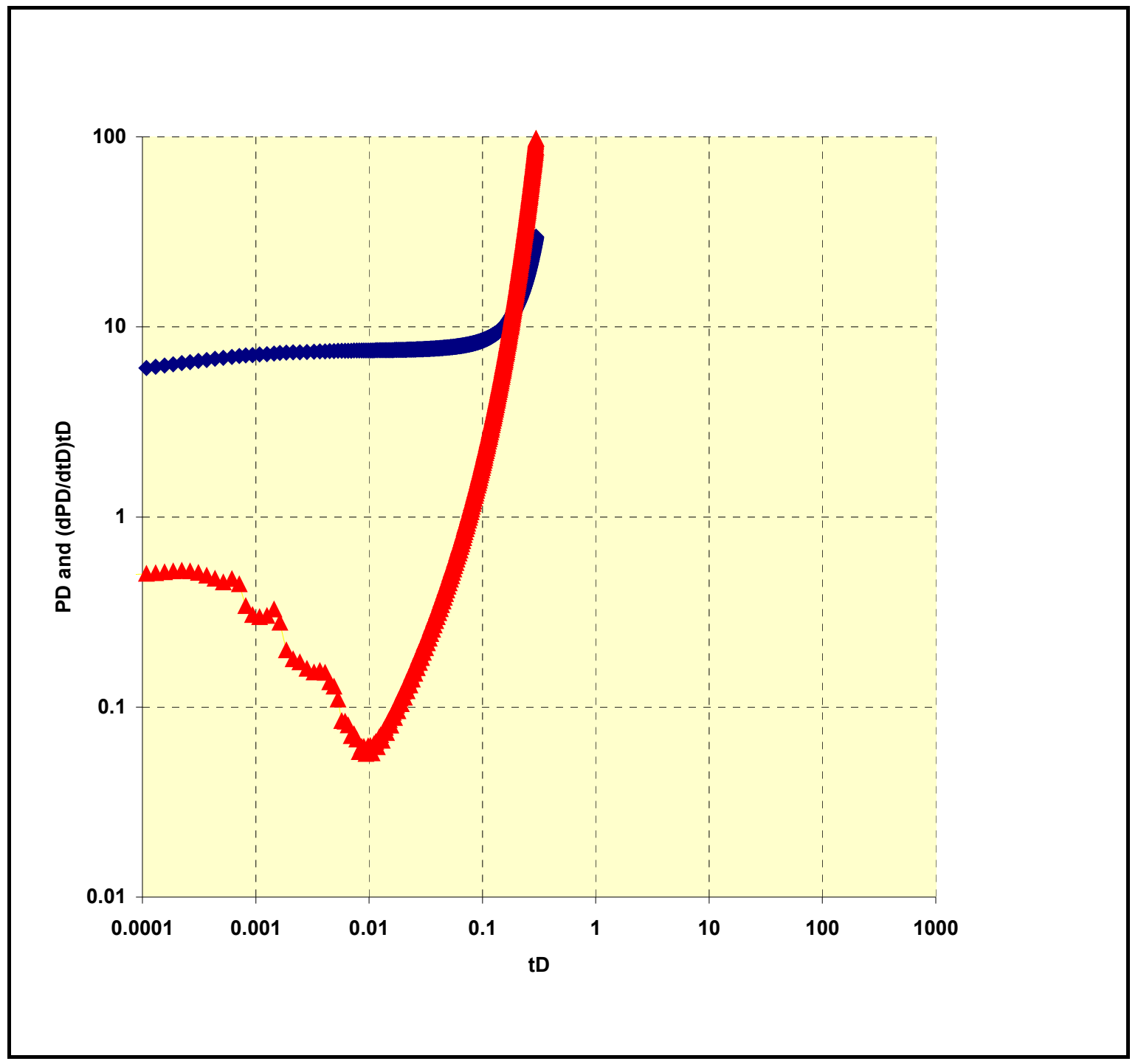

Figure 5.14: Variation of dimensionless pressure and its derivative with dimensionless time for a Dual Lateral well with $1500 \mathrm{ft}$ lateral lengths, which are at the same depth. 
The results for the $2000 \mathrm{ft}$. Dual Lateral (laterals at same depth) well for productivity index values are presented in Figure 5.15. As shown in Figure 5.15 the productivity index value shows a linear trend for 1 year 6 months and decreases to zero at the end of a dimensionless time of 9500 days. Compared to a vertical well completed in the same reservoir the productivity values are $34 \%$ greater indicating a larger production.

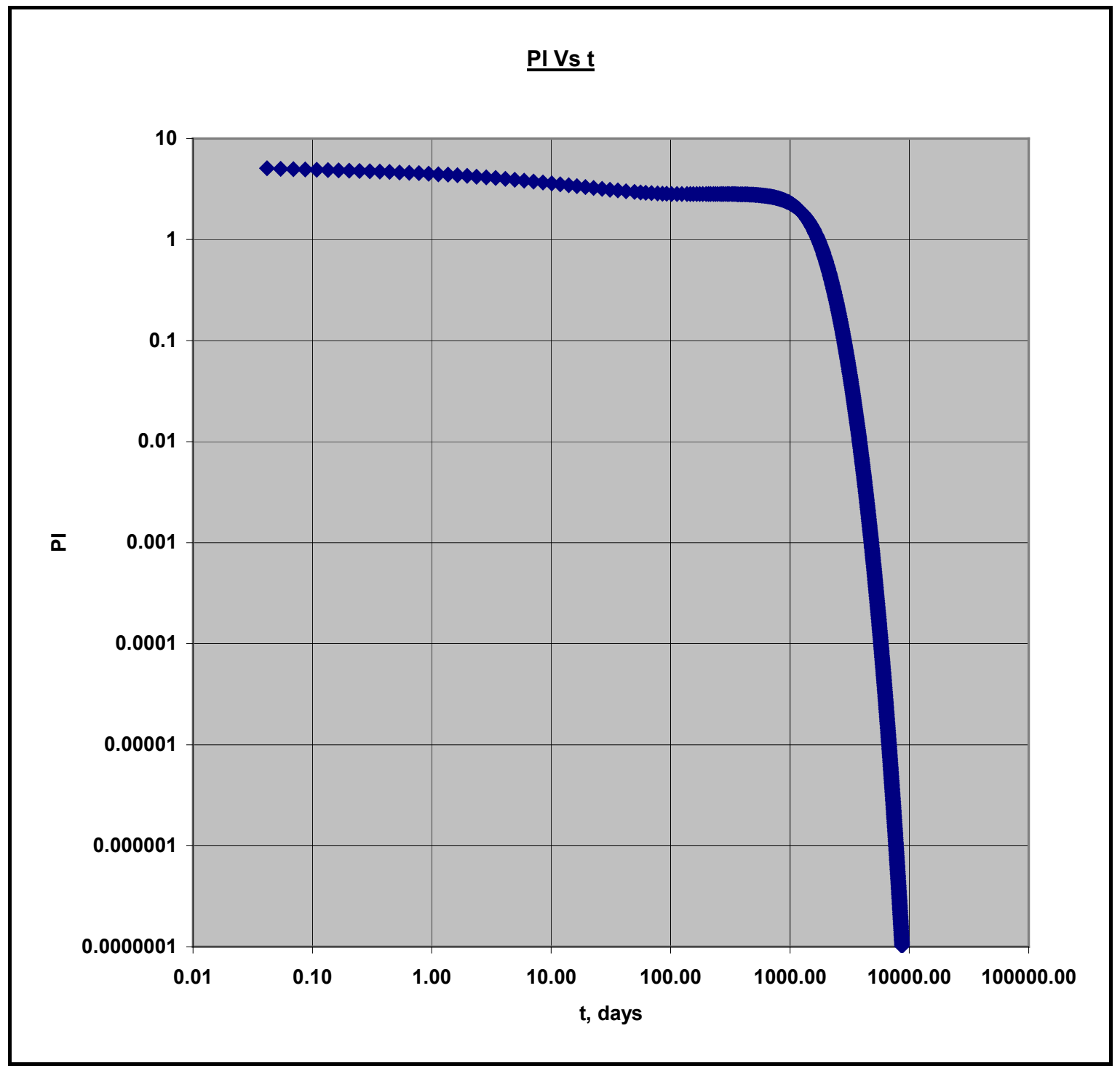

Figure 5.15: Variation of Productivity Index with time for a Dual Lateral well with $2000 \mathrm{ft}$ lateral lengths, which are at the same depth. 
Figure 5.16 shows the variation of dimensionless pressure and its derivative with dimensionless time for a Dual Lateral well with $2000 \mathrm{ft}$ lateral length, which are at same depth.

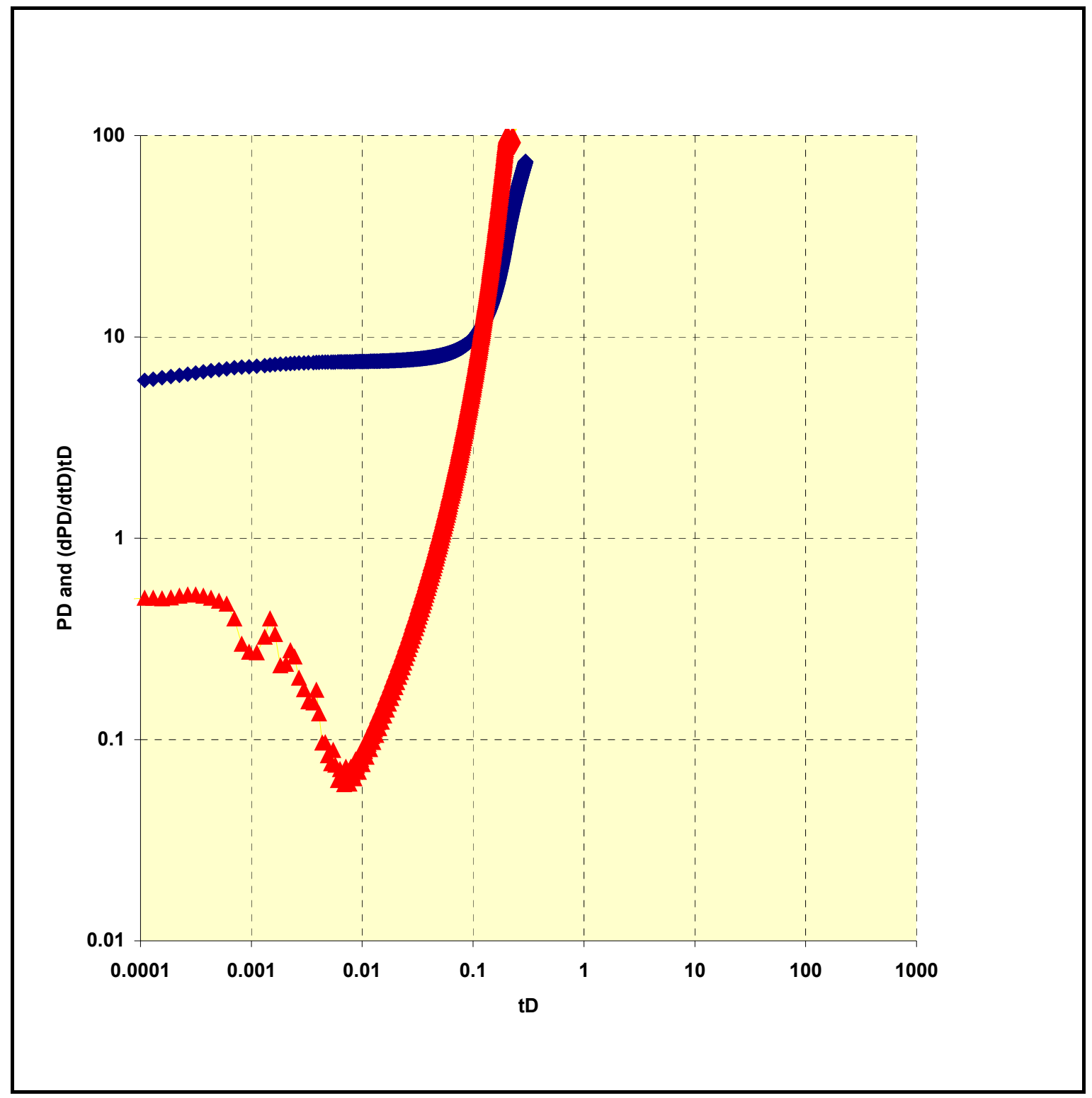

Figure 5.16: Variation of dimensionless pressure and its derivative with dimensionless time for a Dual Lateral well with $2000 \mathrm{ft}$ lateral lengths, which are at the same depth. 


\section{Dual Lateral Well with Laterals at different height:}

The results for the $500 \mathrm{ft}$. Dual Lateral (laterals at different depths separated by $50 \mathrm{ft}$ ) well for productivity index values are presented in Figure 5.17. As shown in Figure 5.17 the productivity index value shows a linear trend for 2 years 7 months Compared to a vertical well completed in the same reservoir the productivity values are $49 \%$ greater indicating a larger production.

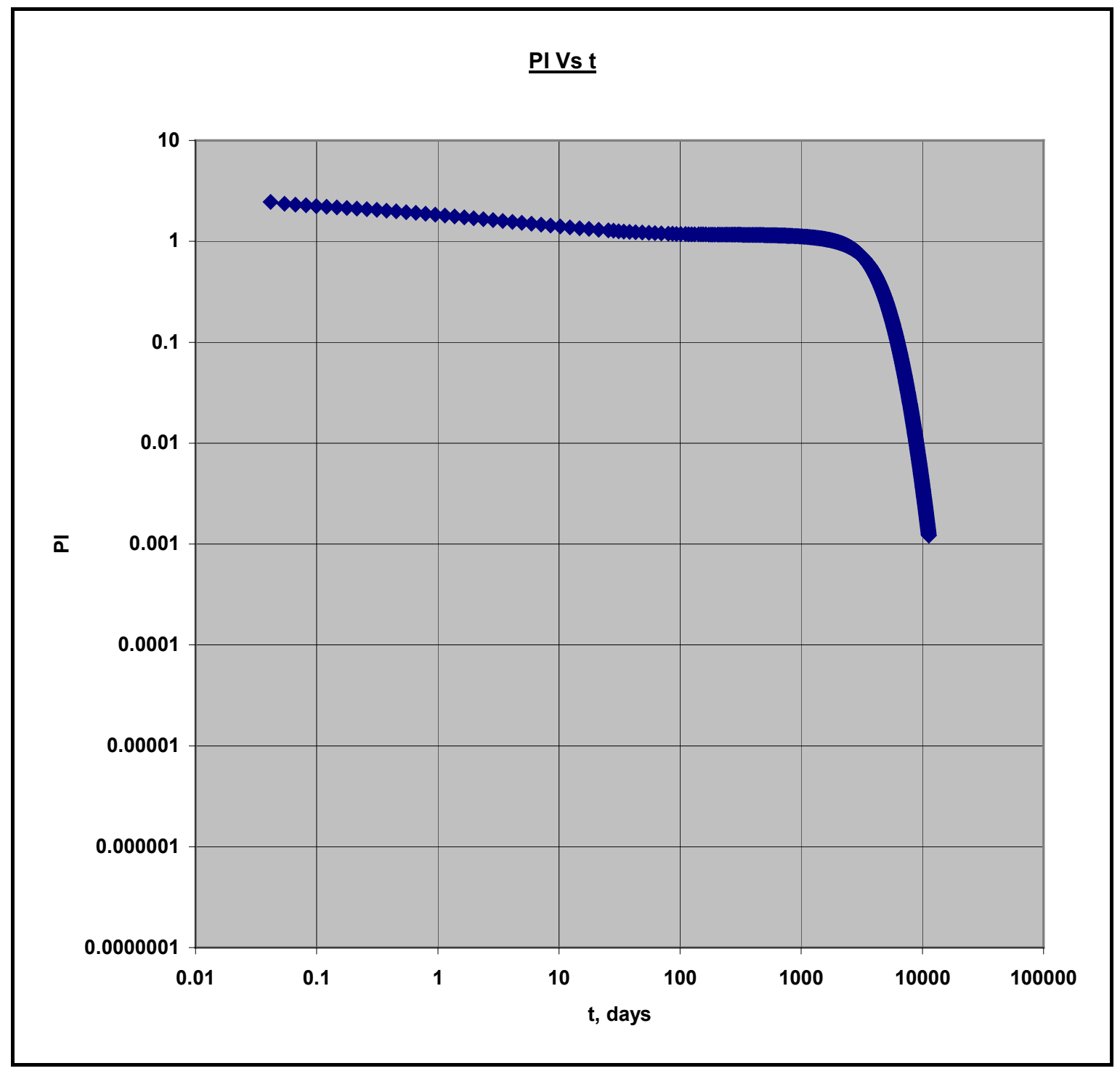

Figure 5.17: Variation of Productivity Index with time for a Dual Lateral well with $500 \mathrm{ft}$ lateral lengths, which are at different depths. 
Figure 5.18 shows the variation of dimensionless pressure and its derivative with dimensionless time for a Dual Lateral well with $500 \mathrm{ft}$ lateral length, which are at different depths.

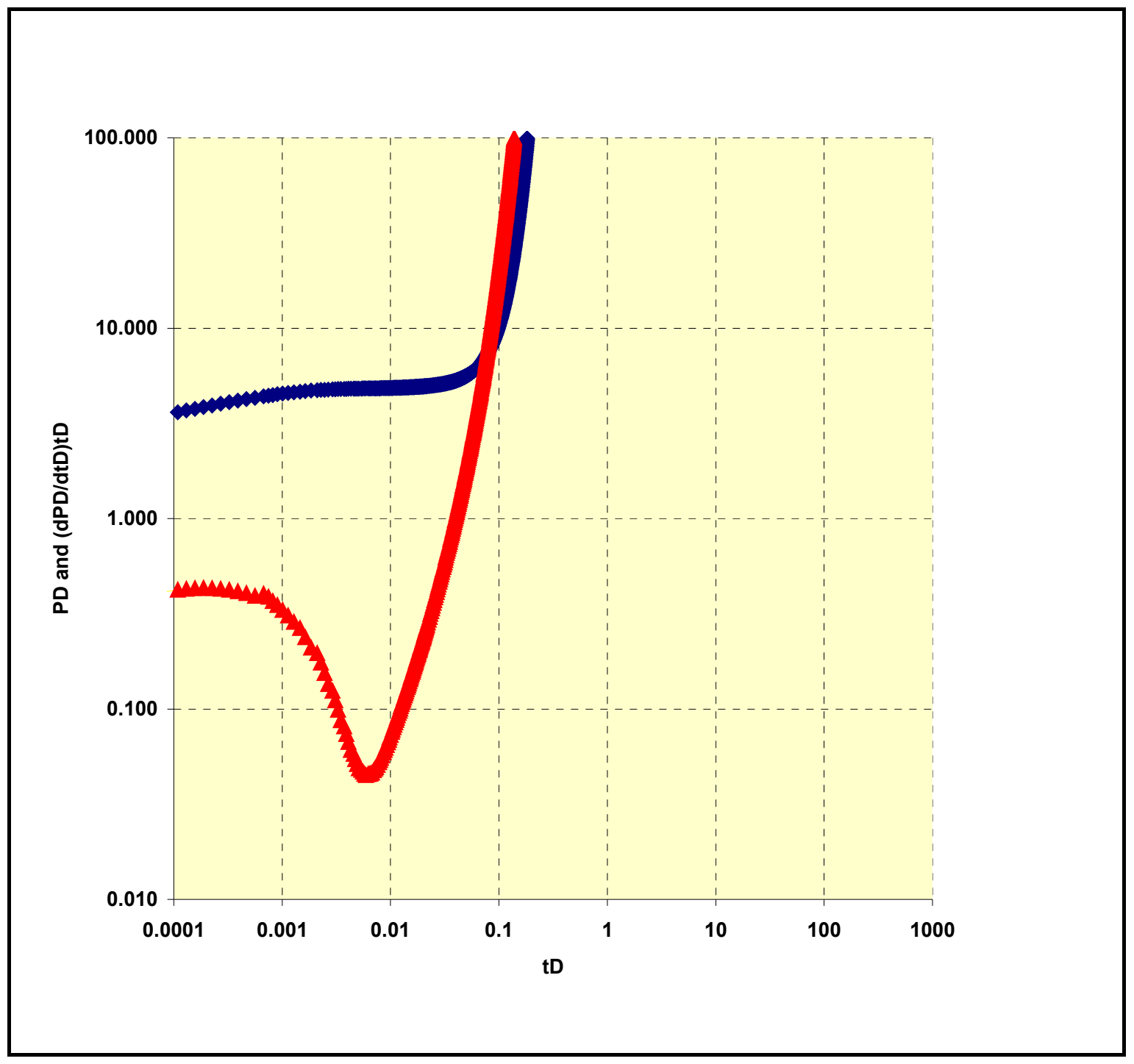

Figure 5.18: Variation of dimensionless pressure and its derivative with dimensionless time for a Dual Lateral well with $\mathbf{5 0 0} \mathrm{ft}$ lateral lengths, which are at different depths. 
The results for the $1000 \mathrm{ft}$. Dual Lateral (laterals at different depths separated by $50 \mathrm{ft}$ ) well for productivity index values are presented in Figure 5.19. As shown in Figure 5.19 the productivity index value shows a linear trend for 1 years 5 months Compared to a vertical well completed in the same reservoir the productivity values are $48 \%$ greater indicating a larger production.

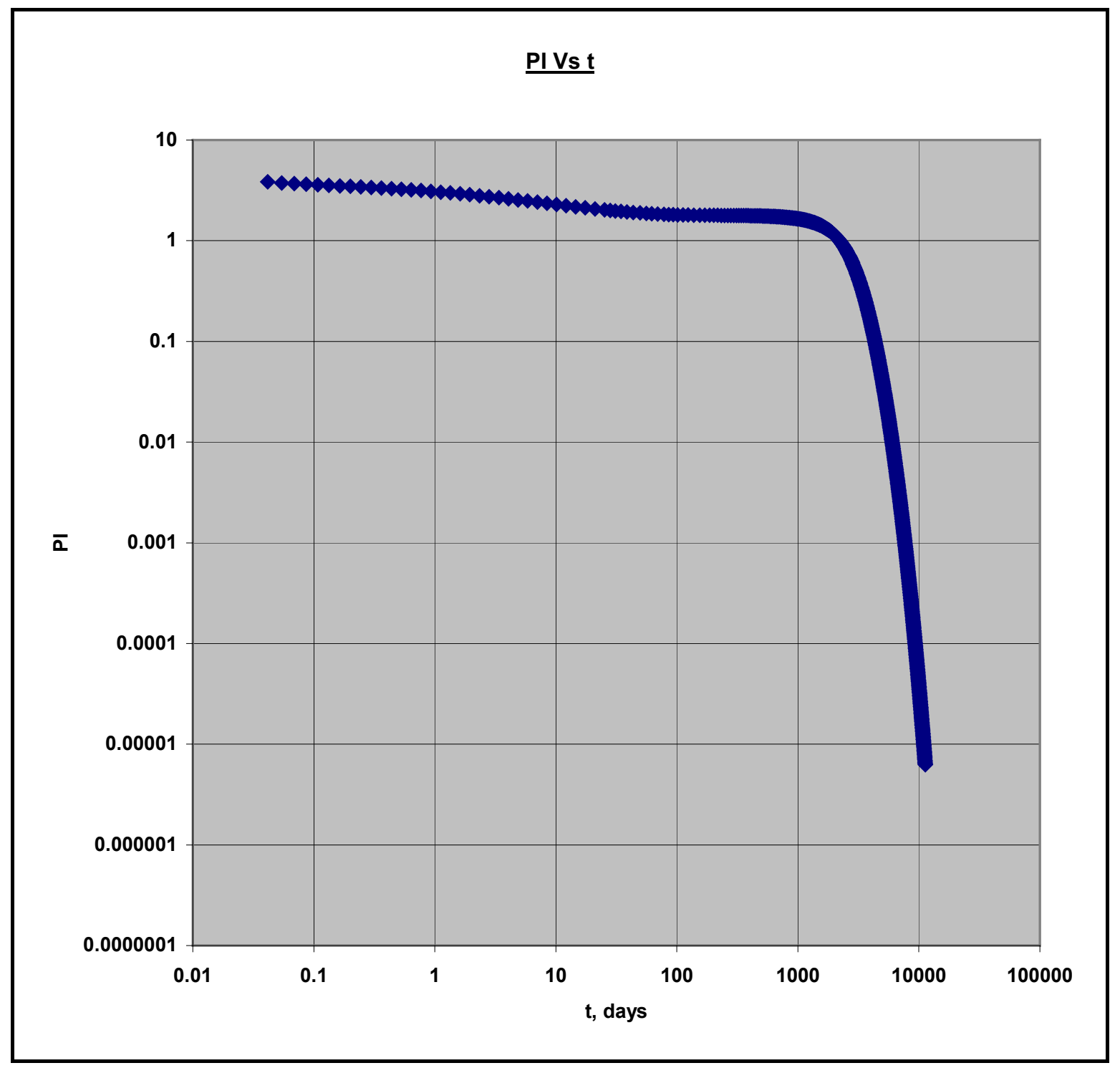

Figure 5.19: Variation of Productivity Index with time for a Dual Lateral well with $1000 \mathrm{ft}$ lateral lengths, which are at different depths. 
Figure 5.20 shows the variation of dimensionless pressure and its derivative with dimensionless time for a Dual Lateral well with $1000 \mathrm{ft}$ lateral length, which are at different depths.

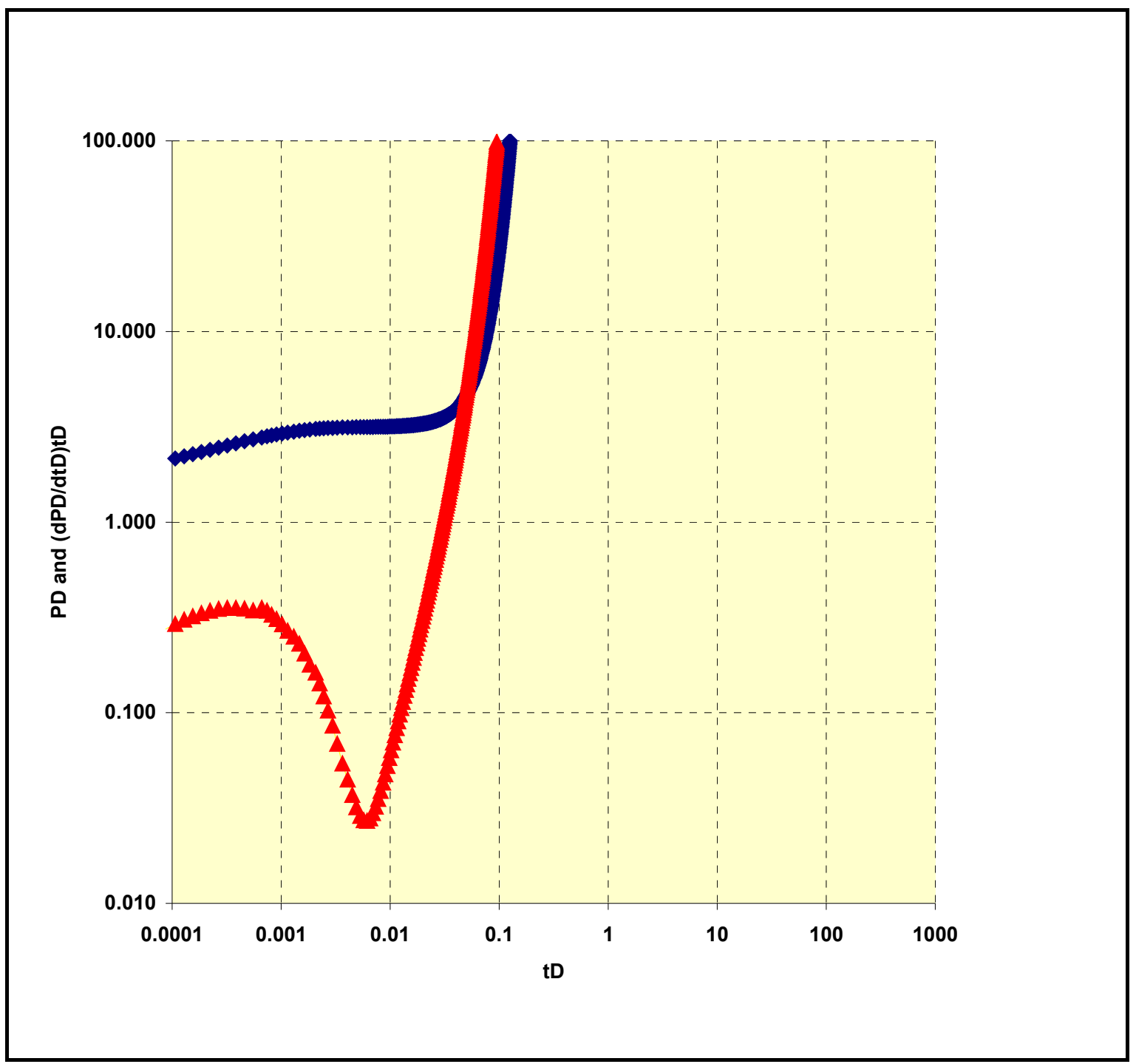

Figure 5.20: Variation of dimensionless pressure and its derivative with dimensionless time for a Dual Lateral well with $1000 \mathrm{ft}$ lateral lengths, which are at different depths. 
The results for the $1500 \mathrm{ft}$. Dual Lateral (laterals at different depths separated by $50 \mathrm{ft}$ ) well for productivity index values are presented in Figure 5.21. As shown in Figure 5.21 the productivity index value shows a linear trend for 1 year 3 months and decreases to zero at the end of a dimensionless time of 11000 days. Compared to a vertical well completed in the same reservoir the productivity values are $43 \%$ greater indicating a larger production.

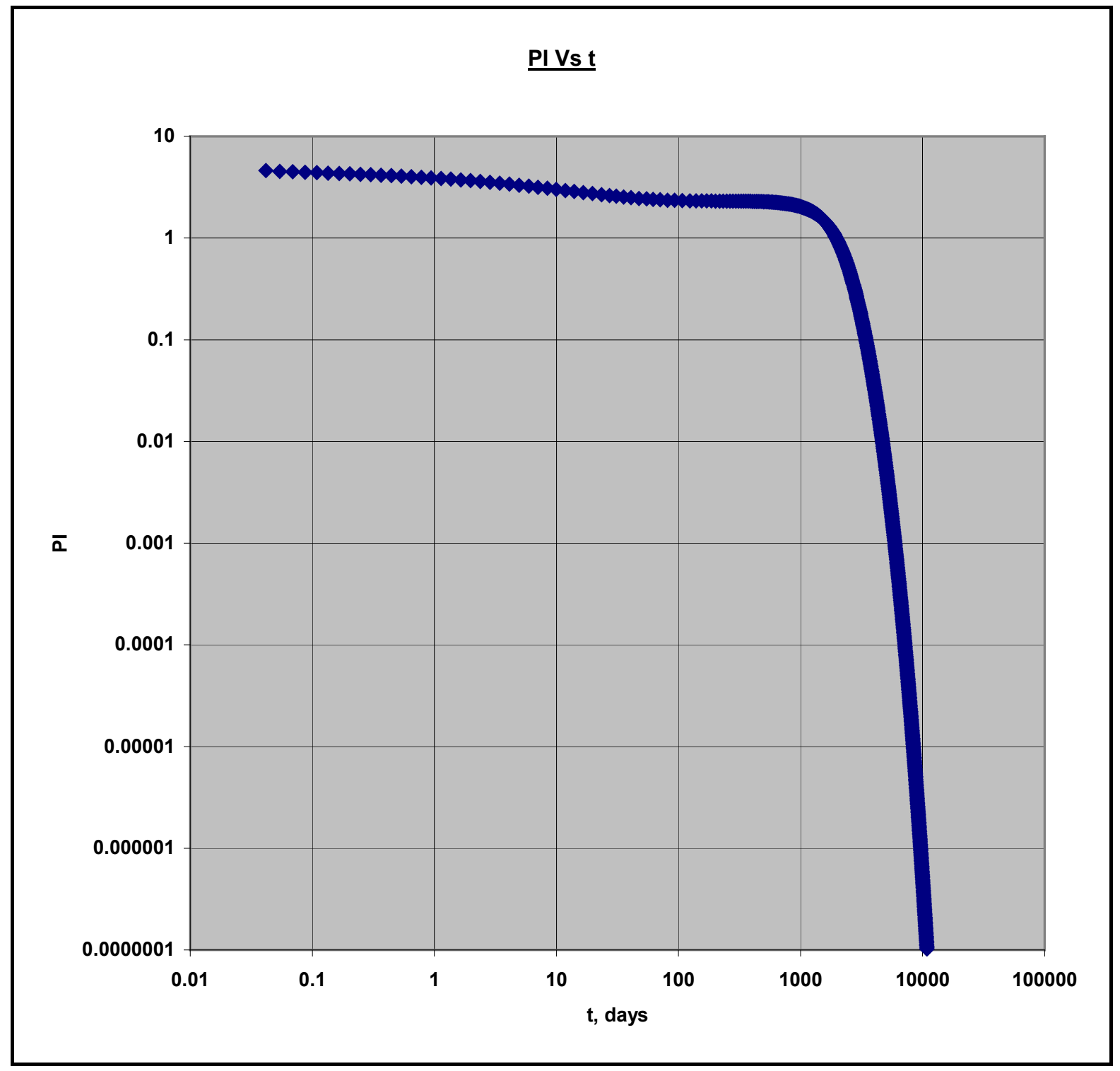

Figure 5.21: Variation of Productivity Index with time for a Dual Lateral well with $1500 \mathrm{ft}$ lateral lengths, which are at different depths. 
Figure 5.22 shows the variation of dimensionless pressure and its derivative with dimensionless time for a Dual Lateral well with $1500 \mathrm{ft}$ lateral length, which are at different depths.

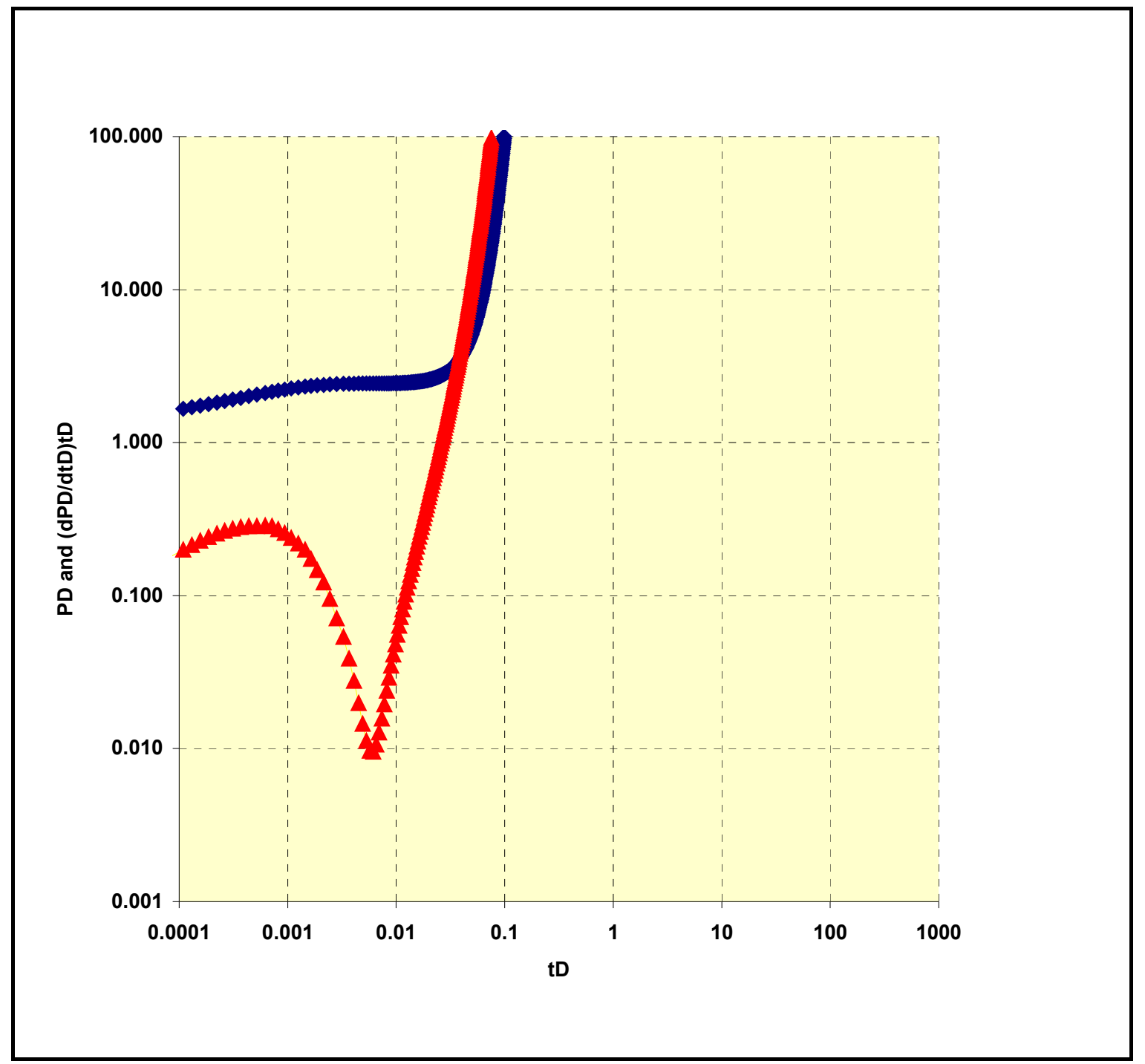

Figure 5.22: Variation of dimensionless pressure and its derivative with dimensionless time for a Dual Lateral well with $1500 \mathrm{ft}$ lateral lengths, which are at different depths. 
The results for the $2000 \mathrm{ft}$. Dual Lateral (laterals at different depths separated by $50 \mathrm{ft}$ ) well for productivity index values are presented in Figure 5.23. As shown in Figure 5.23 the productivity index value shows a linear trend for 1 years 6 months and decreases to zero at the end of a dimensionless time of 9500 days. Compared to a vertical well completed in the same reservoir the productivity values are $34 \%$ greater indicating a larger production.

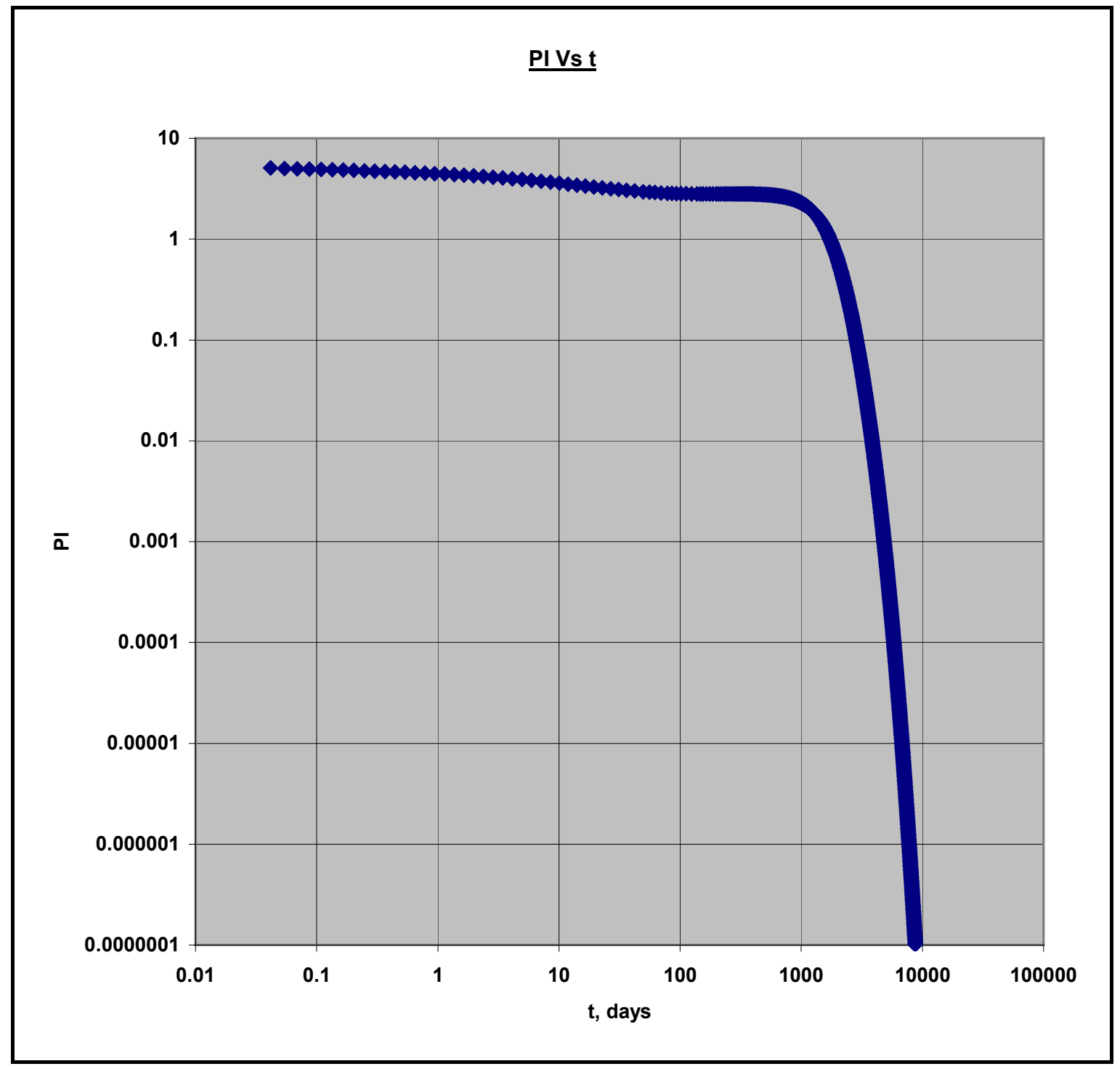

Figure 5.23: Variation of Productivity Index with time for a Dual Lateral well with $2000 \mathrm{ft}$ lateral lengths, which are at different depths. 
Figure 5.24 shows the variation of dimensionless pressure and its derivative with dimensionless time for a Dual Lateral well with $2000 \mathrm{ft}$ lateral length, which are at different depths.

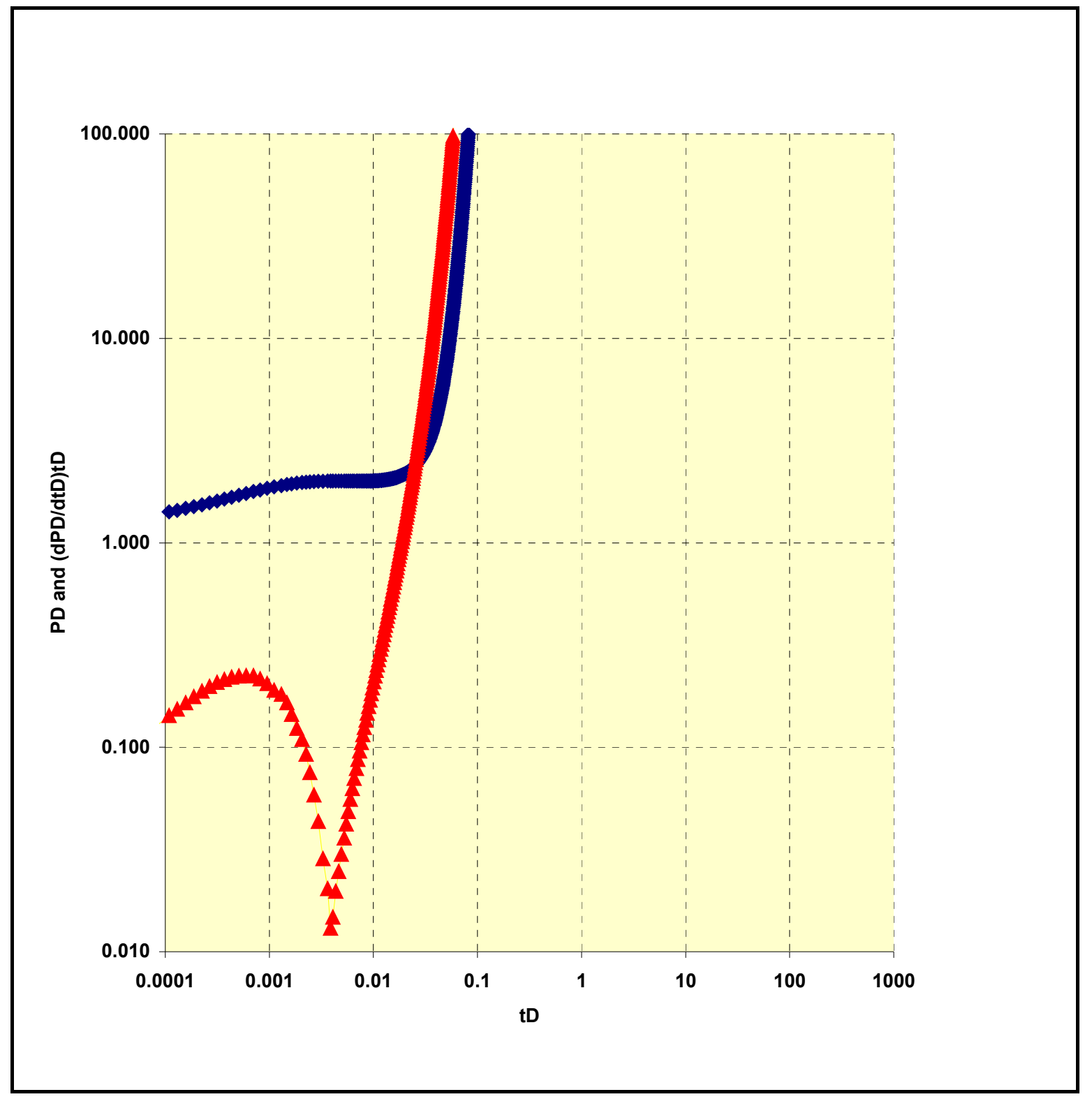

Figure 5.24: Variation of dimensionless pressure and its derivative with dimensionless time for a Dual Lateral well with $2000 \mathrm{ft}$ lateral lengths, which are at different depths. 
Four Laterals well:

The results for the $500 \mathrm{ft}$. Four Laterals (laterals at same depth) well for productivity index values are presented in Figure 5.25. As shown in Figure 5.25 the productivity index value shows a linear trend for 1 year 3 months. Compared to a vertical well completed in the same reservoir the productivity values are $47 \%$ greater indicating a larger production.

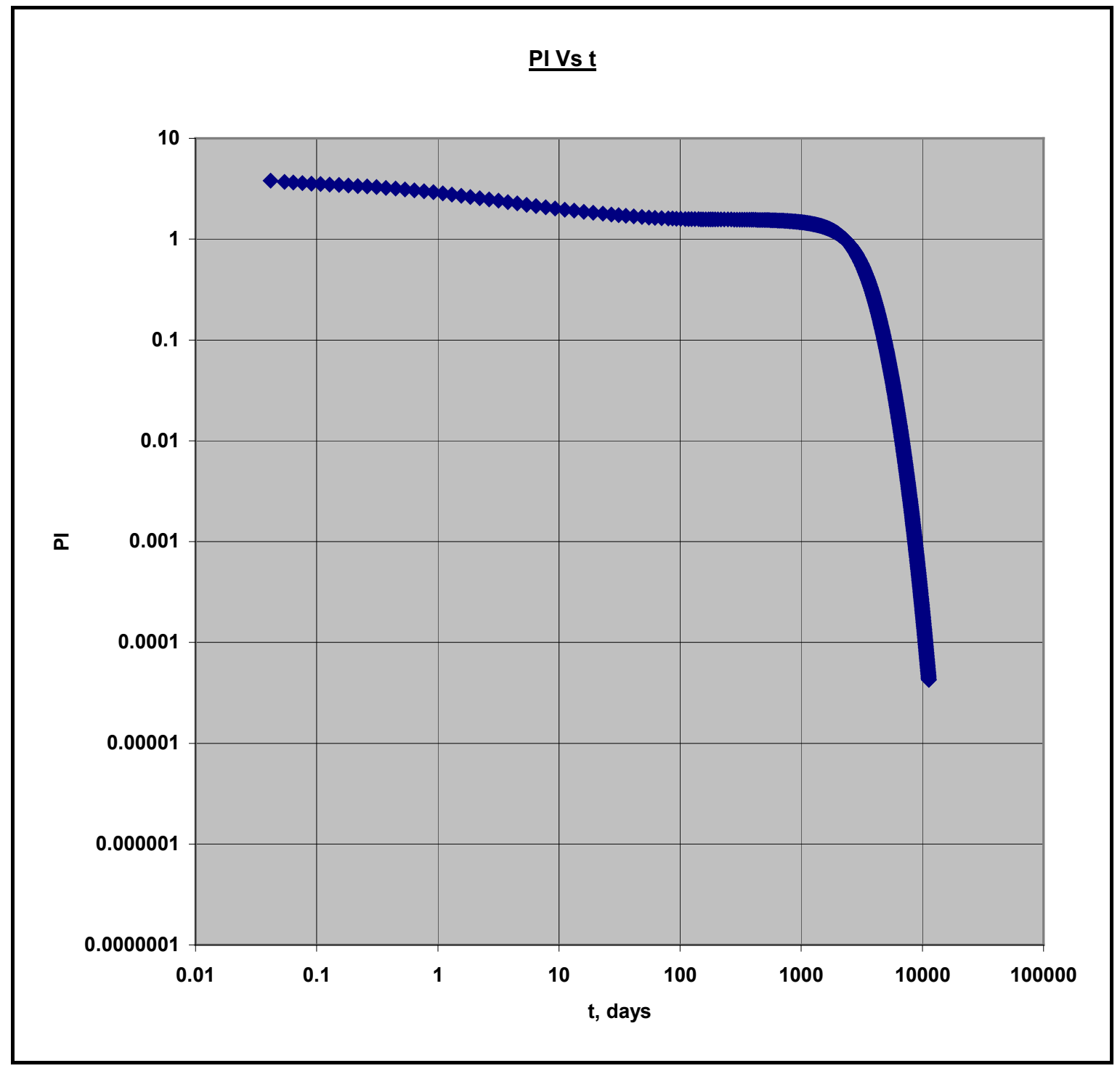

Figure 5.25: Variation of Productivity Index with time for a 4-lateral well with $500 \mathrm{ft}$ lateral lengths, which are at the same depth. 
Figure 5.26 shows the variation of dimensionless pressure and its derivative with dimensionless time for a 4-lateral well with $500 \mathrm{ft}$ lateral length, which are at same depth.

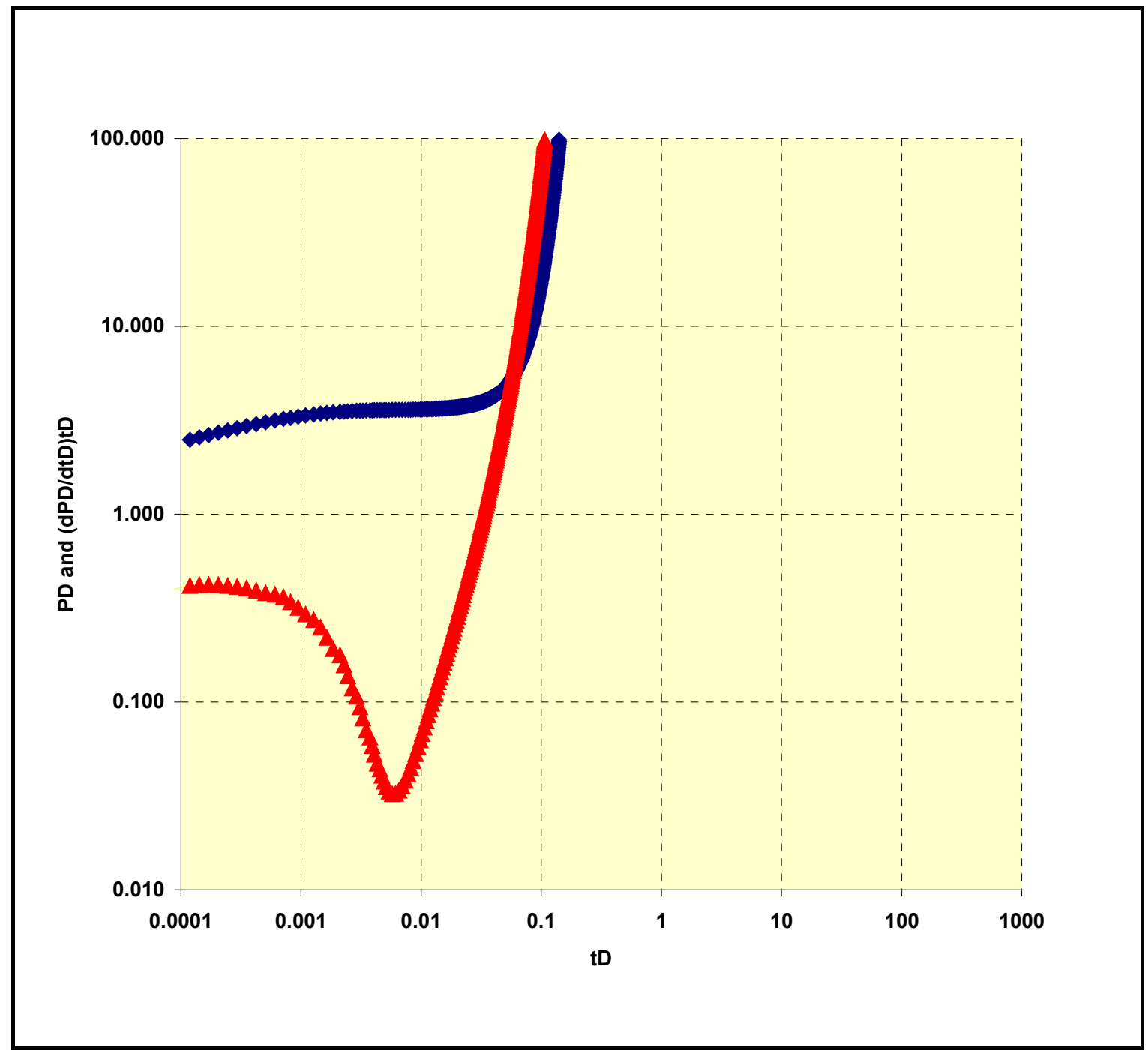

Figure 5.26: Variation of dimensionless pressure and its derivative with dimensionless time for a 4-lateral well with $500 \mathrm{ft}$ lateral lengths, which are at the same depth. 
The results for the $1000 \mathrm{ft}$. Four Laterals (laterals at same depth) well for productivity index values are presented in Figure 5.27. As shown in Figure 5.27 the productivity index value shows a linear trend for 1 year 3 months and decreases to zero at the end of a dimensionless time of 11000 days. Compared to a vertical well completed in the same reservoir the productivity values are $35 \%$ greater indicating a larger production.

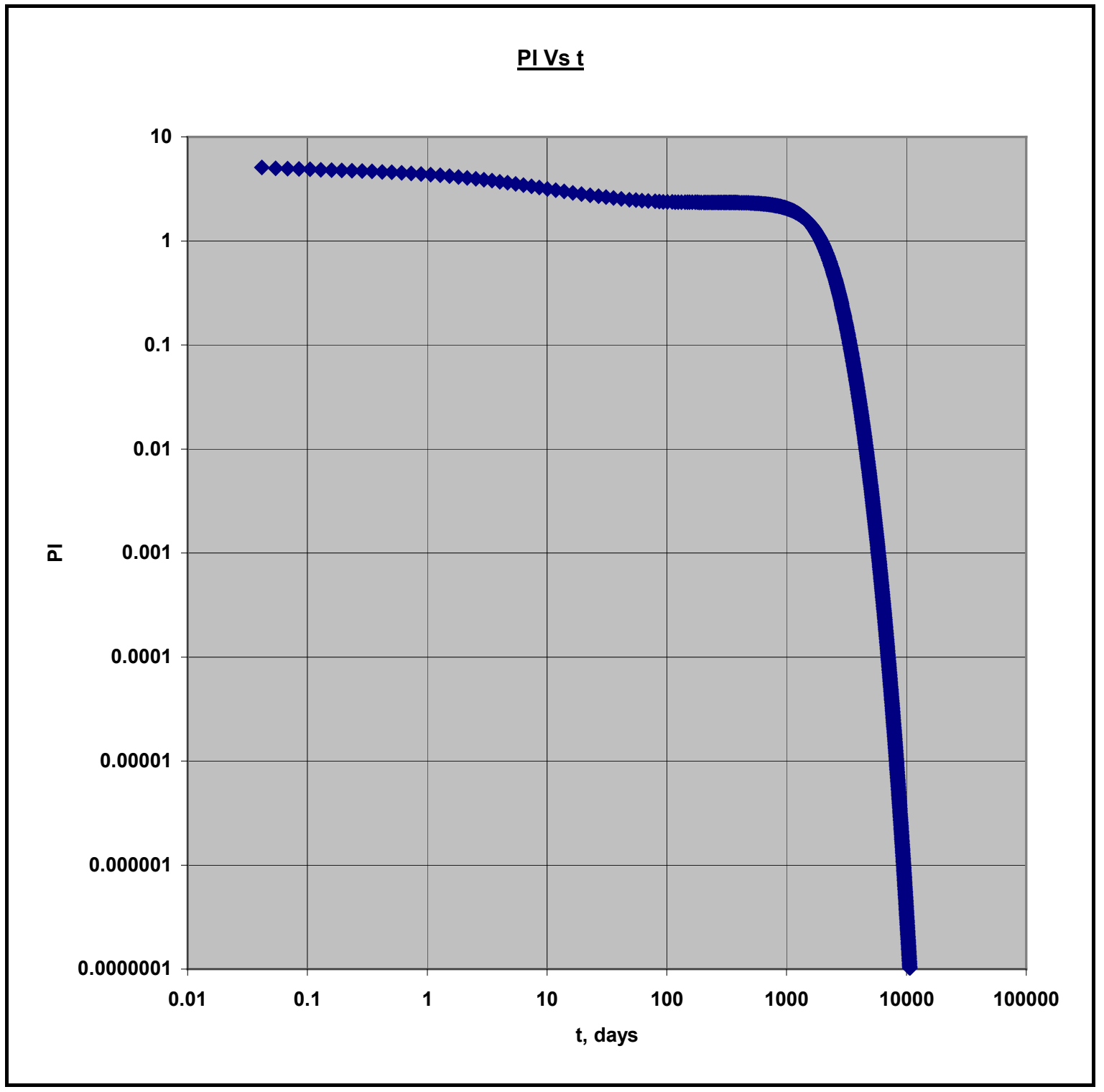

Figure 5.27: Variation of Productivity Index with time for a 4-lateral well with $1000 \mathrm{ft}$ lateral lengths, which are at the same depth. 
Figure 5.28 shows the variation of dimensionless pressure and its derivative with dimensionless time for a 4-lateral well with $1000 \mathrm{ft}$ lateral length, which are at same depth.

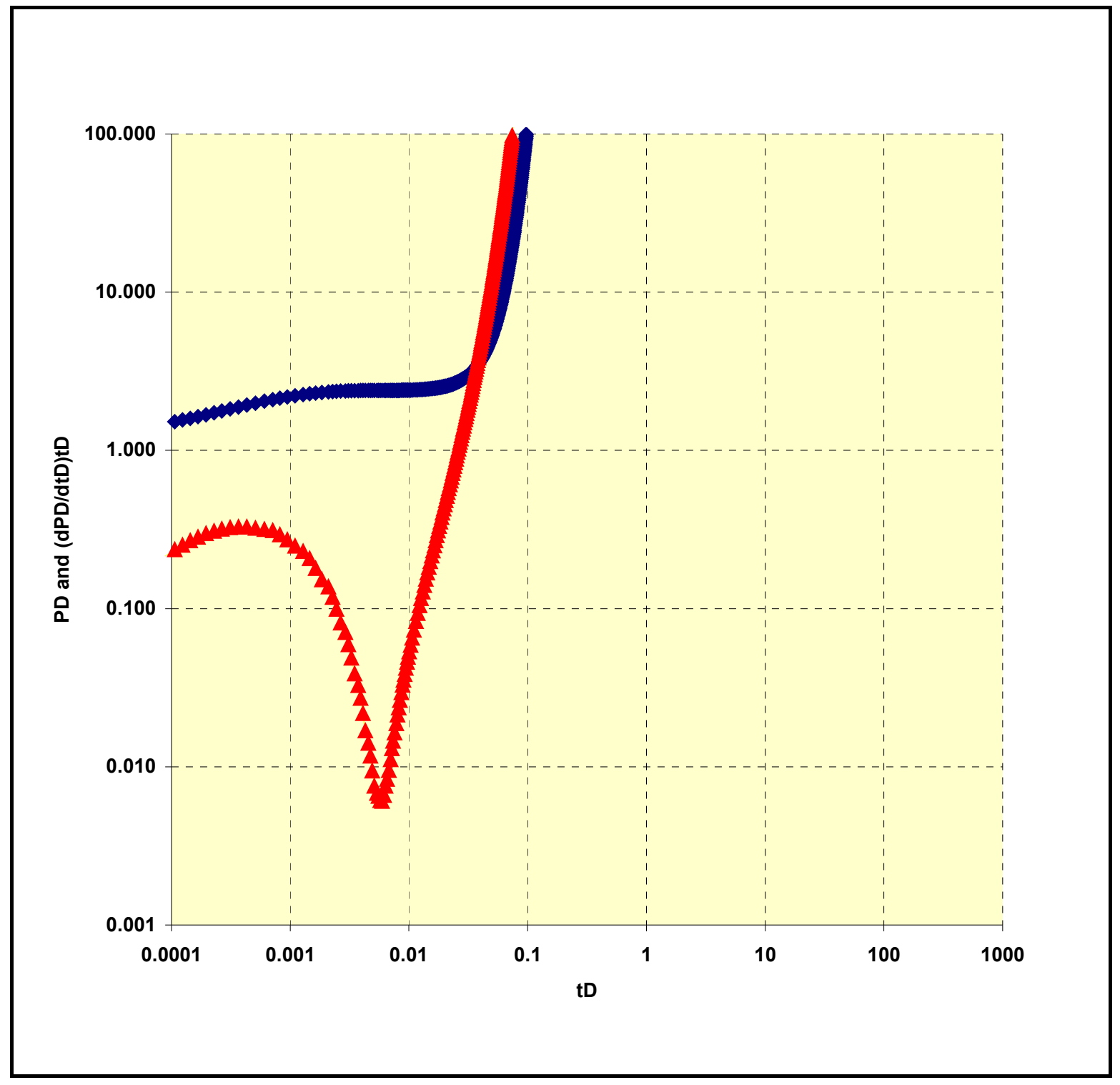

Figure 5.28: Variation of dimensionless pressure and its derivative with dimensionless time for a 4-lateral well with $1000 \mathrm{ft}$ lateral lengths, which are at the same depth. 
The results for the $1500 \mathrm{ft}$. Four Laterals (laterals at same depth) well for productivity index values are presented in Figure 5.29. As shown in Figure 5.29 the productivity index value shows a linear trend for 1 year and decreases to zero at the end of a dimensionless time of 7500 days. Compared to a vertical well completed in the same reservoir the productivity values are $32 \%$ greater indicating a larger production.

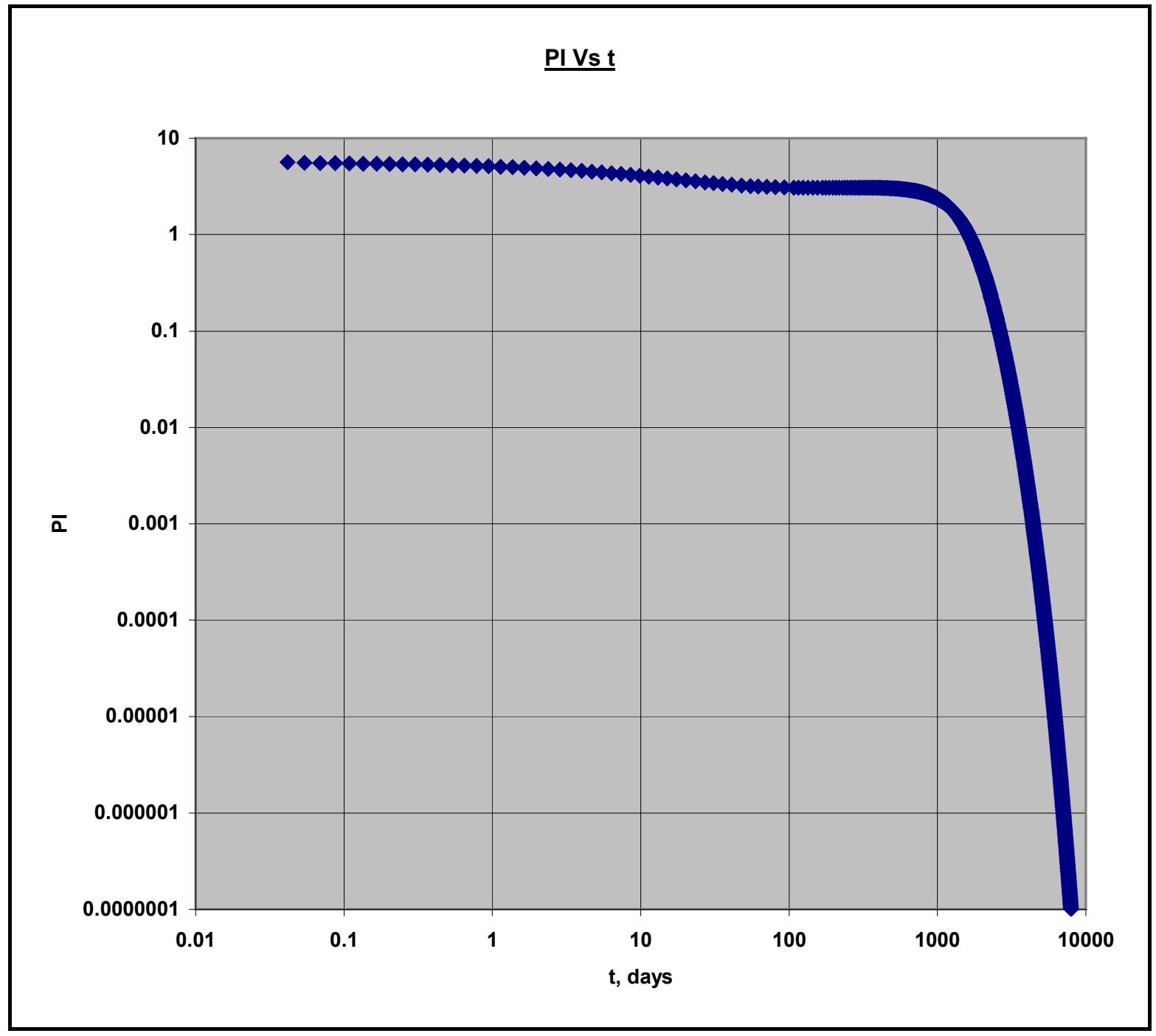

Figure 5.29: Variation of Productivity Index with time for a 4-lateral well with $1500 \mathrm{ft}$ lateral lengths, which are at the same depth. 
Figure 5.30 shows the variation of dimensionless pressure and its derivative with dimensionless time for a 4-lateral well with $1500 \mathrm{ft}$ lateral length, which are at same depth.

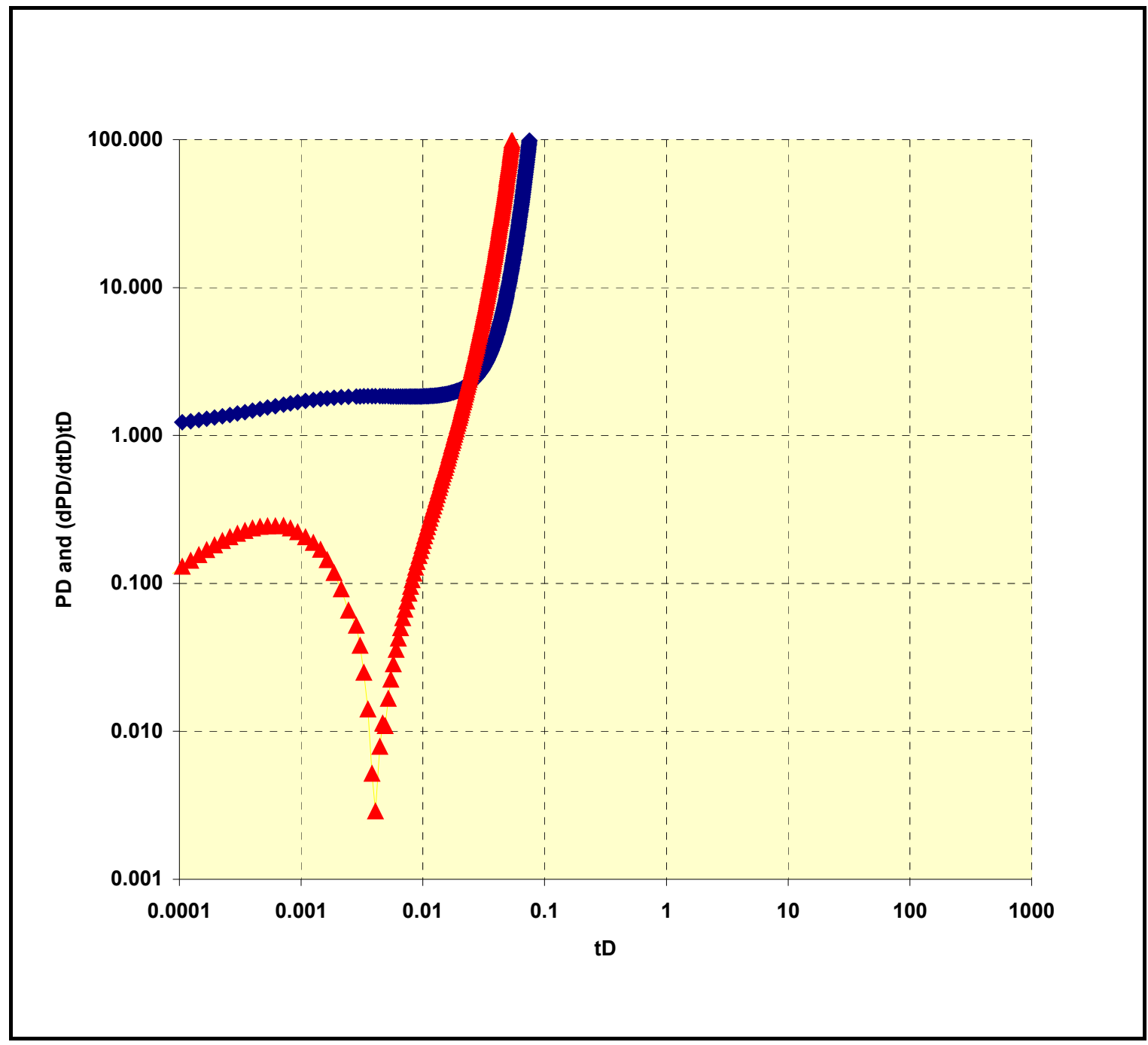

Figure 5.30: Variation of dimensionless pressure and its derivative with dimensionless time for a 4-lateral well with $1500 \mathrm{ft}$ lateral lengths, which are at the same depth. 
The results for the $2000 \mathrm{ft}$. Four Laterals (laterals at same depths) well for productivity index values are presented in Figure 5.31. As shown in Figure 5.31 the productivity index value shows a linear trend for 8 months and decreases to zero at the end of a dimensionless time of 6500 days. Compared to a vertical well completed in the same reservoir the productivity values are $29 \%$ greater indicating a larger production.

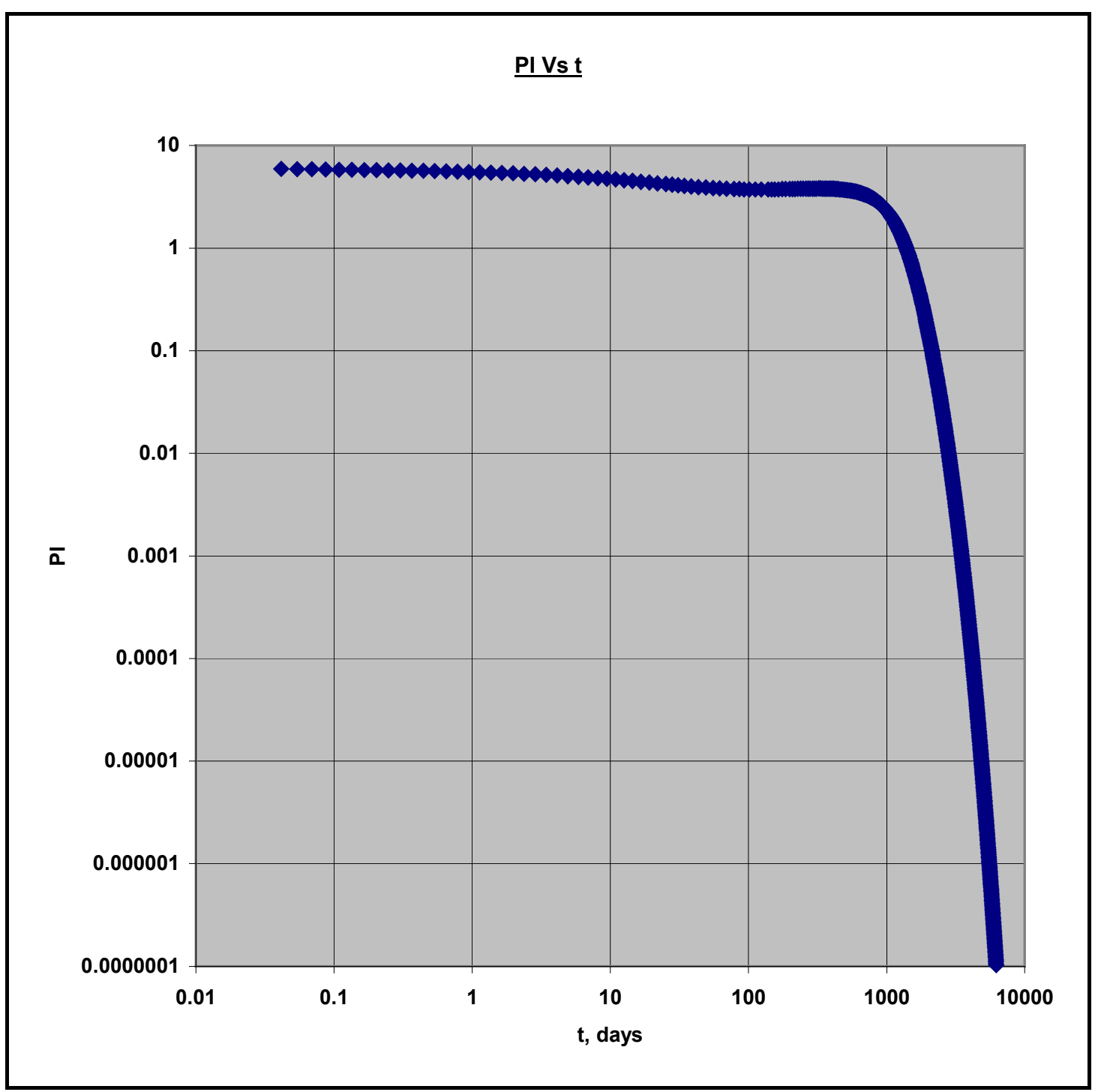

Figure 5.31: Variation of Productivity Index with time for a 4-lateral well with $2000 \mathrm{ft}$ lateral lengths, which are at the same depth. 
Figure 5.32 shows the variation of dimensionless pressure and its derivative with dimensionless time for a 4-lateral well with $2000 \mathrm{ft}$ lateral length, which are at same depth.

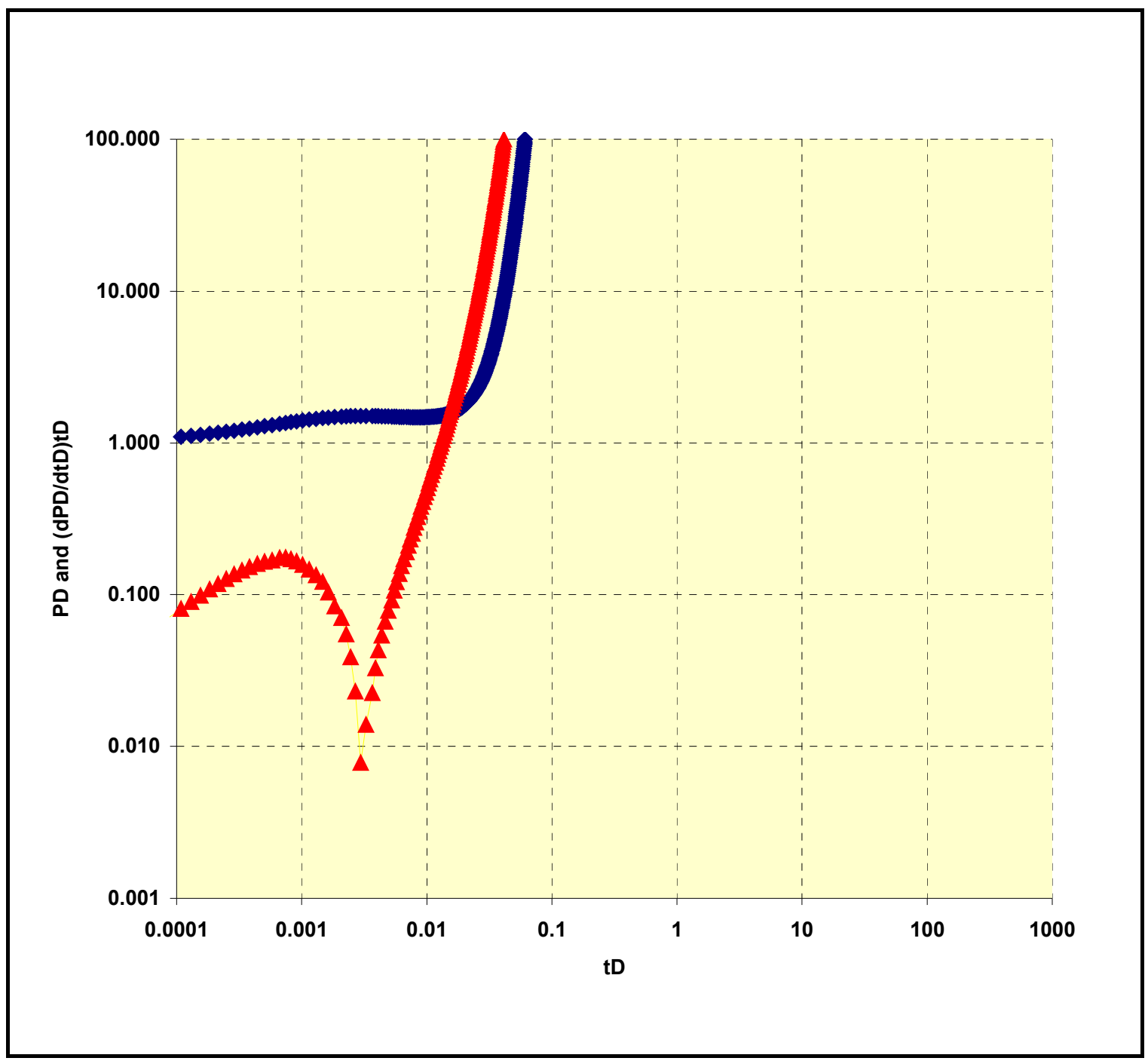

Figure 5.32: Variation of dimensionless pressure and its derivative with dimensionless time for a 4-lateral well with $2000 \mathrm{ft}$ lateral lengths, which are at the same depth. 
The results for the single Vertical well for productivity index values are presented in Figure 5.33. As shown in Figure 5.33 the productivity index value shows a linear trend for 6 years.

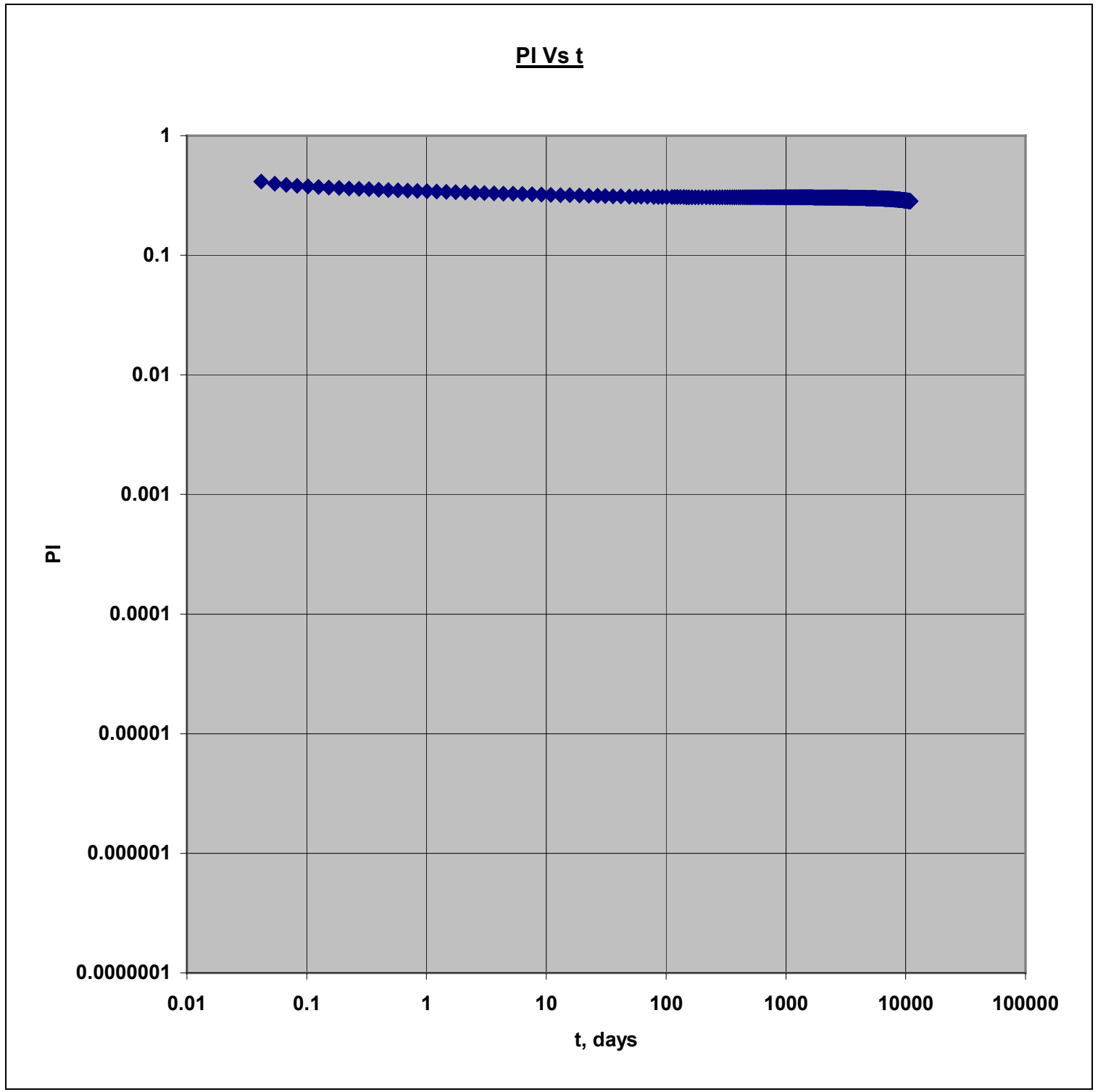

Figure 5.33 Variation of Productivity Index with time for a single Vertical Well. 
Figure 5.34 shows the variation of dimensionless pressure and its derivative with dimensionless time for a single Vertical Well.

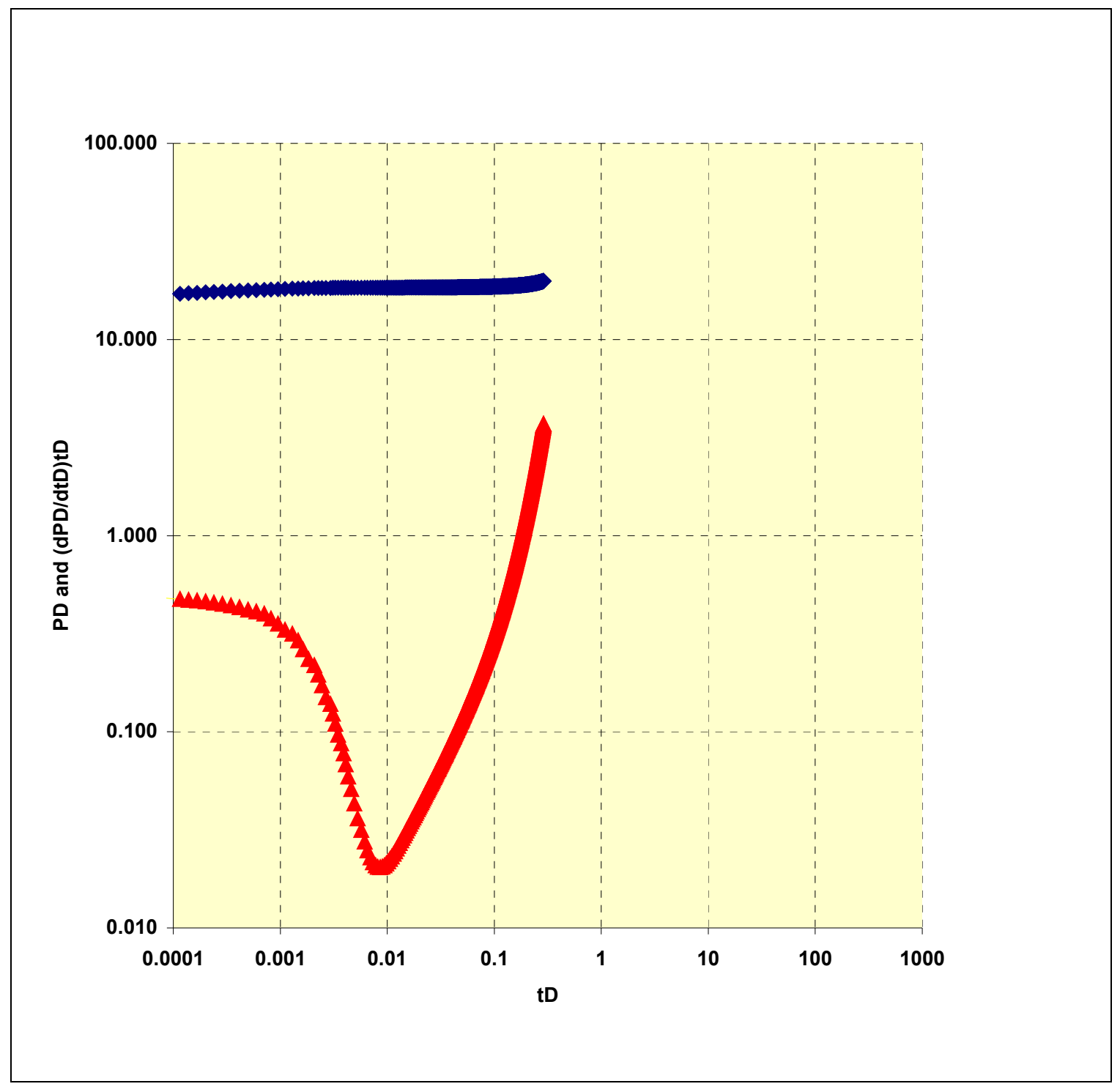

Figure 5.34: Variation of dimensionless pressure and its derivative with dimensionless time for a single Vertical Well. 
Figure 5.35 shows the variation of Productivity Index with time for a single lateral well with $500 \mathrm{ft}$, $1000 \mathrm{ft}, 1500 \mathrm{ft}$ and $2000 \mathrm{ft}$ lateral lengths.

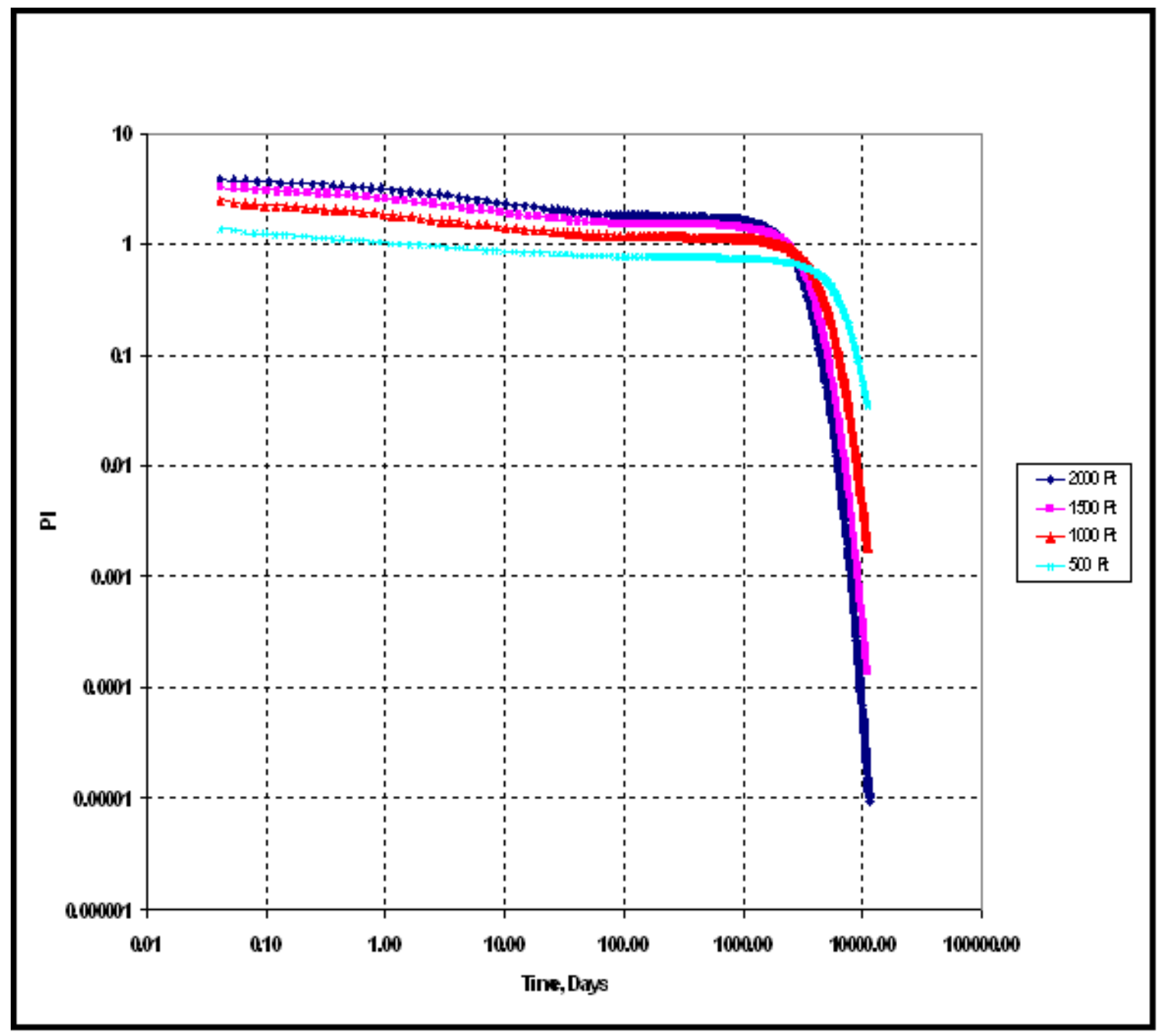

Figure 5.35: Variation of Productivity Index with time for a single lateral well with $500 \mathrm{ft}$, $1000 \mathrm{ft}, 1500 \mathrm{ft}$ and $2000 \mathrm{ft}$ lateral lengths. 
Figure 5.36 shows the variation of Productivity Index with time for a dual lateral well with $500 \mathrm{ft}$, $1000 \mathrm{ft}, 1500 \mathrm{ft}$ and $2000 \mathrm{ft}$ lateral lengths, which are at the same depth.

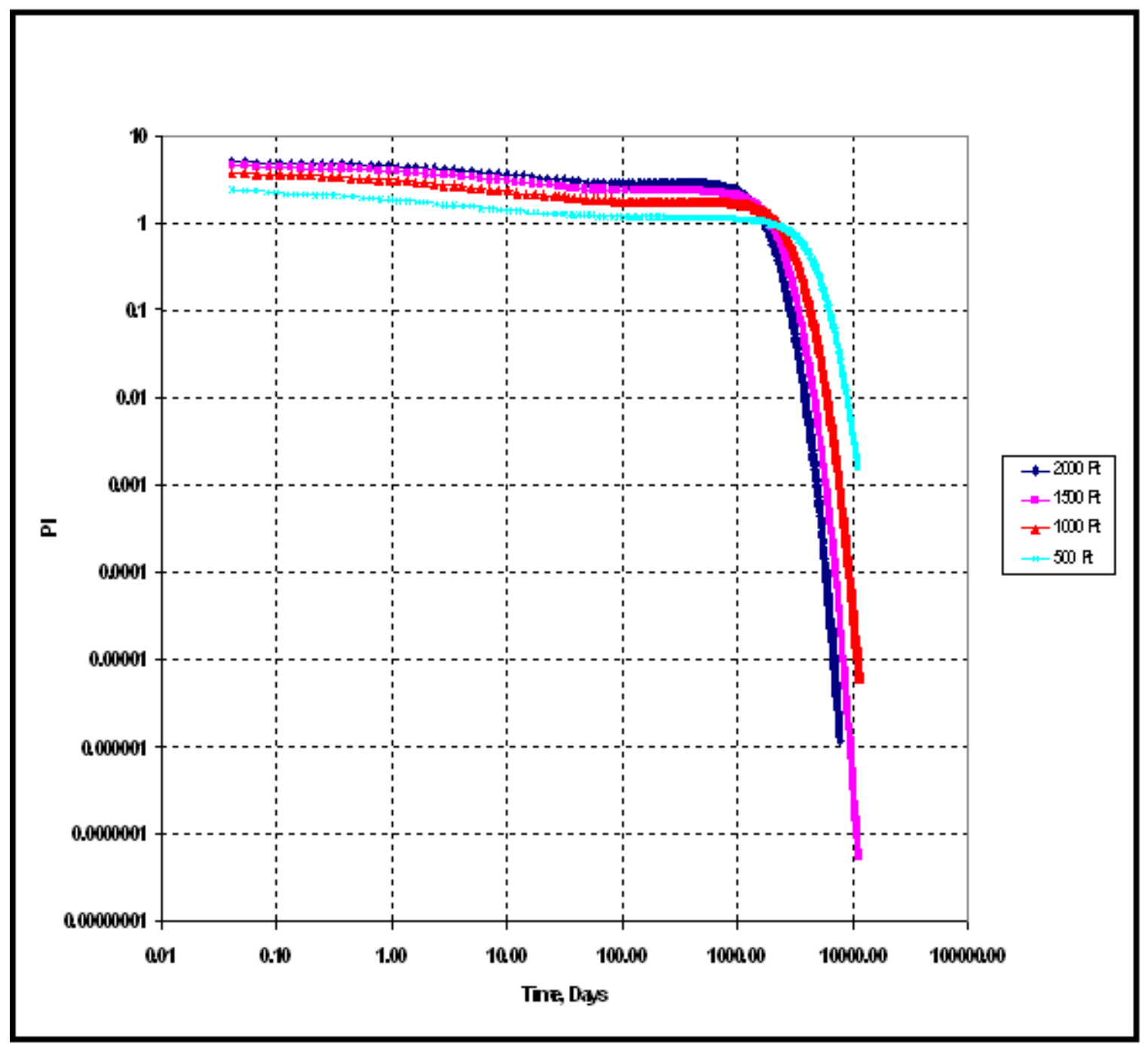

Figure 5.36: Variation of Productivity Index with time for a dual lateral well with $500 \mathrm{ft}, 1000$ $\mathrm{ft}, 1500 \mathrm{ft}$ and $2000 \mathrm{ft}$ lateral lengths, which are at the same depth. 
Figure 5.37 shows the variation of Productivity Index with time for a dual lateral well with $500 \mathrm{ft}$, $1000 \mathrm{ft}, 1500 \mathrm{ft}$ and $2000 \mathrm{ft}$ lateral lengths, which are at the different depth.

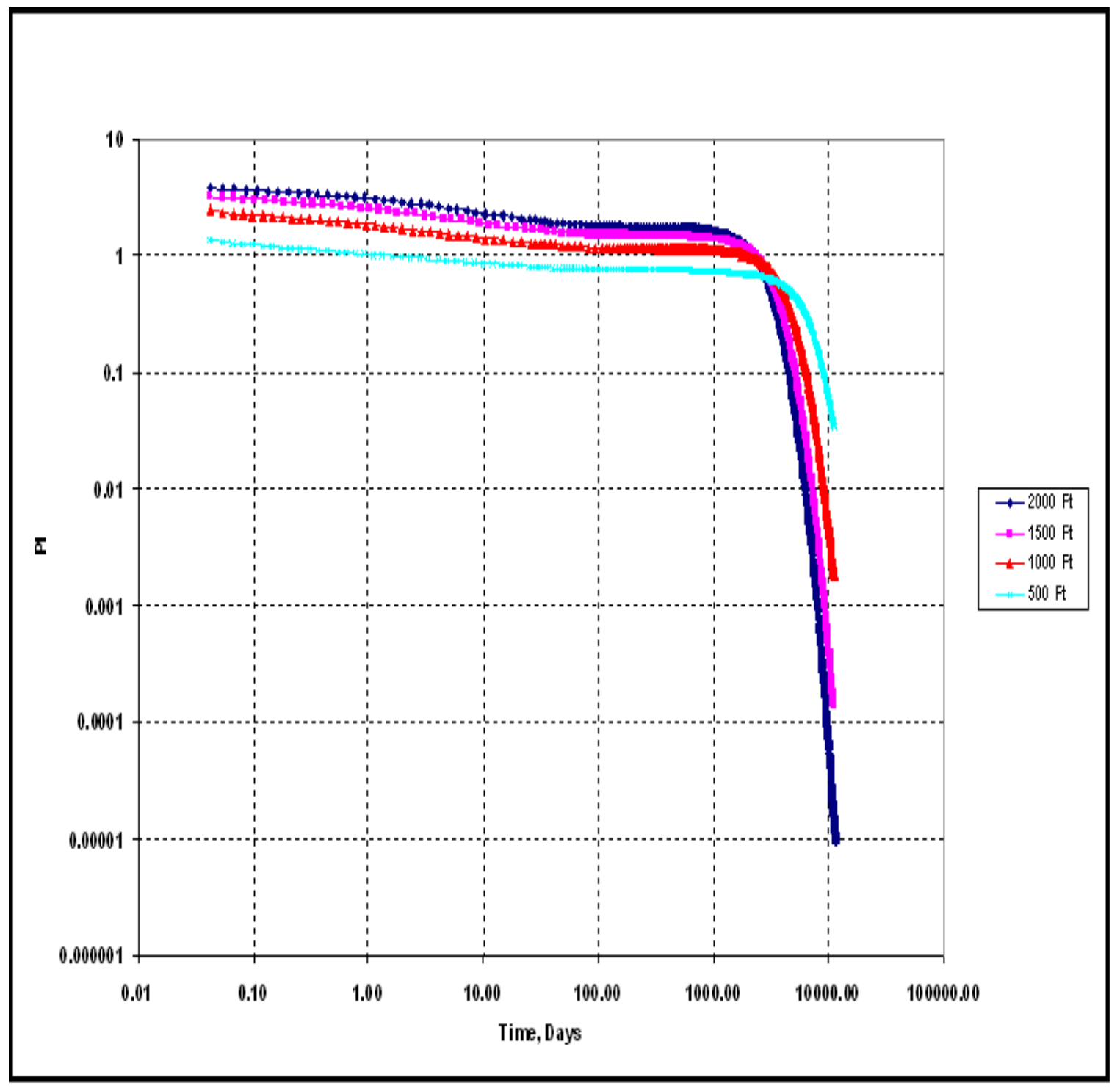

Figure 5.37: Variation of Productivity Index with time for a dual lateral well with $500 \mathrm{ft}, 1000$ $\mathrm{ft}, 1500 \mathrm{ft}$ and $2000 \mathrm{ft}$ lateral lengths, which are at the different depth. 
Figure 5.38 shows the variation of Productivity Index with time for a 4-lateral well with $500 \mathrm{ft}, 1000$ $\mathrm{ft}, 1500 \mathrm{ft}$ and $2000 \mathrm{ft}$ lateral lengths, which are at the same depth.

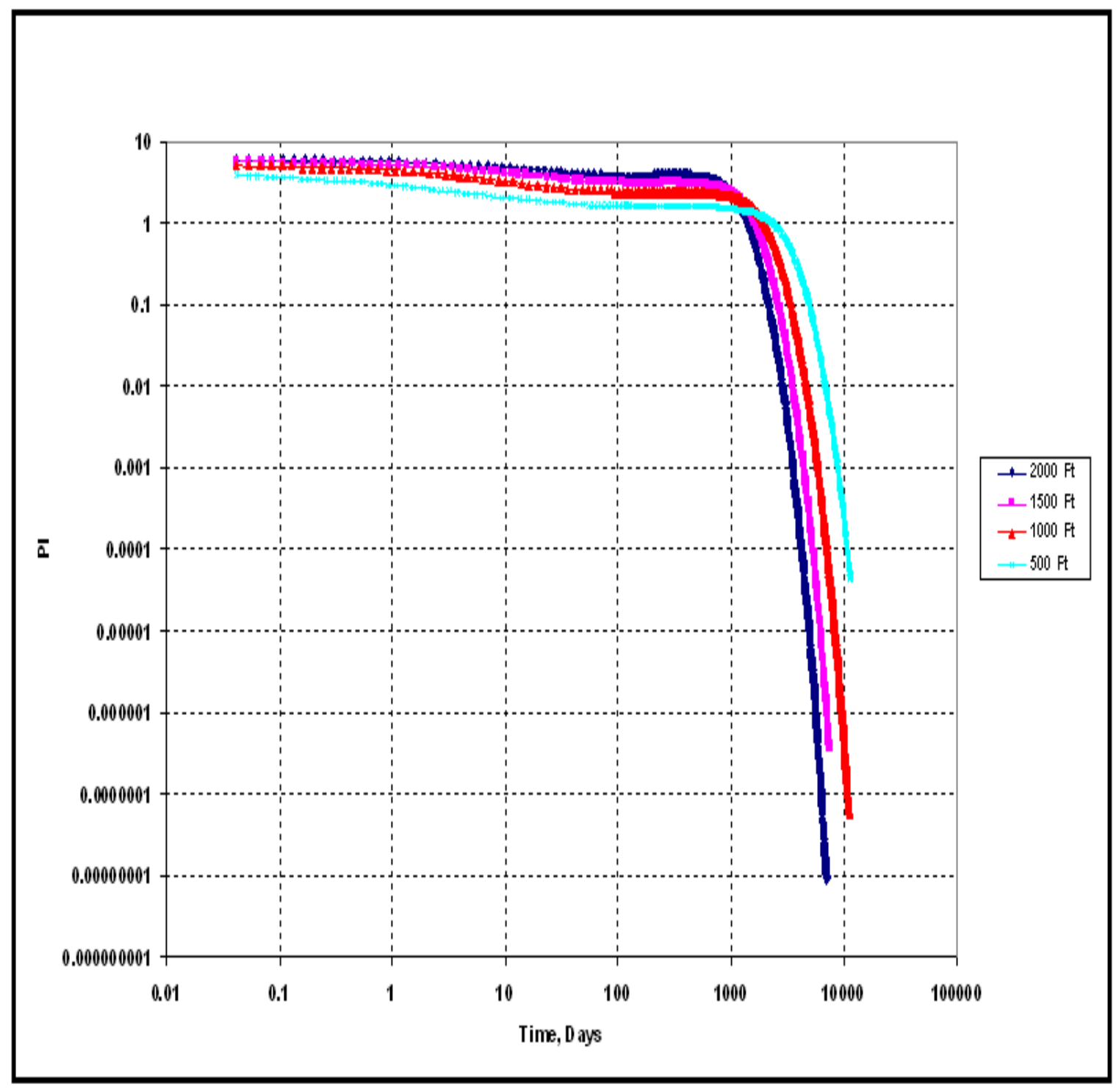

Figure 5.38: Variation of Productivity Index with time for a 4-lateral well with $500 \mathrm{ft}, 1000 \mathrm{ft}$, $1500 \mathrm{ft}$ and $2000 \mathrm{ft}$ lateral lengths, which are at the same depth. 
Figure 5.39 shows the variation of dimensionless pressure and its derivative with dimensionless time for a single lateral well with $500 \mathrm{ft}, 1000 \mathrm{ft}, 1500 \mathrm{ft}$ and $2000 \mathrm{ft}$ lateral lengths.

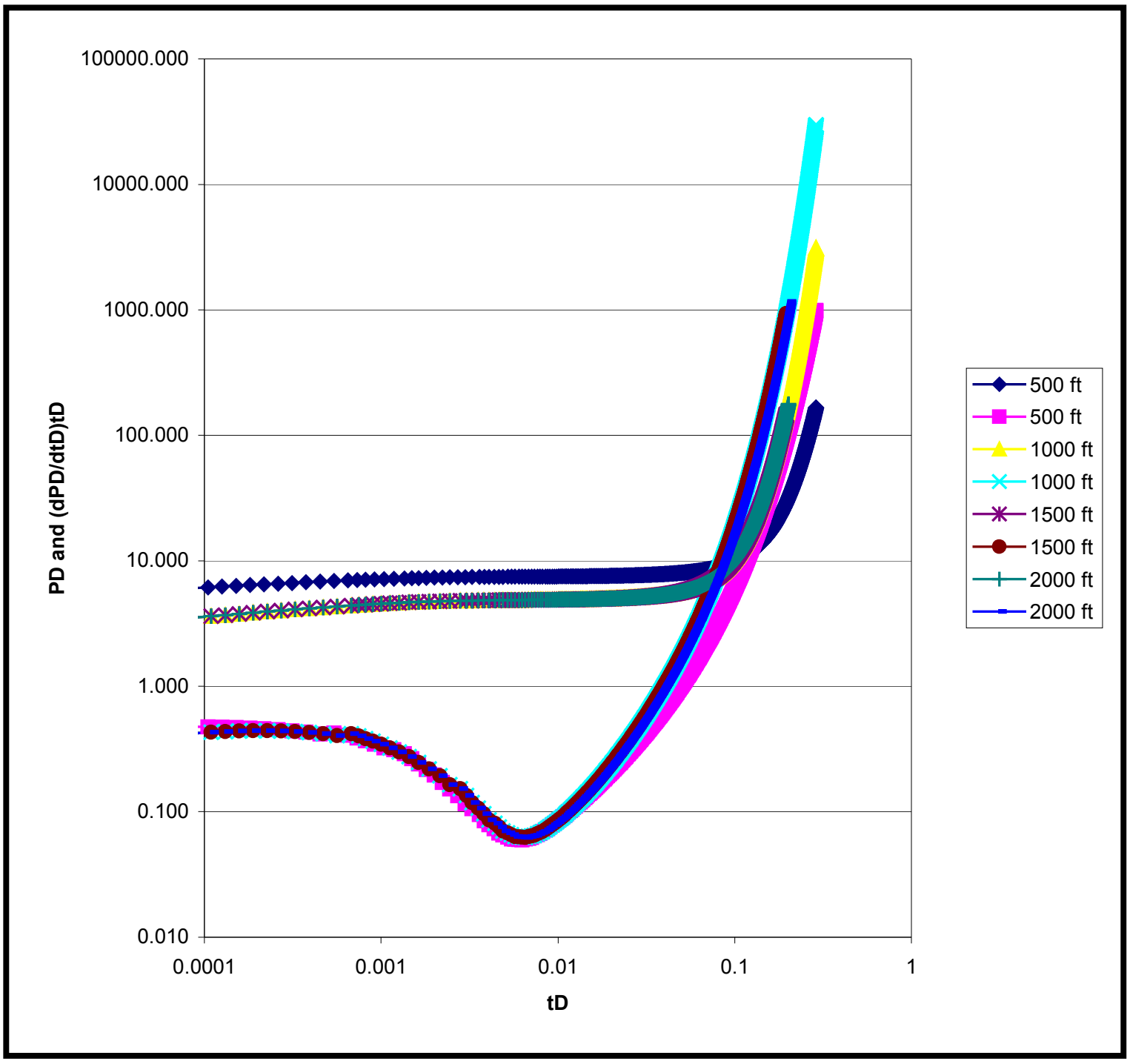

Figure 5.39: Variation of dimensionless pressure and its derivative with dimensionless time for a single lateral well with $500 \mathrm{ft}, 1000 \mathrm{ft}, 1500 \mathrm{ft}$ and $2000 \mathrm{ft}$ lateral lengths. 
Figure 5.40 shows the variation of dimensionless pressure and its derivative with dimensionless time for a dual lateral well with $500 \mathrm{ft}, 1000 \mathrm{ft}, 1500 \mathrm{ft}$ and $2000 \mathrm{ft}$ lateral lengths, which are at same depths.

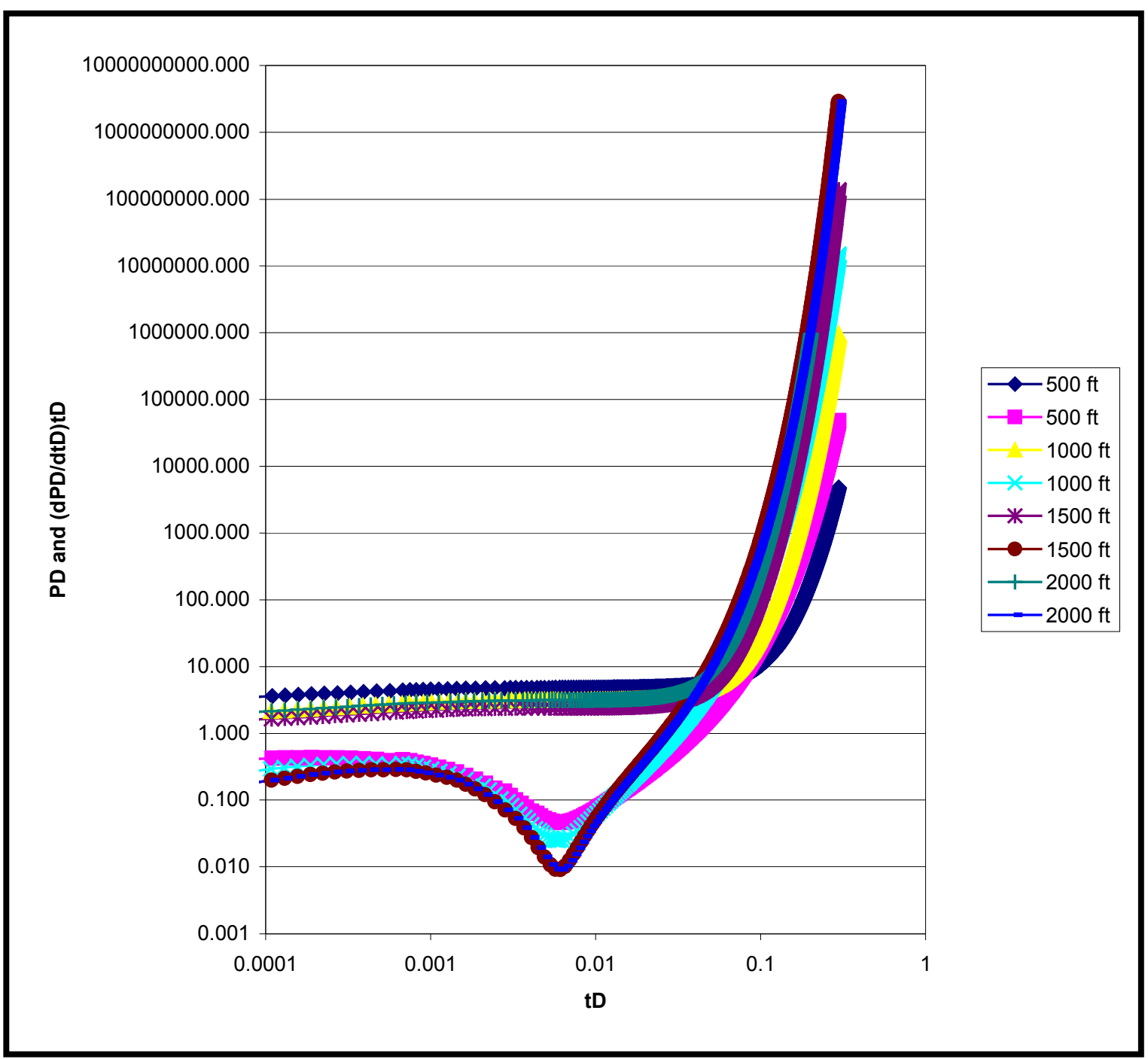

Figure 5.40: Variation of dimensionless pressure and its derivative with dimensionless time for a dual lateral well with $500 \mathrm{ft}, 1000 \mathrm{ft}, 1500 \mathrm{ft}$ and $2000 \mathrm{ft}$ lateral lengths, which are at the same depth. 
Figure 5.41 shows the variation of dimensionless pressure and its derivative with dimensionless time for a dual lateral well with $500 \mathrm{ft}, 1000 \mathrm{ft}, 1500 \mathrm{ft}$ and $2000 \mathrm{ft}$ lateral lengths, which are at different depths.

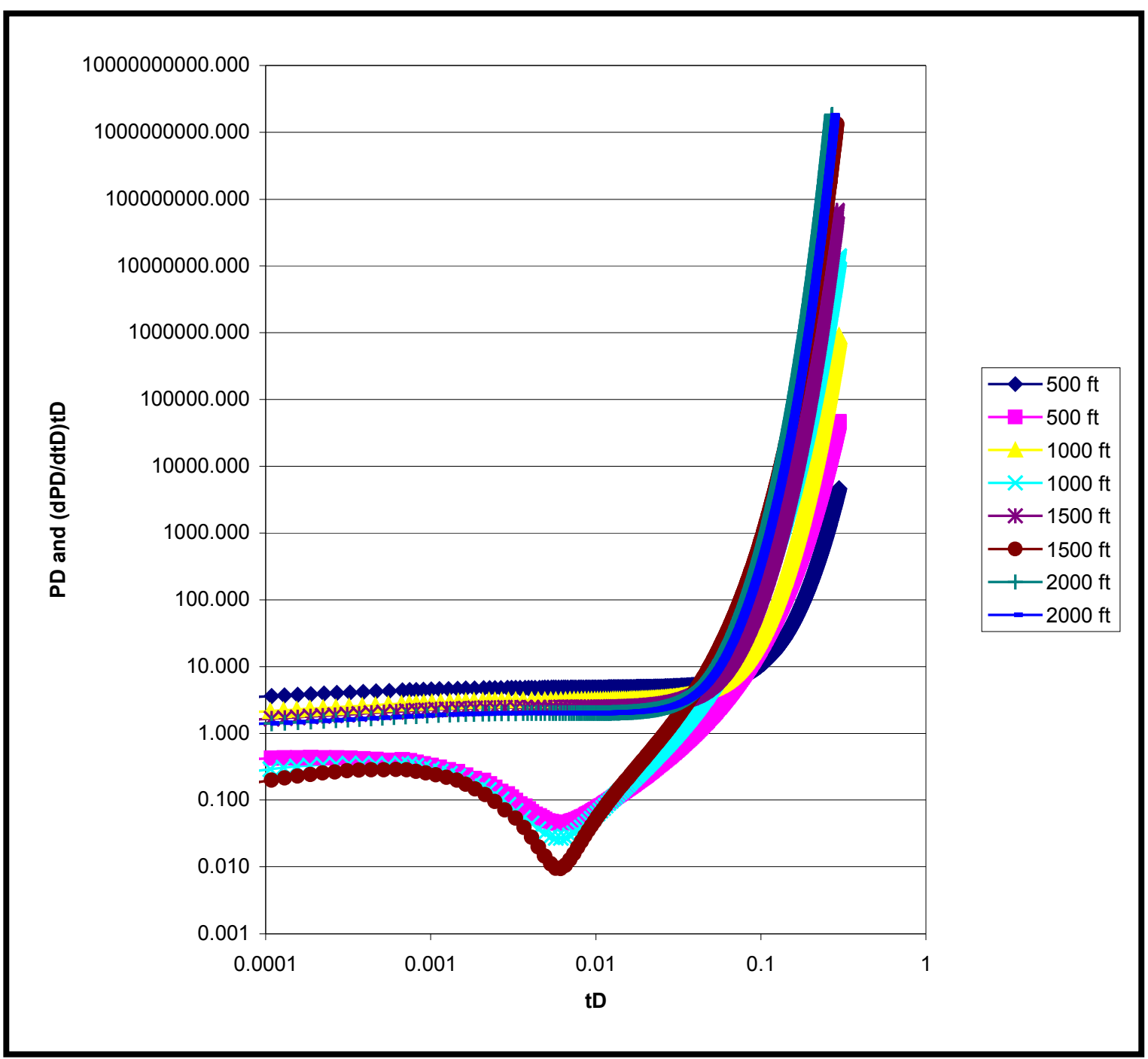

Figure 5.41: Variation of dimensionless pressure and its derivative with dimensionless time for a dual lateral well with $500 \mathrm{ft}, 1000 \mathrm{ft}, 1500 \mathrm{ft}$ and $2000 \mathrm{ft}$ lateral lengths, which are at different depths. 
Figure 5.42 shows the variation of dimensionless pressure and its derivative with dimensionless time for a 4-lateral well with $500 \mathrm{ft}, 1000 \mathrm{ft}, 1500 \mathrm{ft}$ and $2000 \mathrm{ft}$ lateral lengths, which are at same depths.

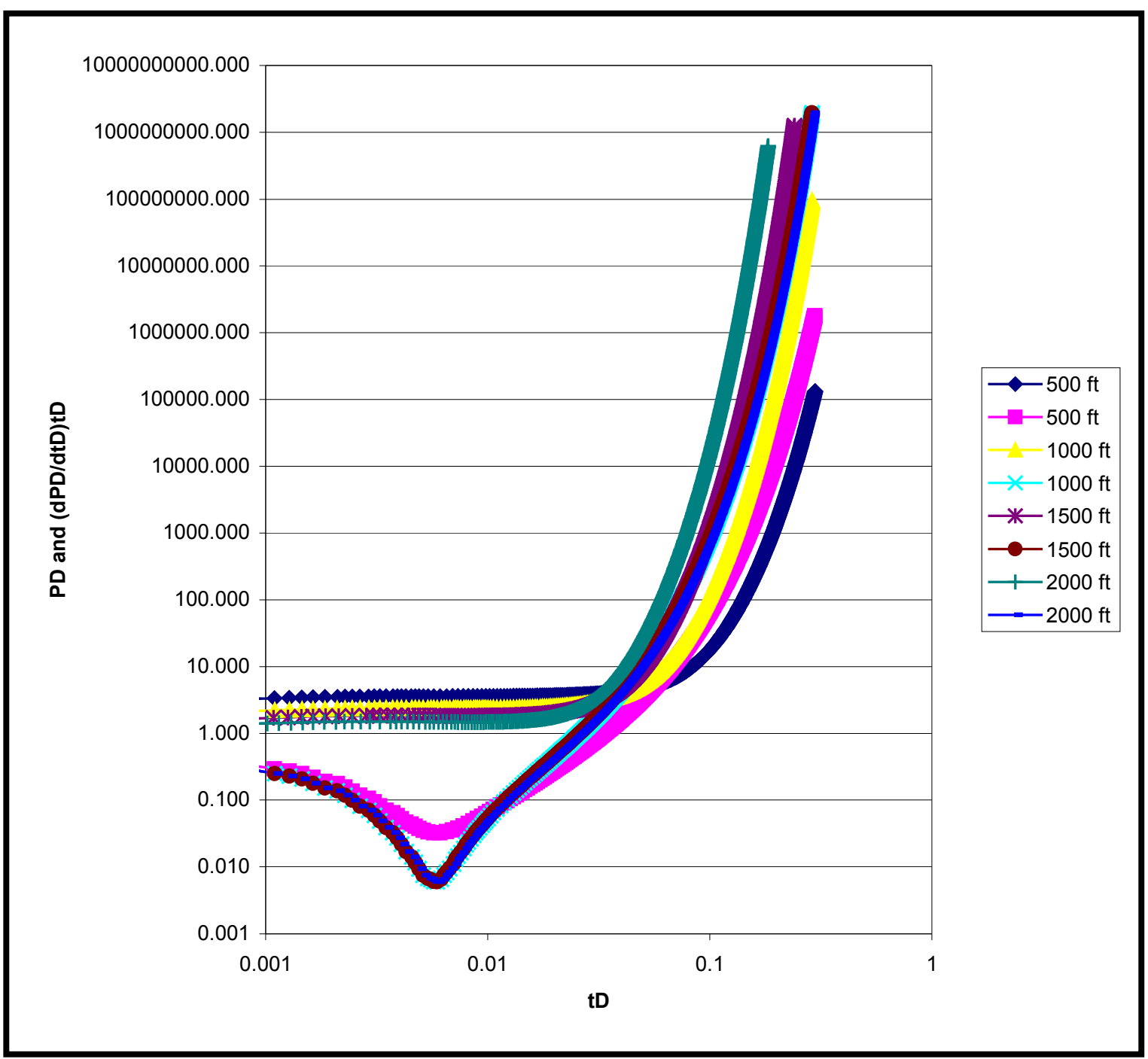

Figure 5.42: Variation of dimensionless pressure and its derivative with dimensionless time for a 4-lateral well with $500 \mathrm{ft}, 1000 \mathrm{ft}, 1500 \mathrm{ft}$ and $2000 \mathrm{ft}$ lateral lengths, which are at the same depth. 


\section{PI, Dimensionless Pressure and Dimensionless Pressure Derivative Curve trends:}

The productivity index values curve show a linear trend initially for all the configurations (single lateral, dual laterals (laterals at same and different depths), 4-laterals) that were considered and start declining at a later stage. The dimensionless pressure values show a linear trend initially for all the configurations (single lateral, dual laterals (laterals at same and different depths), 4laterals) that were considered and start increasing at the later stage. The dimensionless pressure derivative values show a declining trend initially for all the configurations (single lateral, dual laterals (laterals at same and different depths), 4-laterals) that were considered and increase at the later stage.

The productivity index value shows a linear trend for 10 years 9 months for a $500 \mathrm{ft}$ single lateral well and the productivity values are $57 \%$ greater when compared to a vertical well completed in the same reservoir. The productivity index value shows a linear trend for 4 years 1 month for a $500 \mathrm{ft}$ dual lateral well with laterals at same depth and the productivity values are $49 \%$ greater when compared to a vertical well completed in the same reservoir. The productivity index value shows a linear trend for 2 years 7 months for a $500 \mathrm{ft}$ dual lateral well with laterals at different depth and the productivity values are $49 \%$ greater similar to the Dual Laterals at the same depth. However, the boundary effects are observed earlier at the Dual Laterals with laterals at different depths when compared to Dual Laterals well with laterals at same depths. The productivity index value shows a linear trend for 1 year 3 months for a $500 \mathrm{ft}$ 4-lateral well with laterals at same depth and the productivity values are $47 \%$ greater when compared to a vertical well completed in the same reservoir. The productivity index value shows a linear trend for 5 years 5 months for a $1000 \mathrm{ft}$ single lateral well and the productivity values are $50 \%$ greater when compared to a vertical well completed in the same reservoir. The productivity index value shows a linear trend for 2 years 7 months for a $1000 \mathrm{ft}$ dual lateral well with laterals at same depth and the productivity values are $46 \%$ greater when compared to a vertical well completed in the same reservoir. The productivity index value shows a linear trend for 1 year 5 months for a $1000 \mathrm{ft}$ dual lateral well

with laterals at different depth and the productivity values are $48 \%$ greater almost similar to the 
Dual Laterals at the same depth. However, the boundary effects are observed earlier at the Dual Laterals with laterals at different depths when compared to Dual Laterals well with laterals at same depths. The productivity index value shows a linear trend for 1 year 3 months for a $1000 \mathrm{ft}$ 4-lateral well with laterals at same depth and the productivity values are $35 \%$ greater when compared to a vertical well completed in the same reservoir. The productivity index value shows a linear trend for 2 years 7 months for a $1500 \mathrm{ft}$ single lateral well and the productivity values are $50 \%$ greater when compared to a vertical well completed in the same reservoir. The productivity index value shows a linear trend for 1 year 9 months for a $1500 \mathrm{ft}$ dual lateral well with laterals at same depth and the productivity values are $43 \%$ greater when compared to a vertical well completed in the same reservoir. The productivity index value shows a linear trend for 1 year 3 months for a $1500 \mathrm{ft}$ dual lateral well with laterals at different depth and the productivity values are $43 \%$ greater similar to the Dual Laterals at the same depth. However, the boundary effects are observed earlier at the Dual Laterals with laterals at different depths when compared to Dual Laterals well with laterals at same depths. The productivity index value shows a linear trend for 1 year for a $1500 \mathrm{ft}$ 4-lateral well with laterals at same depth and the productivity values are $32 \%$ greater when compared to a vertical well completed in the same reservoir. The productivity index value shows a linear trend for 1 year 9 months for a $2000 \mathrm{ft}$ single lateral well and the productivity values are $46 \%$ greater when compared to a vertical well completed in the same reservoir. The productivity index value shows a linear trend for 1 year 6 months for a $2000 \mathrm{ft}$ dual lateral well with laterals at same depth and the productivity values are $34 \%$ greater when compared to a vertical well completed in the same reservoir. The productivity index value shows a linear trend for 1 year 6 months for a $2000 \mathrm{ft}$ dual lateral well with laterals at different depth and the productivity values are $34 \%$ greater similar to the Dual Laterals at the same depth. However, the boundary effects are observed earlier at the Dual Laterals with laterals at different depths when compared to Dual Laterals well with laterals at same depths. The productivity index value shows a linear trend for 8 months for a $2000 \mathrm{ft}$ 4-lateral well with laterals at same depth and the productivity values are $29 \%$ greater when compared to a vertical well completed in the same 
reservoir. 


\section{CHAPTER VI: CONCLUSION AND FUTURE WORK}

The main focus of this work is to calculate the productivity indexes for different types of configurations using a numerical solution method and examine the variation of dimensionless pressure with respect to dimensionless time for all these configurations. To achieve the above mentioned objective five different types of configurations were considered. They were single vertical well, single horizontal well (for lateral length of $500 \mathrm{ft}, 1000 \mathrm{ft}, 1500 \mathrm{ft}, 2000 \mathrm{ft}$ ), dual lateral well with laterals at same depth (for lateral lengths of $500 \mathrm{ft}, 1000 \mathrm{ft}, 1500 \mathrm{ft}, 2000 \mathrm{ft}$ ), dual lateral well with laterals at different depths (for lateral lengths of $500 \mathrm{ft}, 1000 \mathrm{ft}, 1500 \mathrm{ft}, 2000 \mathrm{ft}$ ), 4-lateral well with laterals at same depth (for lateral lengths of $500 \mathrm{ft}, 1000 \mathrm{ft}, 1500 \mathrm{ft}, 2000 \mathrm{ft}$ ). Using a three-phase black oil simulator (ECLIPSE) configurations were created and runs were conducted for a period of 30 years. Results of these runs were tabulated and productivity indexes for these configurations were calculated and plotted. Along with this dimensionless pressure, dimensionless time and derivative of dimensionless pressure are also calculated and plotted. Based on results, the following conclusions were drawn from this research:

1. Productivity Indexes show a linear trend until the boundary effects are felt. This linear trend sections are shorter for longer laterals as a result of oil recoveries in a shorter time.

2. All lateral configurations show increase in PI values when compared to the PI value obtained from a vertical well completed in the same reservoir.

3. PI values show a decreasing trend with increase in time while the dimensionless PI values show decreasing trend with increase in dimensionless time.

4. The derivative curves for the dimensionless PI values show a minimum value. And the dimensionless times corresponding to the minimum point exhibit similar values for all configurations considered in this study.

5. In the case of wells with two lateral configurations where one considers both laterals at same depths and the second one considers laterals extending from vertical at different depths, PI values are similar. Thus, the location of deviation points for laterals do not affect the PI values for the two configurations used in the runs. 


\section{FUTURE WORK:}

Future work can include the following:

- More configurations (like 4 or more lateral well with laterals at different depths, 4-lateral well with laterals placed at some angle etc.) should be considered and productivity index should be calculated for all the configurations.

- For all configurations, runs should be made with different skin factors and permeabilities.

- Runs should be conducted to show the effect of well completion effects such as hole size and completion intervals. 


\section{Appendix}

\section{Nomenclature}

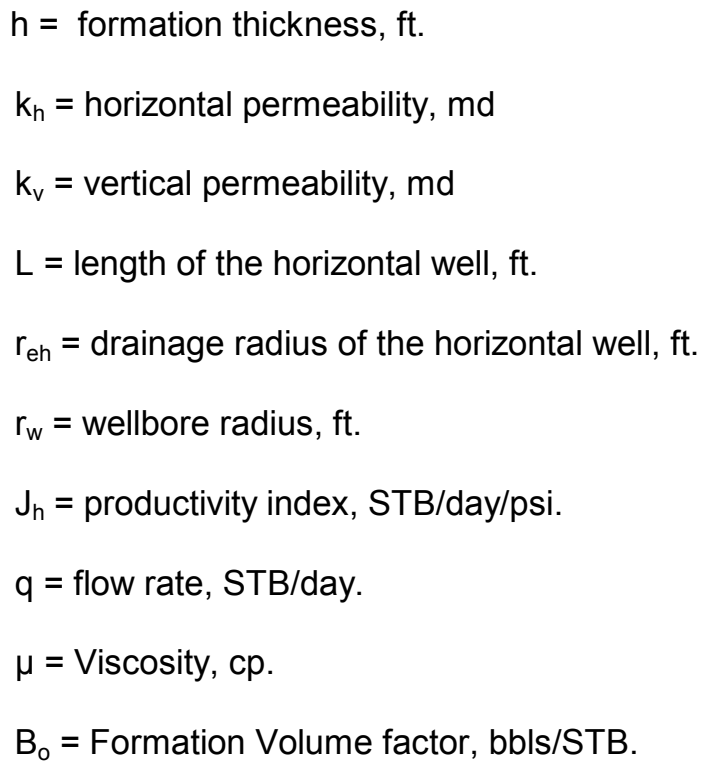




\section{References}

1. Technical Advancements of Multilaterals (TAML) - URL: www.taml.net.

2. Retnanto, A, Frick, T.P, Brand, C.W., and Economides, M.J.: "Optimal Configurations of Multiple-Lateral Horizontal Wells," SPE Paper 35712, (1996).

3. Ahmed, T.: "Reservoir Engineering Handbook,": Butterworth - Heinemann (March 15, 2000).

4. Kuppe, F. and Settari, A.: "A Practical Method for Determining the Productivity of Multi-fractured Horizontal wells", paper 96-22, presented at the 47th Annual Technical Meeting of the Petroleum Society of CIM, Calgary, 10-12 June (1996).

5. Economides, M.J., Brand, C.W., and Frick, T.P.: "Well Configurations in Anisotropic Reservoirs," SPE Paper 27980, (1996).

6. Giger, F.M., Reiss, L.H. and Jourdan, A.P.,: "The Reservoir Engineering Aspects of Horizontal Drilling", SPE 13024, (September 1984).

7. Giger, F.M.,: "Horizontal Wells Production Techniques in Heterogeneous Reservoirs," Middle East Oil Technical Conference and Exhibition, Bahrain, (March 1985).

8. Borisov, J.P.: Oil Production using Horizontal and Multiple Deviation Wells, Nedra, Moscow (1964). Translated by J. Strauss, S.D. Josh (ed.), Phillips Petroleum Co., the R\&D library translation, Bartlesville, Oklahoma (1984).

9. Joshi, S.D.: "Augmentation of Well Productivity with Slant and Horizontal Wells," JPT 729-739, (June 1988).

10. Economides, M.J., Deimbacher, F.X., Brand, C.W., and Heinemann, Z.E.: "Comprehensive simulation of Horizontal well Performance," SPEFE, 418-426 (December 1991). 
11. Babu, D.K. and Odeh, A.S.,: "Productivity of a Horizontal Well," SPERE, 417-421, (November 1989).

12. Goode, P.A. and Thambynayagam, R.K.M.: "Pressure Drawdown and Build-up analysis of Horizontal wells in Anisotropic Media," SPEFE, 683-697 (December 1987).

13. Kuchuk, F.J and Goode, P.A., Brice, B.W., Sherrard, D.W., and Thambynayagam, R.K.M.: "Pressure Transient Analysis and Inflow Performance of Horizontal wells," paper SPE 18300, (1988).

14. Salas, J.R., Clifford, P.J., and Jenkins, D.P.: "Brief multilateral well Performance Predictions," JPT, (May 1996).

15. Economides, M.J., Smith, J. and Frick, T.P.: "Reducing economic risk in Areally Anisotropic Formations with Multi-Lateral Horizontal Wells," paper SPE 30647, (1995).

16. Retnanto, A., Economides, M.J.: "Performance of Multiple Horizontal Well Laterals in Low- to Medium-Permeability Reservoirs," SPE Paper 29647, (1996).

17. Madden, M.V. and Vo, D.T.: "Performance Evaluation of Trilateral Wells: Field Examples," SPERE, (February 1995).

18. Karakas, M., Yokoyama, Y.M., and Arima, E.M.: "Well Test Analysis of a Well with Multiple Horizontal drain holes," paper SPE 21424, (1991).

19. Raghavan, R. and Ambashta, A.K.: “ An Assessment of Productivity of Multilateral Completions," Journal of Canadian Petroleum Technology, V.37, No.10, (October 1998).

20. Ozkan, E., Yildiz, T., and Kuchuk, F.J.:"Transient Pressure Behavior of Dual-Lateral 
Wells," SPEJ, (June 1998).

21. Basquet, R et al: “ A Semianalytical Approach for Productivity Evaluation of Complex Wells in Multi-layered Reservoirs," SPERE, (December 1999).

22. Larsen, L.: "Pressure-Transient Behavior of Multibranched Wells in Layered Reservoirs," SPERE, 68-73, (February 2000).

23. Ding, Y.: " Transient Pressure Solution in the Presence of Pressure Drop in the Wellbore," paper SPE 56614, (1999).

24. Ouyang, L.B. and Aziz, K.: "A General Single-Phase Wellbore/Reservoir Coupling Model for Multilateral Wells," SPERE, 327-335, (August 2001).

25. Yildiz, T.: "Multilateral Pressure-Transient Response," SPEJ, (March 2003).

26. Hall, S.D.:" Multi-Lateral Horizontal Wells Optimizing a 5-Spot Waterflood," paper SPE 35210, (1996).

27. Longbottom, J.R.: “ Development and Testing of a Multi-Lateral System.” Paper SPE 35545, (1996)

28. Lee, S.S., Veeken, C.A.M., and Frens, A.M.: "Multi-Lateral Well Modeling to Optimize Well Design and Cost," paper SPE 68728, (2001).

29. Stalder, J.L. et al.: " Multilateral-Horizontal Wells Increase Rate and Lower Cost per Barrel in the Zuata Field, Faja, Venezuela" paper SPE 69700, (2001).

30. Yaliz, A.: " Case Study of a Quard-Lateral Horizontal well in the Lennox Field: A Triassic Oil-Rim Reservoir," paper SPE 75249, (2002). 